Measuring personal autonomy and social participation in older adults with a chronic physical illness

Godelief Mars

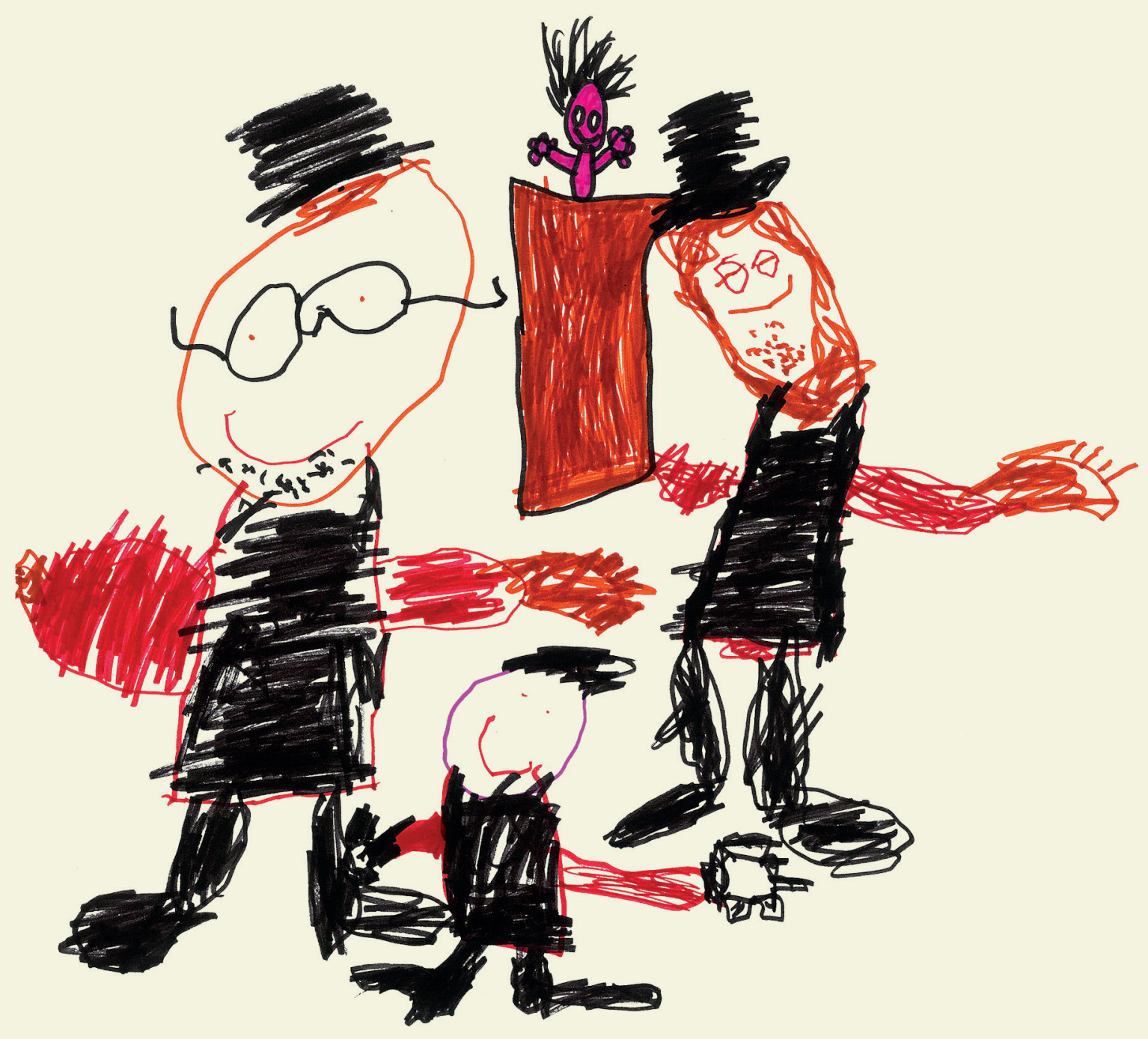





\section{Measuring personal autonomy and social participation in older adults with a chronic physical illness}


(c) Godelief Mars, Maastricht 2013.

Vormgeving en druk: Datawyse | Universitaire Pers Maastricht Omslagtekening: Thomas en Julian Scheenen

\section{ISBN 9789461592514}




\title{
Measuring personal autonomy and social participation in older adults with a chronic physical illness
}

\author{
PROEFSCHRIFT \\ ter verkrijging van de graad van doctor aan de Universiteit Maastricht, \\ op gezag van de Rector Magnificus, Prof dr. L.L.G. Soete \\ volgens het besluit van het College van Decanen, \\ in het openbaar te verdedigen \\ op vrijdag 1 november 2013 om 12.00 uur \\ door
}

Godelief Maria Johanna Mars

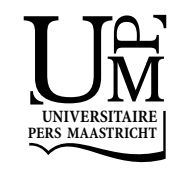




\section{Promotores}

Em. prof. dr. J. Th. M. van Eijk

Prof. dr. G. I. J. M. Kempen

\section{Beoordelingscommissie}

Prof. dr. R. A. de Bie (voorzitter)

Dr. M. Cardol (Kenniscentrum Zorginnovatie Rotterdam; NIVEL, Utrecht)

Prof. dr. L. V. van de Poll-Franse (Tilburg University)

Prof. dr. T. van der Weijden

Prof. dr. L. P. de Witte 


\section{Contents}

$\begin{array}{ll}\text { Chapter } 1 & 7\end{array}$

Introduction

Chapter 2

Conceptualizing autonomy in the context of chronic physical illness:

relating philosophical theories to social scientific perspectives

Chapter 3

How do people with COPD or diabetes type 2 experience autonomy?

An exploratory study

\section{Chapter 4}

The Maastricht Personal Autonomy Questionnaire (MPAQ):

development and psychometric properties in older adults with a chronic physical illness

\section{Chapter 5}

Characteristics of social participation as defined by older adults with a chronic physical illness

\section{Chapter 6}

The Maastricht Social Participation Profile (MSPP): development and clinimetric properties in older adults with a chronic physical illness

\section{Chapter 7}

General discussion

Summary

Samenvatting

Dankwoord

Curriculum vitae

Appendix A Maastricht Personal Autonomy Questionnaire (MPAQ)

Appendix B Maastricht Social Participation Profile (MSPP) 

Chapter 1

Introduction 
CHAPTER 1 


\section{Introduction}

Many people face the challenge to come to terms with chronic disease, but chronic disease is particularly common among older adults. In the European Union, more than half of the adults from 65 to 74 years are estimated to have a long-standing illness or health problem and 70 percent of the adults over 85 years do so [1]. In the Netherlands, four fifths of the population aged 75 years or older had one or more chronic diseases in 2011 [2]. The number of people with a chronic disease is expected to increase dramatically due to life style changes, earlier diagnosis, better treatment, ageing, and population growth. Between the years 2005 and 2025, 100000 additional cases of Chronic Obstructive Pulmonary Disease (COPD) are expected in the Netherlands. The number of diabetics is expected to increase in this period by 300000 . The majority of these additional cases of diabetes and COPD will concern older adults [3].

The increase in the number of people with a chronic disease is accompanied by an expansion of chronic disease over the life span. While we may expect to live longer, we may also expect to spend a larger part of life with chronic disease [4]. Between 1981 and 2011, life expectancy of Dutch men at age 65 increased from 14 to 18 years, while their chronic disease-free life expectancy decreased from 7 to 4 years. Life expectancy of women increased from 19 to 21 years, while chronic disease-free life expectancy decreased from 7 to 4 years [5].

Older adults with a chronic illness have been found to consider their illness as an inevitable feature of ageing, while at the same time experiencing it to disrupt their everyday lives [6-9]. Social roles and valued activities may become difficult to perform or turn out to be at odds with instructions of health professionals, future plans may need adjustment, and dependency on others may increase [1012].

People with a chronic illness may sometimes act in the best interest of their health, while at other times they give priority to valued activities and social roles [10]. It may be difficult for health care professionals to identify patients' main concerns [13]. Also, what is considered a good or important outcome by patients, may not be considered so by health care professionals and vice versa [14]. These situations are a common source of tensions to health care professionals striving to promote health, but also to support autonomous choices of their patients [15].

A range of concepts is used to study and understand what it means to live with the limitations of chronic illness. The focus of the present study is on the concepts personal autonomy and social participation. The social participation concept captures the impact of chronic illness on the performance of valued activities and social roles. The personal autonomy concept draws attention to the fact that different persons value different activities and social roles. While all people are embedded in a social context, they harbour different ideas and preferences 
about how these embeddings take shape. Moreover, personal autonomy is considered to be realized through relations and interactions with others. The combination of the concepts personal autonomy and social participation allows a comprehensive understanding of living with chronic illness, since people are individuals embedded in a social context.

The importance of personal autonomy to people with a chronic illness in the Netherlands is illustrated by the heavy protests against the drastic cutbacks on the system of personal budget ("PGB") in 2011. Having more control over the care received is the most mentioned reason to apply for a personal budget [16 in: 17]. In Europe, personal autonomy appears to have developed into an enforceable human right [18]. Generally, self-direction has high priority in value hierarchies in many countries [19].

Social participation benefits individuals and society. It makes people feel happy to feel that they matter to their friends and to spend time with them [20,21]. 90 Percent of Dutch adults who are at least once a month in touch with their family and friends feel happy, in contrast to 57 percent of those who are less frequent in touch with family and friends [22]. Symptoms of depression appear to be less common in older adults who are more socially involved [23]. Social participation, besides, produces social cohesion through social contact and commitment. It involves people helping each other out and taking care of each other, either informally or formally through organized volunteer work. As such, social participation contributes to a 'good society' [24].

Many studies on living with a chronic illness use qualitative research methods. To facilitate quantitative research on the subject, quantitative measurement instruments are needed. Existing instruments for autonomy far mostly assess autonomy as a trait rather than a state [25] or refer to contexts other than chronic illness, like adolescence or gender identity [26, 27]. Instruments referring to the context of chronic illness mostly focus on the medical domain [28, 29]. Autonomy of older adults with a chronic illness goes, in our view, beyond the medical context, into other domains of life as well. For example, domains of family life or leisure activities.

The same holds for social participation. Participation has a central place in the International Classification of Functioning, Disability and Health [30]. Much attention goes to participation regarding daily living. Less attention is paid to the ICF domains of interpersonal relationships, major life areas and, community, social and civic life. Also, existing instruments of social participation so far lack the measurement of diversity and the actuality of social activities [e.g. 31-33]. In this study, special attention will be paid to social participation.

Our conclusion is that existing instruments to measure autonomy or participation mostly focus on the medical context of chronic disease. A notable exception is the Impact on Participation and Autonomy (IPA) questionnaire [34], which 
measures people's chances to participate autonomously in several domains of life. The application of the IPA in research and its translation into multiple languages [35] illustrates the need for quantitative measuring instruments for participation and autonomy in relation to disability and chronic illness. The IPA covers the intersection of participation and autonomy. We will focus on developing instruments that allow separate measurement of autonomy and social participation in the broader context of living with the limitations of chronic disease, especially valued activities related to social functioning.

The aim here is to develop instruments that measure personal autonomy and social participation of older adults with a chronic physical illness corresponding with their own experience of autonomy and social participation.

\section{Aims and outline}

The aim of our study is to develop:

1. a valid, reliable and responsive measurement instrument for personal autonomy of older adults with a chronic physical illness with the purpose of discrimination and evaluation.

2. a valid, reliable and responsive measurement instrument for social participation of older adults with a chronic physical illness with the purpose of discrimination and evaluation.

Personal autonomy and social participation are related, but distinct concepts. For this reason, two distinct instruments were developed. The development of the actual instruments was preceded by pre-studies to conceptualize personal autonomy and social participation in the context of chronic physical illness in older adults. This was considered to be of crucial importance, because validity requires not only a sound operationalization, but also a clear conceptualization [36].

Chapter 2 conceptualizes personal autonomy in the context of chronic physical illness based on a review of the literature. Contemporary philosophical theories of autonomy are compared and contrasted with social scientific perspectives on chronic illness. Chapter 3 develops an empirically grounded conceptualization of personal autonomy in the light of chronic illness based on a qualitative study. Chapter 4 reports on the development and measurement properties of the Maastricht Personal Autonomy Questionnaire (MPAQ). Chapter 5 combines a literature study and qualitative study to conceptualize social participation in line with the experiences of older adults with a chronic physical illness. Chapter 6 reports on the development and measurement properties of the Maastricht Social Participation Profile (MSPP). Chapter 7 presents a general discussion, where we formulate some general conclusions, and in which we reflect on the relationship between the concepts of personal autonomy and social participation, together with the 
strengths and limitations of the study. This chapter concludes with suggestions for further development of the instruments and suggestions when to apply these instruments in other research. 


\section{References}

1. Eurostat database (2013). People having a long-standing illness or health problem, by sex, age and educational level (\%). Available from: http://appsso.eurostat.ec.europa.eu/nui/show.do?dataset=hlth_silc_05\&lang=en

2. CBS Statline (2012). Gezondheid aandoeningen beperkingen; persoonskenmerken. Available from: http://statline.cbs.nl/StatWeb/publication/?VW=T\&DM=SLNL\&PA=81173NED\&D1=27-30\&D2=1213\&D3=a\&D4=|\&HD=130203-1140\&HDR=G3,T\&STB=G1,G2

3. Blokstra, A., Baan, C. A., Boshuizen, H. C., Feenstra, T. L., Hoogenveen, R. T., Picavet HS, J., Smit, H. A., Wijga, A. H., and Verschuren WM, M. (2007). Vergrijzing en toekomstige ziektelast. prognose chronische ziektenprevalentie 2005-2025 [Impact of the ageing population on burden of disease. Projections of chronic disease prevalence for 2005-2025]. RIVM rapport 260401004, available from: http://www.rivm.nl/bibliotheek/rapporten/260401004.html.

4. Bruggink, J.W., M.J. Garssen, B.J.H. Lodder en M. Kardal, 2009, Trends in gezonde levensverwachting. Bevolkingstrends, 57(1), blz. 60-66.

5. CBS Statline (2013). Gezonde levensverwachting; vanaf 1981. Available from: http://statline.cbs.nl/Stateb/publication/?VW=T\&DM=SLNL\&PA=71950NED\&D1=0,5\&D2=a\&D3=14\&D4=a\&D5=a\&HD=130203-1056\&HDR=G2,G1,T,G3\&STB=G4

6. Faircloth, C.A., Boylstein, C., Rittman, M., Young, M.E. and Gubrium J. (2004). Sudden illness and biographical flow in narratives of stroke recovery. Sociology of Health \& Illness, doi:10.1111/j.1467-9566.2004.00388.x.

7. Sanders, C., Donovan, J. and Dieppe, P. (2002). The significance and consequences of having painful and disabled joints in older age: co-existing accounts of normal and disrupted biographies. Sociology of Health and IIIness, doi:10.1111/1467-9566.00292.

8. Williams, S. (2000). Chronic illness as biographical disruption or biographical disruption as chronic illness? Reflections on a core concept, Sociology of Health and Illness, doi:10.1111/14679566.00191.

9. Pound, P., Gompertz, P. and Ebrahim, S. (1998). Illness in the Context of Older Age: The Case of Stroke, Sociology of Health \& Illness, doi:10.1111/1467-9566.00112.

10. Townsend, A., Wyke, S. and Hunt, K. (2006). Self-managing and managing self: practical and moral dilemmas in accounts of living with chronic illness. Chronic Illness, DOI: 10.1177/17423953060020031301.

11. Drummond, N. and Mason C. (1990). Diabetes in a social context: just a different way of life in the Age of Reason, p. 37-54 in: Readings in Medical Sociology, S. Cunningham-Burley and N. McKeganey (Editors). Routledge: London.

12. Bury, M. (1982). Chronic illness as biographical disruption. Sociology of Health \& Illness, 4(2), 16782.

13. Woodcock, A., and Kinmonth, A. L. (2001). Patient concerns in their first year with type 2 diabetes: patient and practice nurse views. Patient education and counseling, 42(3), 257-270.

14. Siegert, R. J. and Taylor, W. J. (2004). Theoretical aspects of goal-setting and motivation in rehabilitation. Disability and Rehabilitation, 26(2), 1-8.

15. Hunt, M. R. and Ells, C. (2010). Partners towards autonomy: risky choices and relational autonomy in rehabilitation care. Disability and Rehabilitation, 33(11), 961-967.

16. Ramakers, C. (2010). Op weg naar een solide pgb. Beleidssamenvatting. Nijmegen: Instituut voor Toegepaste Sociologie.

17. Sadiraj, K. , Oudijk, D., Van Kempen, H. and Stevens, J. (2011). De opmars van het pgb; De ontwikkeling van het persoonsgebonden budget in nationaal en internationaal perspectief. Den Haag: Sociaal en Cultureel Planbureau.

18. Koffeman, N.R. (2010). (The right to) personal autonomy in the case law of the European Court of Human Rights. Leiden: Leiden University. Report. 
19. Schwartz, S. H. and Bardi, A. (2001). Value hierarchies across cultures. Journal of Cross-Cultural Psychology, 32(3), 268-290.

20. Demir, M., A. Özen, A. Doğan, N.A., Bilyk, F.A. and Tyrell (2010). I matter to my friend, therefore I am happy: Friendship, mattering, and happiness. Journal of Happiness Studies, DOI: 10.1007/s10902-010-9240-8.

21. Argyle, M. (2001). The psychology of happiness (second edition). Routledge, Hove.

22. Mars, G. and Schmeets, H. (2011). Meer sociale samenhang, meer geluk? [ More social cohesion, more happiness?] Bevolkingstrends, 59(3), 39-44.

23. Abu-Rayya, H. M. (2006). Depression and social involvement among elders, The internet journal of health, doi:10.5580/1df2.

24. Wallace, C. and Pichler, F. (2009). More participation, happier society? A comparative study of civil society and the quality of life. Social Indicators Research (93)2, 255-274.

25. Clark, D.A., et al. (1995). Psychometric characteristics of revised Sociotropy and Autonomy Scales in college students. Behaviour Research and Therapy, 33(3), p. 325-334.

26. Anderson, R.A., et al., (1994). The development of an autonomy scale. Contemporary Family Therapy, 16(4), p. 329-345.

27. Bekker, M.H. (1993). The development of an Autonomy scale based on recent insights into gender identity. European Journal of Personality, 7, 177-194.

28. Stiggelbout, A.M., Molewijk, A.C., Otten, W., Timmermans, D.R.M., Van Bockel, J.H. and Kievit, J. (2004). Ideals of patient autonomy in clinical decision making: a study on the development of a scale to assess patients' and physicians' views. Jounal of Medical Ethics, 30, 268-274.

29. Williams, G. C., Freedman, Z.R., Deci. E.L. (1998). Supporting Autonomy to Motivate Patients With Diabetes for Glucose Control, Diabetes Care, 21, 1644-1651.

30. World Health Organization (2001) International Classification of Functioning, Disability and Health (ICF). Geneva: World Health Organization.

31. Wilkie, R., Peat, G., Thomas, E., Hooper, H., \& Croft, P. R. (2005). The Keele assessment of participation: A new instrument to measure participation restriction in population studies. Combined qualitative and quantitative examination of its psychometric properties. Quality of Life Research, 14(8), 1889-1899.

32. Noreau, L., Desrosiers, J., Robicaud, L., Fougeyrollas, P., Rochette, A., \& Viscogliosi, C. (2004). Measuring social participation: Reliability of the LIFE-H in older adults with disabilities. Disability and Rehabilitation, 26(6), 346-352.

33. Holbrook, M., \& Skilbeck, C. E. (1983). An activities index for use with stroke patients. Age and Ageing, 12(2), 166-170.

34. Cardol, M., De Haan, R. J., de Jong, B. A., Van den Bos, G. A. M., \& De Groot, I. J. M. (2001). Psychometric properties of the 'Impact on Participation and Autonomy' (IPA) questionnaire. Archives of Physical medicine and Rehabilitation, 82(2), 210-216.

35. Nivel (2013). IPA - The questionnaire Impact on Participation and Autonomy. Available from: http://www.nivel.nl/en/ipa.

36. Carmines, E.G. and R.A. Zeller, Reliability and validity assessment. Quantitative Applications in the Social Sciences, ed. M.S. Lewis-Beck. Vol. 07-017. 1979, Newbury Park: Sage Publications 


\section{Chapter 2}

Conceptualizing autonomy in the context of chronic physical illness: relating philosophical theories to social scientific perspectives

Godelief M.J. Mars, Gertrudis I.J.M. Kempen, Guy A.M. Widdershoven, Peter P.M. Janssen* and Jacques T.M. van Eijk

Health (2008) 12, $333-348$

DOI: $10.1177 / 1363459308090052$ 


\begin{abstract}
The aim of this article is to conceptualize autonomy in the context of chronic physical illness. To this end, we compare and contrast a selection of contemporary philosophical theories of autonomy with social scientific perspectives on chronic illness, particularly models of disability and symbolic interactionism. The philosophical theories mainly depart from a positive conceptualization of autonomy, which involves actively shaping one's life and identifying with fundamental values. This conceptualization is preferred over a negative conceptualization, which defines autonomy as noninterference, for its compatibility with social models of disability and with the assumption that people are interdependent. Interference may disable, but also enable people with a chronic illness to shape their lives. What matters is that people can realize what they want to realize. We suggest that, in the context of chronic physical illness, autonomy might be conceptualized as correspondence between what people want their lives to be like and what their lives are actually like. Disturbed autonomy might be restored either by expanding opportunities to arrange life or by adjusting how one wants life to be arranged. The grounds for the latter approach might be questioned, first, if people have not adjusted what they want carefully, and second, if reorganization of the material and social environment would have made it unnecessary to adjust one's arrangement of life.
\end{abstract}




\section{Introduction}

Chronic physical illness may bring about pervasive changes in people's lives. For example, it may become difficult to perform valued activities and social roles, dependency on others may increase and future plans may need adjustment. Under these circumstances, it is a real challenge to preserve self-determination. People with a chronic illness continuously have to negotiate autonomy in their daily activities and in their relationships with family, friends and society [1].

Previous research has uncovered various threats to autonomy, such as functional decline, institutionalization, professionals' paternalistic approach, people's negative mindset and lack of clarity about goals, aspirations and purpose in life [26]. Opportunities to promote autonomy have been suggested as well, including cognitive behavioral therapy and a patient-centered approach by health professionals $[7,8]$.

The fact that previous research on autonomy has identified different threats and opportunities might be due to the use of different conceptualizations of autonomy. These may have different implications for research, policy and practice aimed at autonomy support. Consider, for example, the relationship between autonomy and dependence. As Berlin [9] already has pointed out, some scholars equate autonomy with independence and non-interference, which implies that dependence conflicts with autonomy. Yet other scholars conceptualize autonomy as actively shaping life in accordance with one's own values [9]. Other people may facilitate this, which means that dependence may enable autonomy. Then there are scholars who argue that all people depend on others during the entire life cycle, albeit to various degrees, which means that autonomy can only take shape through this interdependence [10]. Hence, depending on its conceptualization, autonomy may be promoted or impinged on by reducing dependence.

Which of the different conceptualizations of autonomy is 'the right one', is an issue unlikely to be resolved, because who should decide this and on what grounds [11]? We might, however, argue on pragmatic grounds why we favour a particular conceptualization in a particular context [11]. The implications of different conceptualizations of autonomy have been discussed in the contexts of different disciplines such as gerontology [4], nursing [e.g. 12-16], and rehabilitation [16]. In the context of chronic physical illness, however, the implications of different conceptualizations have not been discussed yet. It therefore remains unclear how autonomy might be understood with regard to chronic physical illness.

This article aims to conceptualize autonomy in the context of chronic physical illness. To this end, we compare and contrast a selection of contemporary philosophical theories of autonomy with social scientific perspectives on chronic illness. The philosophical theories offer a thorough debate on autonomy, while the 
social scientific perspectives provide a rich source of insights into living with chronic illness. Some of these philosophical theories adopt a view of human beings that has been criticized for its focus on reason and consciousness and its disregard of the social reality people are embedded in $[10,17,18]$. Although this criticism is deserved, we think the conceptual clarity of these theories may still help to conceptualize autonomy in the context of chronic physical illness, particularly in combination with the other theories that will be discussed.

First, we discuss the difference between negative and positive autonomy, an important classification of contemporary philosophical theories of autonomy. Next, we discuss four philosophical theories of autonomy in greater depth. The first theory [19] discusses prerequisites for autonomy, while the three other theories $[2,17,20-22]$ focus primarily on the conceptualization of autonomy. The second [20-22] has an individualistic, psychological focus, while the third [2] and fourth [17] put more emphasis on social conditions and practical circumstances. We relate each theory to social scientific perspectives on living with chronic illness, particularly social models of disability and symbolic interactionism. Furthermore, we relate each theory to the case of Anne, which is described in the next section. Finally, we suggest how autonomy might be conceptualized in the context of chronic physical illness and we briefly discuss some additional critical views on this concept of autonomy.

\section{The case of Anne}

Anne is a middle-aged woman who is married and has two sons away at college. Anne worked as a head nurse at the local hospital, when she was diagnosed with emphysema a few years ago. Emphysema is a lung disease that is characterized by shortness of breath and that gets worse gradually. At first, Anne continued her job full time with support of her colleagues, but then she got to the point where she was so tired when she got home from work, that all she could do was eat and go to bed. Her husband and sons took a larger share in housekeeping, but eventually, Anne decided to work shorter hours. It was tough on her, because she had to give up her post as a head nurse. Last year, Anne's company doctor told her that she had to quit her job entirely. Anne felt pushed out and had difficulty reconciling to disability. She therefore volunteered as a counsellor for people with a terminal illness, because she expected that as a counsellor, she could truly be there for patients, which she often had felt she could not when she was head nurse. Today, the positive feedback from patients and colleagues gives Anne much satisfaction and she enjoys counselling.

How might autonomy be understood in Anne's case? Is it impinged on, because she first lost her position as head nurse and then her entire job? Or is this a 
prime illustration of autonomy, because Anne makes her own decisions, takes initiative, and finds a solution?

\section{Negative and positive autonomy}

An important classification of contemporary philosophical theories of autonomy is the distinction between negative and positive autonomy, which was first made by Berlin [9]. While negative autonomy refers to non-interference, positive autonomy refers to actively shaping one's life and identifying with fundamental values. It is about being in charge of life [9].

In negative conceptualizations of autonomy, a person is autonomous if no one interferes with his/her actions. In the context of chronic illness, concerned family members who prevent certain activities or, in case of institutionalization, restrictive regulations may impinge on negative autonomy. In the case of Anne, negative autonomy is not impinged on by working shorter hours, because no one interfered to make this happen. It is however impinged on by the eventual job loss, because the company doctor ordered this.

Since negative autonomy may be promoted by minimizing interference, it is compatible with medical models of disability, which present disability as an individual attribute, which is caused by disease and may be solved by medical intervention [23]. Furthermore, it is in line with a particular version of social models of disability, the minority group approach. This approach considers people with disabilities as a minority group whose civil rights must be protected by antidiscrimination legislation. Discrimination is an impingement on negative autonomy, because people are hindered in their actions by others [24].

Generally speaking though, negative autonomy is not compatible with social models of disability because these models argue that interference may be enabling as well as disabling. In particular, social models contend that restrictions and opportunities exist side by side, because the material and social organization of the environment varies in the degree in which the needs of people with a chronic illness are taken into account [24]. Hence, a social model might for example reason, that when Anne lost her position as head nurse, her autonomy could have been preserved if her employer had assigned another head nurse to share the position with Anne part-time.

In positive conceptualizations of autonomy, a person is autonomous if she actively shapes her life and identifies with fundamental values. In Anne's case, positive autonomy is impinged on because Anne does not succeed in holding down her job although she wants to work. Positive autonomy is compatible with social and socio-medical models of disability. The latter relate restrictions in activities and social participation to an interaction between person, disease and environ- 
ment [e.g. 25, 26]. Hence, in this view, Anne loses her job because she has emphysema and both she and her employer do not adapt to this circumstance adequately.

Positive autonomy may be promoted by increasing people's opportunities to arrange their lives. As mentioned earlier, the minority group version of the social model wants to create equal opportunities by means of anti-discrimination legislation. Another version of the social model calls for universalizing disability policy: rather than focusing on special needs, policy should acknowledge the wide variation between people and commit to 'universal design, not merely for public buildings and transportation, but across the board for housing, workplaces and other human environments' [24: 1183].

As mentioned briefly in the introduction, the difference between negative and positive autonomy is also relevant to the relationship between autonomy and dependence. Gignac and Cott [27] distinguish four types of dependence/independence: dependence (needs and receives assistance), imposed dependence (does not need, but receives assistance), independence (does not need and does not receive assistance), and non-independence (needs, but does not receive assistance). As mentioned earlier, we might also think of people as interdependent, that is, dependent on each other, rather than distinguishing between dependence and independence [10]. Anne's case has elements of dependence (her colleagues and family provided assistance that Anne needed), independence (Anne does not need and does not receive assistance to do her volunteer work), non-independence (Anne did not receive the assistance she needed to keep her paid job in general and her position as head nurse in particular) and interdependence (Anne's family, patients and colleagues depend on her support, care, instructions etcetera).

In negative conceptualizations, dependence, imposed dependence and interdependence are impingements on autonomy (interference), while independence and non-independence are not (non-interference). Put differently, in negative conceptualizations of autonomy, it matters whether people receive assistance and not whether they need it. If people do not receive the assistance they need, the environment may not be enabling, but what matters here is that it is not interfering either.

In positive conceptualizations, independence, dependence and interdependence are compatible with autonomy, while non-independence is not. Imposed dependency is compatible if it is self-imposed. Baltes [28] has called this selfregulated dependence: people accept dependence in certain domains in order to have enough energy for other domains that they value more. In other words, in positive conceptualizations of autonomy, it matters whether people get what they need. 
In summary, chronic illness may impinge on both negative and positive autonomy, but the circumstances under which this occurs differ. Negative autonomy is impinged on if someone receives assistance (regardless of whether or not she needs it), while positive autonomy is impinged on if someone does not receive the assistance she needs. Generally, we would argue for a positive conceptualization of autonomy in the context of chronic physical illness, because it takes account of people's actual needs and is compatible with social models of disability and with the assumption that people are interdependent. Despite this compatibility, not all positive philosophical theories of autonomy actually discuss autonomy in a social context, as the discussion of split-level theory below will show. First, we turn to Feinberg [19], who has presented a model of prerequisites for autonomy, which includes both positive and negative elements.

\section{Prerequisites for autonomy}

According to Feinberg [19], people are autonomous if they display a certain blend of virtues, including authenticity, identification, initiative and responsibility for self. This condition of autonomy depends on three necessary - but not sufficient prerequisites. First, people need the capacity to govern themselves, which is determined by the ability to make rational choices. Second, people need the right to be a sovereign authority. In order to acquire this right, the capacity to govern oneself should be above a certain threshold. Third, people need opportunities, which depend on luck according to Feinberg.

It seems that all three prerequisites for autonomy might be affected by chronic illness. First, diseases like Alzheimer's disease or stroke might affect one's capacity. In these cases, someone may not only experience difficulty in reflecting on what they want, but also in making her wishes known to others (impingement on positive autonomy). Pain or fatigue may also influence decision-making. Second, the right to be a sovereign authority is at stake if people's legal capacity is questioned or if people have to submit to restrictive regulations in institutions (impingement on negative autonomy). Third, if we extend Feinberg's theory using models of disability, opportunities may be restricted as a result of disease and/or the material and social organization of the environment, which may not adequately take into account the needs of people with a chronic illness (impingement on positive autonomy).

In our example, Anne has both the capacity and the right to be a sovereign authority, but there is a lack of opportunity to hold down her job. This may be explained differently, depending on the model of disability used. From a medical point of view, Anne might not be fit enough physically to hold down her job. Social models might focus on the efforts of Anne's employer to meet her special 
needs. A socio-medical model might consider not only medical and social, but also personal factors like activity accommodation and coping.

Feinberg's model does not reveal clearly in which circumstances Anne might actually be considered autonomous, because Feinberg does not specify the exact composition of characteristics that make up the condition of autonomy. Might Anne be considered autonomous because she takes initiative and responsibility for herself, first by reducing her working hours and then by volunteering as a counsellor? Or might she not be considered autonomous because she does not identify with disability? The theories in the following three sections present positive conceptualizations of the condition of autonomy.

\section{Split-level theory}

Split-level theory consists of a theory of the person developed by Frankfurt [22] and a theory of autonomy developed by Dworkin [20,21].

Frankfurt [22] bases his theory on the capacity of persons to reflect on what they want to be motivated by. This capacity leads to a hierarchical order of desires. First-order desires express what a person wants. A person can have multiple desires, which may possibly, but not necessarily conflict. Not all desires result in action. If a first-order desire leads to action, it is called an effective desire. For example, a person with congestive heart failure may have both the desire to take the bus to work as usual, and to travel to work by bicycle, as advised by her doctor to get regular exercise. If the person takes the bus, this is the effective desire. Second-order desires express what a person wants to want, i.e. what she wants to be motivated by. They are formed through rational, reflective self-evaluation. The person in the example might decide that she wants to be motivated by the desire to travel by bike, lifting this desire to the second order.

Dworkin $[20,21]$ adds to this, stating that second-order desires do not have to be unique or attained uninfluenced, but they must undergo critical scrutiny in order to become one's own. The desires that people have are theirs, but not automatically their own. For example, health promotion programs may make people feel that they should exercise regularly, adhere to a balanced diet or quit smoking, but in order to make these kinds of lifestyle modifications second-order desires, people have to ask themselves whether these modifications are something that they really want themselves. It is crucial to autonomy that people possess the capacity to raise the question of whether I will identify with or reject the reasons for which I now act' [20: 15]. This evaluation must occur free from subverting influences, such as manipulation or coercive persuasion. Spouses who keep on about regular exercise and authoritarian medical professionals who tell people to modify their lifestyle, present obstacles to an evaluation made in freedom. 
Dworkin further argues that autonomy is not a mere reflective notion, but also includes the attempt to make the outcome of evaluation effective. This means that people should try to act for the reasons for which they want to act (e.g. try to travel to work by bike). Dworkin emphasizes that it is the attempt that matters, not whether people actually succeed in acting for the reasons for which they want to act. One of Dworkin's arguments is that people might otherwise realize autonomy via intuitively wrong ways. In particular, Dworkin feels that there is something wrong with scaling down second-order desires in order to become autonomous.

The issue is particularly relevant in the context of chronic illness because scaling-down is exactly what may happen in response to chronic illness. Charmaz [29] describes how people move up and down an identity hierarchy in response to the course of illness and their social situations. An identity hierarchy consists of identity goals, which represent what or who a person wants to be, strives or hopes for, either explicitly or implicitly. Moving up and down the hierarchy, people weigh different identities against each other and determine which to give up in order to retain others (identity trade-offs). Generally, deterioration in physical functioning will force people to scale down their identity goals, while an improvement in physical functioning will encourage people to scale up their identity goals. Some people are hesitant to scale down identity goals, because they underestimate their decline, find the resulting identity losses too great or have strong feelings of commitment and responsibility. Other people are hesitant to scale up identity goals, because they fear failure or relapse [29].

According to Dworkin, people who scale down identity goals are not autonomous. On closer reading, however, Dworkin seems to be particularly concerned that people might scale down second-order desires too easily in order to realize autonomy. Dworkin would have difficulty accepting that a person who has decided she wants to travel to work by bike realizes autonomy by taking the bus at the first sight of rain and then deciding that traveling by bike is not what she wants after all. However, Dworkin would probably agree that scaling down second-order desires might produce autonomy after critical self-evaluation, as is the case in identity trade-offs. For example, a person may discover that she could really use a shower when she travels to work by bike, but that there are no facilities. After carefully considering whether she really wants to travel to work by bike under these circumstances, she might decide that she would rather travel by bus.

Applying Dworkin's argumentation to the case of Anne, what Anne does is not really all that relevant in the end, as long as she does it after careful consideration. Whether she would have volunteered as counsellor or protested against the loss of her job or decided that she wanted to spend her limited energy on, say, social activities, she is considered autonomous if she identifies with the reasons for her actions. 


\section{Actual autonomy}

In contrast to Feinberg [19] and Dworkin [20, 21], Agich [2] approaches autonomy as embedded in the practical, social world of everyday life. Rather than making autonomy an abstract ideal, Agich focuses on actual autonomy. He is critical of the idea proposed by split-level theory, that second order desires are formed through reflective self-evaluation. According to Agich, higher order principles (i.e. Dworkin's second order desires) are not a top-down affair, as claimed by splitlevel theory, but the product of a two-way process. Higher-level principles are constructed from actual experiences and choices; they guide future actions. These actions in turn influence the higher-level principles. Rather than an end-state, autonomy should be conceived as an on-going process: 'To be an autonomous person in the world is to develop (...) as an integrative process of accommodating oneself to new circumstances and adapting those circumstances to one's unique structures of meaning' [2: 106].

Certainly, Agich does not deny that people might reflect on who they are or what guides them. In particular, existential crises, life transitions or sickness may bring people to consciously consider such matters. But this is not how autonomy is displayed in daily life. In daily life, people display autonomy through constant adjustment of their intentions to the opportunities and limitations encountered in their interaction with the world. A sense of self can be derived from people's actual choices, motivations and experiences, which can be expressed in terms of higher level principles. These principles guide future action and are subject to change. Agich's point is that these principles are the product of real life, rather than critical reflection. Autonomy is an on-going process in which people develop, express and confirm their identity in interaction with the world around them.

Agich's presentation of autonomy including accommodation and identity development shows close parallels to symbolic interactionist work on biographies $[30,31]$. According to this work, people experience a biographical disruption when they are confronted with chronic illness, meaning that they can no longer rely on assumptions and behaviours that they formerly took for granted [30]. Restoring a biography requires the fulfilment of four tasks, which occur simultaneously and interact with each other. People have to integrate the course of illness into their biography, they must reach a certain degree of understanding and acceptance of the consequences of illness, they must reconstruct their identity, and finally, they must give their biography a new direction [31: 68].

Both the symbolic interactionists and Agich assume an on-going process, in which events and experiences in daily life may disturb people and their identities, but may then be integrated and guide future actions. In this view, then, changing higher order principles is a valid and natural way to establish correspondence between higher order principles and actions. In fact, from Agich's point of view, it 
is a necessary course to restore autonomy, since Agich considers accommodating to circumstances as necessary for the process of autonomy.

In Anne's case, autonomy would thus involve an adjustment of her intentions to disability. Anne would have to reconstruct her identity, incorporating disability. She actually does this by volunteering for counsellor, which enables her to continue to work with patients despite disability.

\section{Relational autonomy}

The developmental nature of autonomy and its embeddedness in the social world, which Agich [2] stresses, have also been addressed by feminist scholars [17]. They criticize the inherent individualism and rationalism of prevailing conceptualizations of autonomy. In contrast, they conceptualize autonomy relationally, aiming to express that people are not only rational, but emotional and creative as well, and that they are embedded and socialized in a social and historical context in which they depend on each other. Through social relationships and in networks, people constitute their identity and find recognition of it. Only through the social context, can autonomy take shape [32].

Unlike Agich [2] and like split-level theory [20-22], the relational scholars attribute a central place to conscious reflection in the realization of autonomy. However, unlike split-level theory and like symbolic interactionism [31, 33], they contend that reflection does not necessarily have to be rational, but may also involve emotions, creativity or imagination [34, 35]. Symbolic interactionism too describes how people make sense of and give meaning to their lives by daydreaming, imagining and constructing stories [31, 33]. According to the relational scholars, reflection is not primarily an individual matter, but a process that takes place through interaction and communication. Autonomy thus is based upon dialogical hermeneutic procedures. This entails a view of autonomy as self-development through dialogue [36].

In the case of Anne, relational autonomy is illustrated by the support of family and colleagues who help Anne, first, to continue her job and then to make a tough decision and give up her position as head nurse to reduce work hours. Relational autonomy is impinged on when Anne hears that she will lose her job and feels pushed out. The company doctor does not have attention for Anne's circumstances and does not offer any support. Relational autonomy requires that Anne can take account of her feelings in this difficult situation and gets support from others to find a solution that fits her needs. One might question whether the situation could not have been changed in such a way that Anne would have been able to continue working at the hospital. After this phase, Anne is able to find a new way of living, in interaction with others. The position as a counsellor seems 
an opportunity for Anne to develop herself and the positive feedback from colleagues and patients seems to reinforce her satisfaction with the position.

\section{Discussion}

We have presented a selection of philosophical theories of autonomy in relation to the context of chronic physical illness as described by social scientific perspectives. The emphasis was on positive autonomy, although chronic illness might also impinge on negative autonomy. A negative conceptualization of autonomy seems however unsatisfactory in the context of chronic illness because it focuses on impingements on autonomy due to interference from the environment. In contrast, a positive approach is compatible with interference provided it meets people's needs, although not all positive theories of autonomy take account of the social and practical context of daily life in which people depend on each other, as split-level theory illustrates.

Dworkin [20, 21], Agich [2] and the relational scholars [17] all present positive conceptualizations of autonomy, but Dworkin focuses on an individual, psychological process, while Agich and the relational scholars focus on accommodation to the social, practical world of daily life. According to Dworkin, critical reflection on desires is the key to autonomy. Hence, as long as chronic illness does not affect the capacity to reflect, it does not threaten autonomy. Agich argues, that chronic illness may change some one's daily reality in such a way that she can no longer identify with it. Autonomy then requires accommodation to the changed circumstances.

When accommodation is difficult, Agich suggests that the circumstances might need to be changed to facilitate identity development. Likewise, social and socio-medical models of disability point out, that a restrictive material and social organization of the environment may restrict opportunities. Hence, reorganization of the environment might increase opportunities and make accommodation superfluous.

If this is so, then Dworkin is right to express his concern that people might scale down second-order desires too easily. Not because people might scale down desires without careful consideration, but rather because people might accommodate to opportunity ranges that are unnecessarily restrictive. In the case of Anne, allowing part-timers to share the position of head nurse might have enabled Anne to keep her position as head nurse while she worked at the hospital.

The importance of opportunities is recognized by Feinberg [19], who presents opportunities as a necessary prerequisite of autonomy. Feinberg's model offers conceptual clarity, putting the condition of autonomy at the centre, with capacity, right and opportunities as prerequisites. However, it also has three important 
shortcomings. First, it ignores the social context people are embedded in, because it presents opportunities simply as the result of bad luck. As already indicated above, this might be 'fixed' in the context of physical chronic illness by extending Feinberg's model with a model of disability. We would suggest a socio-medical model, because it considers the interplay between person, disease and environment instead of focusing on one aspect. Second, Feinberg's model narrows the capacity to direct one's life down to the ability to make rational choices, which feminist scholars, amongst others, have long agitated against [17]. And third, it does not specify the exact composition of characteristics that make up the condition of autonomy.

The second and third shortcoming of Feinberg's model might be fixed by combining it with the theories of the condition of autonomy (split-level theory, actual autonomy and relational autonomy). In all these three theories, achieving correspondence between higher order principles and actions appears to be the 'ultimate goal' of autonomy. However, split-level theory still has in common with Feinberg's model an ignorance of the social context and a focus on rational reflection. Also, its conceptualization of autonomy implies that autonomy requires that people know their desires. Yet this assumption has been criticized from different perspectives. Psychoanalysts, for instance, argue that persons do not know all their desires, because unconscious psychological processes may be at work. Marxist structuralist scholars argue that persons can never truly know what they want, because they are always shaped by circumstances formed by former generations. And poststructuralist scholars, for example, add to this, that the meaning of an identity can never be completely fixed, as meanings in general never are, because they are expressed in language, which is a social system in which meanings arise and vary in relation to others [18].

These points of critique have led scholars to reject the idea of autonomous persons altogether. Alternatively, the relational scholars and Agich present conceptualizations of autonomy which meet those critiques to some extent. Relational and actual autonomy can only take shape through the social, historical environment. Furthermore, the relational scholars broaden the capacity to direct one's life from rational reflection to involve emotions, creativity and dialogue as well, while Agich argues that conscious reflection is a possible, but not the usual way in which principles are developed and modified. Higher order principles are rather the product of choices and experiences in real life.

We therefore suggest conceptualizing autonomy in the context of physical chronic illness as correspondence between what people want their lives to be like and what their lives are actually like. To achieve this correspondence, people need to develop principles expressing what they want their lives to be like. They furthermore need the opportunities to arrange their lives. People generally develop these principles in daily life, as they interact, make choices and gather experienc- 
es. Reflection - involving ratio, emotions, creativity, imagination or dialogue can, however, also play a role in the process of developing and modifying principles. If chronic illness has disturbed the correspondence between what people want their lives to be like and what their lives are actually like, the correspondence may be restored either by increasing the opportunities to arrange life or by adjusting how one wants life to be arranged. The grounds for the second approach might be questioned, first, if people have not carefully changed what they want, and second, if reorganization of the material and social environment would have made it unnecessary to adjust principles about the arrangement of life. 


\section{References}

1. Williams, G.H. and Wood, P.H.N. (1988). Coming to terms with chronic illness: the negotiation of autonomy in rheumatoid arthritis. International Disability Studies, 10, 128-133.

2. Agich, G.J. (1993). Autonomy and Long-Term Care. New York: Oxford University Press.

3. Becker, G. (1994). The Oldest-Old - Autonomy in the Face of Frailty. Journal of Aging Studies, 8, 5976.

4. Collopy, B.J. (1988). Autonomy in Long Term care: Some Crucial Distinctions. The Gerontologist, 28, Supplement, 10-17.

5. Hickey, T. and Stilwell, D.L. (1992). Chronic Illness and Aging - a Personal-Contextual Model of AgeRelated-Changes in Health-Status. Educational Gerontology, 18, 1-15.

6. McWilliam, C.L., Brown, J.B., Carmichael, J.L. and Lehman, J.M. (1994). A new perspective on threatened autonomy in elderly persons: The disempowering process. Social Science \& Medicine, 38, 327-338.

7. Rybarczyk, B., Gallagher-Thompson, D., Rodman, J., Zeiss, A., Gantz, F.E. and Yesavage, J. (1992). Applying Cognitive-Behavioral Psychotherapy to the Chronically III Elderly: Treatment Issues and Case Illustration. International Psychogeriatrics, 4, 127-140.

8. Williams, G.C., Freedman, Z.R. and Deci, E.L. (1998). Supporting Autonomy to Motivate Patients with Diabetes for Glucose Control. Diabetes Care, 21, 1644-1651.

9. Berlin, I. (1969). Four essays on liberty. Oxford: Oxford University Press.

10. Tronto, J.C. (1993). Moral boundaries: A political argument for an ethic of care. New York: Routledge.

11. Seidman, S. (1992). Postmodern Social Theory as Narrative with a Moral Intent. In S. Seidman and D.G. Wagner (Eds.), Postmodernism and social theory: The debate over general theory. Cambridge: Blackwell Publishers.

12. Aveyard, H. (2000). Is there a concept of autonomy that can usefully inform nursing practice? Journal of Advanced Nursing, 32, 352-358.

13. Ballou, K.A. (1998). A concept analysis of autonomy. Journal of Professional Nursing, 14, 102-110.

14. Hertz, J.E. (1996). Conceptualization of perceived enactment of autonomy in the elderly. Issues in Mental Health Nursing, 17, 261-273.

15. Keenan, J. (1999). A concept analysis of autonomy. Journal of Advanced Nursing, 29, 556-562.

16. Proot, I.M., Crebolder, H.F.J.M., Huijer Abu-Saad, H. and Ter Meulen, R.H.J. (1998). Autonomy in the rehabilitation of stroke patients in nursing homes. A concept analysis. Scandinavian Journal of Caring Sciences, 12, 139-145.

17. Mackenzie, C. and Stoljar, N. (Eds.). (2000). Relational autonomy: Feminist perspectives on autonomy, agency, and the social self. New York: Oxford University Press.

18. Hall, S. (1992). The question of cultural identity. In S. Hall, D. Held and T. McGrew (Eds.), Modernity and its futures. Cambridge: Polity Press.

19. Feinberg, J. (1986). Harm to self. The moral limits of the criminal law. New York: Oxford University Press.

20. Dworkin, G. (1988). The Theory and Practice of Autonomy. Cambridge: Cambridge University Press.

21. Dworkin, G. (1989). The Concept of Autonomy. In J. Christman (Ed.), The inner citadel: Essays on individual autonomy. New York: Oxford University Press.

22. Frankfurt, H.G. (1989). Freedom of the Will and the Concept of a Person. In J. Christman (Ed.), The inner citadel: Essays on individual autonomy. New York: Oxford University Press.

23. Barnes, C., Mercer, G. and Shakespeare, T. (1999). Exploring Disability: A Sociological Introduction. Cambridge: Polity Press.

24. Bickenbach, J.E., Chatterji, S., Badley, E.M. and Üstün, T.B. (1999). Models of disablement, universalism and the international classification of impairments, disabilities and handicaps. Social Science \& Medicine, 48, 1173-1187. 
25. Verbrugge, L.M. and Jette, A.M. (1994). The Disablement Process. Social Science \& Medicine, 38, 1-14.

26. WHO (2001). The international classification of functioning, disability and health - ICF. Geneve: World Health Organization.

27. Gignac, M.A.M. and Cott, C. (1998). A conceptual model of independence and dependence for adults with chronic physical illness and disability. Social Science \& Medicine, 47, 739-753.

28. Baltes, M.M. (1996). The Many Faces of Dependency in Old Age. Cambridge: Cambridge University Press.

29. Charmaz, K. (1995). The Body, Identity and Self: Adapting to Impairment. The Sociological Quarterly, 36, 657-680.

30. Bury, M. (1982). Chronic Illness as biographical disruption. Sociology of Health \& Illness, 4, 167182.

31. Corbin, J. and Strauss, A.L. (1988). Unending work and care: Managing chronic illness at home. San Francisco: Jossey-Bass Publishers.

32. Mackenzie, C. and Stoljar, N. (2000). Introduction: Autonomy refigured. In: C. Mackenzie and N. Stoljar (Eds.), Relational autonomy: Feminist perspectives on autonomy, agency and the social self. New York: Oxford University Press.

33. Frank, A.W. (1995). The wounded storyteller: Body, illness and ethics. Chicago: The University of Chicago Press.

34. Friedman, M. (2000). Autonomy, social disruption, and women. In: C. Mackenzie and N. Stoljar (Eds.), Relational autonomy: Feminist perspectives on autonomy, agency and the social self. New York: Oxford University Press.

35. Mackenzie, C. (2000). Imagining oneself otherwise. In C. Mackenzie and N. Stoljar (Eds.), Relational autonomy: Feminist perspectives on autonomy, agency and the social self. New York: Oxford University Press.

36. Widdershoven, G.A.M. (1999). Care, cure and interpersonal understanding. Journal of Advanced Nursing, 29, 1163-1169. 


\section{Chapter 3}

\section{How do people with COPD or diabetes type 2 experience autonomy? An exploratory study}

Godelief M. J. Mars, Ireen M. Proot, Peter P.M. Janssen, Jacques Th. M. van Eijk, Gertrudis I. J. M. Kempen

Disability and Rehabilitation (2007) 29, $485-493$

DOI: 10.1080/09638280600841323 


\section{Abstract}

Purpose. To develop an empirically grounded conceptualization of personal autonomy in the context of chronic physical illness and to investigate the impact of two chronic illnesses on autonomy.

Method. Grounded theory study consisting of 13 in-depth interviews with older adults with Chronic Obstructive Pulmonary Disease (COPD) or diabetes mellitus type 2 (diabetes).

Results. The results indicate that autonomy involves taking account of current circumstances as the frame of reference in which people can arrange their lives. Chronic illness disturbed autonomy by limiting opportunities and by prompting a reappraisal of the value that people placed on different activities or aspects of life. The participants responded to this disturbance differently, in ways that did not always restore autonomy. Limited opportunities occurred more often with COPD, while reappraisal occurred more often with diabetes.

Conclusions. Personal autonomy in the context of chronic physical illness might be conceptualized as correspondence between the way people's lives are actually arranged and the way people want their lives to be arranged, considering the circumstances. Health professionals could stimulate their clients to prevent and overcome impasses in the realisation of autonomy, while broad self-management interventions might improve people's skills for coping with the impact of chronic illness on autonomy. 


\section{Introduction}

Over the last decade, there has been growing attention for the autonomy of patients with a chronic illness, as demonstrated by the development of concepts like client or patient-centeredness [1], shared decision-making [2] and selfmanagement [3]. These concepts stress the need to see people as individuals rather than patients and to take account of their individual life circumstances. This implies that we should not only be concerned with the autonomy people experience in interactions with caregivers, but also with the autonomy that they experience in their lives in general. How does chronic illness affect personal autonomy?

Research into the personal autonomy of people with a chronic illness is scarce [4-7] and besides, the concept has been associated with a variety of interpretations like independence, identification and self-rule [8-10]. The concept is also said to contain a number of inherent polarities [11], one of which, according to Cardol, De Jong and Ward [12], merits particular attention in relation to disabling conditions: the polarity of decisional versus executional autonomy. This refers, on the one hand, to the ability and freedom to have preferences and make decisions, and on the other hand, to the ability and freedom to carry out these decisions. Physical disability may limit executional autonomy but not necessarily decisional autonomy [12].

An important product of decisional autonomy is self-realisation [12]. That is, if people have the freedom and ability to have preferences and make decisions, they may shape their lives into a meaningful existence. The question is, however, whether decisional autonomy results in self-realisation automatically. In other words, people may have the freedom and ability to make decisions, but does that automatically mean that decisions are realised as intended?

Rather than decisional and executional autonomy, a conceptualisation of autonomy might also focus on the way that life is actually arranged. Autonomy might then be conceptualised in terms of outcome, as we concluded in a previous literature study [13]. In particular, personal autonomy might be conceptualised as correspondence between the way a person wants his or her life to be arranged and the way his life actually is arranged [13]. For example, when someone highly values contact with friends, personal autonomy would involve actual contact with friends, for example by visiting them. Decisional autonomy in this context is the freedom and ability to decide to visit a friend, while executional autonomy is the freedom and ability to pay the visit. If someone needs and receives assistance to visit friends, executional autonomy is limited but decisional and personal autonomy are not. Put differently, decisional autonomy concerns the setting of one's own goals, executional autonomy the pursuit of these goals and personal auton- 
omy their actual achievement. Personal autonomy would therefore be particularly relevant as a rehabilitation outcome.

Critics might object that conceptualising autonomy as a correspondence does not clearly distinguish autonomy from related concepts like life satisfaction or quality of life, since these too are typically defined as some kind of correspondence. To improve our understanding of autonomy, we have therefore undertaken a qualitative study that empirically explored personal autonomy in the context of chronic physical illness.

The aim of this study was to develop an empirically grounded conceptualisation of personal autonomy in the light of chronic illness. Furthermore, we wanted to investigate the impact of chronic illness on autonomy, how people cope with this impact and whether the impact differs for different types of illness, in particular Chronic Obstructive Pulmonary Disease (COPD) and diabetes mellitus type 2 (diabetes).

\section{Method}

We conducted a grounded theory study [14], consisting of thirteen in-depth interviews with older adults with diabetes or COPD. By including two chronic diseases it was possible to explore whether different types of chronic illness have a different impact on autonomy. COPD and diabetes both cause a gradual deterioration, but differ in that COPD has intermittent exacerbations while diabetes is characterised by a long stabilisation phase followed by chronic complications [15]. The study was preceded by a pilot study.

Ethics committee approval was granted.

\section{Pilot study}

Pilot interviews were held with one woman with COPD (aged 61), one woman with diabetes (62) and one man with diabetes (48). Both women were relatives of the interviewer; the man was referred by a nurse specialist. The interviews were not used in the analysis, but served to test the interview guide and to check the interview and coding procedure.

The interview guide was adapted as a result of the pilot. Most importantly, the interview now began with questions about the onset and course of illness instead of current circumstances. Author GM and co-author IP both coded the third pilot interview independently to check whether GM approached the interview with an open mind and did not miss important aspects. Although coding by GM and IP showed overall agreement, it also stimulated GM to use more specific codes (for example 'acceptance by colleagues' instead of 'reactions at work'). 


\section{Sample}

We used a purposive sampling strategy, aiming to include older adults with diabetes or COPD with different levels of disease severity. Nurse specialists and a lung specialist referred men and women who had diabetes or COPD, were older than 54 years, who lived at home and agreed to receive more information about the study. To ensure a broad range of disease severity, selection took account of medication type and glycaemic control in the case of diabetes and spirometry outcomes in the case of COPD. Specifically, the selection resulted in two persons with diabetes who used oral medication and were satisfactorily regulated, two who used oral medication and were unsatisfactorily regulated (according to nurse specialist) and two who were insulin dependent. Three persons with COPD were selected with a Forced Expiratory Volume in 1 second (FEV1, frequently used spirometry outcome) above $50 \%$ and three with an FEV1 below $50 \%$. As analysis progressed, an additional person with COPD who continued to smoke was included, to facilitate a comparison between smokers and non-smokers (theoretical sampling [14]).

Potential participants received oral information about the study from the nurse specialist or lung specialist and, when they agreed, additional written and oral information from the researchers. The study was presented as a one-off interview about living with diabetes or COPD. Confidentiality was assured and people were free to withdraw from the study at any time. All but one of the persons referred by the nurse specialists and lung specialist agreed to participate.

The sample consisted of six persons with diabetes (four men, two women) and seven persons with COPD (five men, two women), ranging in age from 59 to 76 years. Of these thirteen participants, nine were married, one was living together, two were widowed and one was divorced. All resided in the south of the Netherlands. Comorbidity was not uncommon and played a considerable role in two persons with COPD: one person had congestive heart failure and the other had angina pectoris.

\section{Data collection}

An interview guide with open-ended questions was developed using sensitising concepts (concepts which broadly suggest directions to approach empirical instances [16]) from the previous literature study of autonomy in the context of chronic illness [13] and feedback from research team members and the three pilot interviews. The following subjects were addressed: course of illness, life changes, past and present activities, coping, arrangement of life, restrictions, opportunities, material and social environment. Initial responses were probed to understand participants' decisions, emotions and what things they valued. All questions were asked in each interview, but their sequence was adapted to par- 
ticipants' responses. Additional topics introduced by participants were explored as well.

Interviews lasted between one and two hours (typically $1 \frac{1}{4}$ hour) and took place at participants' homes, except one interview which was held at the university at the participant's request. In three cases (all COPD), the participant wanted the spouse to be present during the interview. The spouse was allowed to comment or remind the participant of things, but it was stressed that the aim of the interview was to understand the participant's own experiences.

All interviews were conducted by GM, who is a trained interviewer. All interviews but one were audio-taped and transcribed verbatim with all identifying information removed. One participant did not consent to the interview being recorded, but allowed extensive notes to be taken. Field notes were taken during each interview.

\section{Data analysis}

Data were analysed following the grounded theory approach as described by Strauss and Corbin [14]. We adopted this approach because it involves inductive analysis, allowing concepts to emerge from the data. Such concepts may be expected to be true for the experiences of the people interviewed. Furthermore, grounded theory aims at theory generation, explaining how a phenomenon (e.g. autonomy) varies under different conditions. This agreed with our aim to explore whether people with different illnesses have a different experience of autonomy.

Central to the grounded theory approach is the constant comparative method, which means that the researcher constantly compares incidents recorded in the data to other incidents in the data, looking for similarities and differences and thus labelling and specifying concepts and their properties, dimensions and relations. Three types of coding are used: open, axial and selective coding. Open coding refers to deriving codes from the data and starting to categorise these codes. Axial coding refers to developing categories and subcategories systematically and relating these to each other. Selective coding refers to integrating the categories into a theory, which can be done by writing storylines. Ideally, enough data are collected and analysed to reach theoretical saturation, which basically means that additional data add virtually nothing new [14].

In accordance with the grounded theory approach, data collection and data analysis were conducted in parallel. Initially, interviews were analysed in the same order as they had taken place, but as analysis progressed the order was altered to facilitate constant comparison. In other words, which interview was analysed next depended on the questions raised by the analysis of one or more previous interviews (theoretical sampling). For instance, an interview with a person with COPD was selected next for analysis, because the respondent had put great emphasis on 
'going ahead and doing things anyway'. This indicated decisional space, which challenged the pattern which had emerged from the interviews analysed thus far (four diabetes, four COPD), that people with COPD typically lacked decisional space in contrast to people with diabetes.

Analysis involved all three types of coding used in grounded theory. Open coding was primarily used in the first four interviews, while axial coding was primarily used in the fifth through the tenth interview. Theoretical saturation was reached with the tenth interview. Selective coding, in particular the technique of storyline writing, was used in the final three interviews in order to arrive at a theory. During the phases of axial and selective coding, confirmation and disconfirmation (constant comparison) was sought by comparing incidents in the new interviews with incidents in interviews already analysed.

Author GM analysed all thirteen interviews and the research team met to discuss the coding process and memos. The other members of the research team also coded five interviews during the phases of open (GK), axial (IP, GK, JvE) and selective coding (PJ). Coding results were compared and discussed afterwards to clarify the meaning of and relationship between codes, to develop new codes and stimulate open-mindedness. Qualitative analysis and identification of themes were facilitated by the Atlas.ti computer programme [17].

\section{Results}

The results in this section are supported and illustrated by quotations that are representative of larger groups of similar quotations.

\section{Conceptualisation of autonomy in the context of chronic illness}

When respondents talked about how their lives were arranged, they cited various influencing factors. First and foremost, respondents felt that they had to consider the interests of their spouse and/or children next to their own needs and wishes. Another consideration much on respondents' minds was the importance they attached to their health, particularly the wish to prevent future decline. All respondents gave examples of restricted opportunities due to health status and treatment regimen. A few respondents also mentioned obligations like a job or helping out friends. And finally, a couple of respondents indicated that they were unable to do something they would have liked to do because they did not have enough money.

Although the respondents all felt that their opportunities were restricted and that they had to take account of other interests than their own, most did experience a sense of autonomy. That is, they felt that they did arrange their lives as 
they wanted, despite the restrictions and considerations that also had to be taken into account. Respondents seemed to view these restrictions and considerations as the frame of reference within which they could arrange their lives. These respondents said that they might not be completely free and able to do what they would like to do, but that they nevertheless felt that they arranged their lives the way they wanted to, considering the circumstances. Autonomy thus appeared to involve a sense of realism.

But I really do what I want to do. ... Not in a selfish way, but... I don't want to not do things because of my illness. ... I know I can't walk 20 kilometres anymore, I know that. But that's not so important to me. As long as I am still able to walk. Sometimes I can walk a bit further than at other times. But really, if I feel like jumping into my car to go shopping or to go swimming or to see my daughter, well then that's what I'll do. If I feel like doing absolutely nothing today, then that's what I'll do.

(COPD7, 1451-1467)

Respondents who mentioned family needs and financial restrictions appeared to accept this as a matter of course. This frame of reference was not a problem for them.

Well, I don't lead my life the way I want to, of course. I have to take my [social] surroundings into account. Wife, kids. It's not just me. You have to take other people into account. So and so wants this, such and such wants that and this is what I want. Then you have to work things out together. Hundreds of things in life are like that. But why make a big deal about it...

(COPD 4, 956-1007)

The frame of reference created by health and the treatment regimen were accepted in varying degrees. When respondents accepted this frame of reference, they could still, in varying degrees, be unhappy or dissatisfied about things that were not possible or that were consequences of their own choices. Typically, people would decide to give up valued activities that might negatively affect their health and at the same time feel sad about the loss of these activities.

'Why can't you do this, why can't you do that?' These kinds of things. Goodness, [having to] deny yourself so much in the final years of your life. Not being able to enjoy it. But then you think 'you have seen enough examples [of what might happen], so stick with it'.

(Diabetes2, 1465-1472) 
I could eat four plums, but not [right] at that moment. It is not the time that I might [eat]. You could call that a restriction, at that moment. But you know, 'I can [have the plums] presently' (...). You can lead a good life with [diabetes].

(Diabetes1, 1294:1299)

A few people did not experience a sense of autonomy, but felt rather that their treatment regimen or physical health prevented them from leading their lives the way they wanted to. These people did not appear to accept their illness and treatment regimen as part of the frame of reference within which they could arrange their lives.

So when you have this and you have to stick to certain rules, then you can't lead the life you want to. For example, I'd like to be able to get up on a day off and if I felt like eating four buns - I can't have those in any case, I can only have two - that I would be able to eat those four buns, then I wouldn't necessarily have to eat at noon. I could skip lunch and not eat until dinner. And if I was extra hungry, I'd eat more. These kinds of things are not possible. And that is just one example.

(Diabetes4, 586-602)

\section{Disturbances of autonomy}

Chronic illness appeared to disturb autonomy in two ways, namely through a limited opportunity range and by prompting people to reappraise activities and aspects of life. Limited opportunity meant that people said that they were unable to live the way they wanted. Reappraisal made people doubt whether they wanted to continue living in the same way as they did. Both types occurred with both illnesses and could even be simultaneously expressed by one and the same person.

Disturbance through a limited opportunity range occurred if it was no longer possible to do things at all or in the accustomed way, either for health reasons or the demands of the situation. For example, respondents reported that certain jobs and hobbies had become too taxing (provoking breathing difficulties or hypoglaecemia), or that certain holiday destinations were no longer suitable due to climate, landscape or availability of care, and that large social activities like receptions had become hard to attend because poor air caused breathing difficulties.

I don't go dancing anymore. Because you have to stop halfway through the dance and say 'boy, it's too much, I have to sit down'.

(COPD6, 1395-1399) 
Disturbance through reappraisal occurred if it was no longer advisable to do things at all or in the accustomed way because of possible negative health effects. The prospect of deterioration in health could scare people and cause them to reappraise the value they attached to their health. In other words, diagnosis and prognosis could prompt people to reconsider the importance of health.

But you start worrying about that [complications] and then you think: oh God, I have to stop this.

(Diabetes2, 236-238)

Revaluing health could result in tension between the pursuit of healthy behaviour and cherished activities. Respondents talked about how exercising, quitting smoking or following a diet interfered with social activities like meeting with friends for dinner or drinks, an exuberant lifestyle, or a sedentary lifestyle.

It was sometimes ambiguous whether autonomy was disturbed through the opportunity range or through reappraisal, because people viewed things that were not advisable as not being possible. That is, if people knew they should not do something according to the treatment regimen or if they had decided they would not do something, they perceived this as not being able to do something. Put differently, restricted opportunities sometimes were the consequence of a decision to prioritise health and give up certain activities (disturbance through reappraisal).

I have to choose in favour of my health. Although it was tough on me. Some things are not possible. Like in a bar or halls where people smoke a lot [while] playing bingo and the like. I'll never go there. So in fact you live a bit isolated. You can't go anywhere anymore.

(COPD1, 895-905)

\section{Responses to disturbed autonomy}

People responded to disturbed autonomy in different ways which appeared to be related to the type of disturbance.

Responses to changes in the opportunity range

Four types of responses were observed to disturbance of autonomy through the opportunity range. The first type of response consisted of attempts to expand the opportunity range by improving physical fitness, planning ahead (e.g. taking a sandwich when hiking to prevent low blood glucose levels), asking and/or accepting support, asking people to show consideration, or 'laying down the rules' more strictly. An example of the last: 
Last year, I turned 65. I had organised a party together with a friend who had also turned 65. We had written 'no smoking' on every invitation. They could go outside to smoke. And that's what they did. Everyone who wanted to smoke could go outside or into another room.

(COPD1, 829-837)

Secondly, people explored alternatives or alternative ways. The latter refers to doing the same things differently, taking more time to finish tasks or activities, or doing them to the best extent possible. For example, respondents took more time to mow the lawn, chose a holiday destination nearer home, or ordered mineral water instead of beer when meeting with friends in a pub. The former, looking for alternatives, concerned engaging in new activities to replace former ones. For example, people joined clubs, took up reading or bought a motorcycle.

Thirdly, people gave up activities that had become too demanding and tried to accept their changed circumstances as their new frame of reference, and to focus on what they could do in these circumstances. People did not easily turn to this type of response, as was indicated by statements like 'you have to accept it' and rueful statements, in which people said that they were not happy with the course of things, but acknowledged that it was their reality and they had to make the most of it. Indeed, this type of response appeared to be of a different nature than the first two types. While the first two types focused on changing opportunities and actions in such a way that people did not have to change how they wanted their lives to be arranged, this third type involved people actually reconsidering how they wanted their lives to be arranged.

Fourth, people got caught in an impasse, feeling that they had to acknowledge that an activity was no longer possible (at all or in the accustomed way) but unable to think of a meaningful alternative or accept giving the activity up, because it was too important to them. In other words, this type of response would occur when the other three response types had not worked. Consequently, people ended up at odds with themselves: they did not know how to solve the problem, but they could not give the activity up either. For example, a man with COPD could not accept his sexual limitations:

It keeps haunting you and there really isn't a good solution. At least I haven't got one. And how do you cope? It keeps you awake at night sometimes. But as far as finding a solution, there isn't one.

(COPD5, 1866-1874) 
Responses to disturbed appraisal of activities and life aspects

Two types of responses were observed to a disturbance of autonomy through disturbed appraisal of activities and life aspects. The first type consisted of reappraising the value attached to activities or life aspects, setting priorities and trying to stick with these in actions. Setting priorities meant that people decided whether they wanted their health interest to prevail over other things they wanted. Most people in the study prioritised their health and wanted to try to prevent or limit future deterioration by exercising, quitting smoking, following a diet and/or avoiding unhealthy situations. A man with COPD decided for example not to go on a staff outing, because of the smoking at rest stops:

So I don't go along anymore. I don't do that anymore. I don't want that smoke anymore. You see, I would be taking these strong pills during the week and then go sit in the smoke. I'm not going to do that.

(COPD1, 885-891)

In contrast to most respondents, one man with diabetes decided that at least for the time being (as long as there were no complications), he would stick with his exuberant lifestyle and not be so particular about sticking to the diabetes regimen.

I don't want my life to be determined by what is healthy or unhealthy. That is just one part, a little facet of life.

(Diabetes5, 514-517)

A second response type was observed in one man with diabetes, who wanted both to act in the interest of his health and to enjoy a sedentary, exuberant lifestyle. He had not found a way to combine the two, but alternated between sticking to the treatment plan and giving in to other desires. For example, he decided to moderate alcohol intake and did so for a while, but then summer came and he drank beer as he pleased anyway. It seemed like he wanted to prioritise health but was unable or unwilling to give up his former lifestyle completely, and was searching for the middle course.

But now it's completely finished, completely denied. Well, not completely, but I mean: less. To a lesser degree, I [do] eat candy.

(Diabetes2, 208-212)

\section{Differences between diabetes and COPD}

The two ways in which chronic illness disturbed autonomy were observed in both diseases, but examples of a limited opportunity range were primarily given by 
people with COPD. This difference appeared to be related to the immediacy and severity of repercussions characteristic for activity limitations. In COPD, certain activities were simply not possible and if people tried to engage in them anyway, repercussions would follow immediately.

I had swept it together into a pile. But then I had to go inside and sit down. And I was using oxygen. I had to sit like this. For at least fifteen minutes. Until I could get the dustpan and brush and sweep it up. (...) And then I was dead tired. (...) I said to myself 'well, now you've found that out too, that that is too much for you'.

(COPD6, 1938-1962)

In contrast, people with diabetes hardly reported activity limitations, but they were aware that certain activities could raise blood glucose levels, without provoking immediate repercussions (unless levels were extremely high).

You see, [it's different] if your arm or your leg hurts or something like that, but with diabetes, I just don't feel it.

(Diabetes5, 182-185)

Disturbance through reappraisal was observed with both diabetes and COPD, but was more prominent in persons with diabetes. This appeared to be related to the tangibility of long-term consequences. While people with COPD already had a taste of what was in store for them, people with diabetes had to decide whether to take action now, in order to prevent potential, currently absent complications.

These complications, I know they exist, but not everybody gets them. And I don't know what percentage, how frequently the various complications occur, but so far everything is all right.

(Diabetes5, 405-410)

\section{Discussion and conclusion}

In this qualitative study of people with a chronic illness, personal autonomy appeared to involve a sense of realism in the arrangement of life. People took account of their circumstances as a frame of reference when they talked about the way they wanted their lives to be arranged. In particular, respondents felt they had to or said they wanted to consider factors like their health status, treatment regimen, ways to prevent future decline, finances and family needs. In other words, personal autonomy did not appear to be simply about correspondence 
between what people did and wanted, but specifically about correspondence between what people did and wanted considering their circumstances.

Autonomy was disturbed by limited opportunities to arrange life as wanted and by a reappraisal of the way people wanted their lives to be arranged. The former was more common with COPD, while the latter was more prevalent with diabetes. Participants in this study tried to restore correspondence between what they wanted and did in various ways, but sometimes got stuck. This would happen if they could not follow up on something they wanted but could not put it out of their heads either. Respondents also got caught in an impasse if they did not succeed in combining the different things they wanted or in choosing between them.

This empirical study into the context of chronic physical illness may give new insight into the theoretical conceptualisation of autonomy [13]. This study suggests that personal autonomy is not simply about correspondence between what people do and want, but specifically about correspondence between what people do and want considering their circumstances. Personal autonomy in this case involves a sense of realism in the arrangement of life. The results of this study suggest that personal autonomy might be conceptualised as a correspondence between the way life is actually arranged and the way people want their lives to be arranged, considering the circumstances.

\section{Personal autonomy and life satisfaction}

In this study, it was found that people may experience a sense of autonomy, even though they experience restrictions and also have to take into account other interests than their own. People seemed to regard these restrictions and considerations as the frame of reference within which they could arrange their lives. Nevertheless, people could still be unhappy or dissatisfied with this frame of reference, in varying degrees. The fact that they arranged their lives the way they wanted considering the circumstances, did not mean that they would not have preferred to be living in different circumstances. This finding suggests how autonomy and life satisfaction might be related.

Satisfaction with life refers to a 'comparison of one's circumstances with what is thought to be an appropriate standard (...) which each individual sets for him or herself' [18: 71]. Life satisfaction thus concerns people considering what they would like their lives to be like, including the circumstances they live in. Autonomy, on the other hand, concerns people considering what they would like their lives to be like, under the circumstances they live in. This suggests that autonomy and life satisfaction may, though not necessarily, overlap. This overlap might be more likely to occur when people are satisfied with their circumstances. Yet people might also act as they please considering their circumstances (be autonomous), regardless of whether they are satisfied with these circumstances. 
Importantly, it seems that accepting circumstances as the frame of reference for actions does not necessarily mean that these actions might not be targeted at improving the frame of reference. People might determine to improve their frame of reference (e.g. physical fitness) out of dissatisfaction with it. Taking action in order to achieve improvement, then, might give people a sense of autonomy.

\section{Impact of chronic illness on autonomy}

The results suggest that chronic illness may disturb autonomy through limiting opportunities and forcing a reappraisal of life aspects and activities. In case of limited opportunities, autonomy might be restored by expanding the opportunity range, by finding alternative activities and/or alternative ways of doing the same activities, and by adapting wishes and desires to the new circumstances. If none of this works, people may risk ending up in a mental impasse. In case of disturbed appraisal, resetting priorities and following these up in action might restore autonomy. If people do not succeed in setting priorities clearly, they risk becoming torn between the different things they want.

Reappraisal and setting priorities may be necessary to restore autonomy. Yet in the philosophical literature $[13,19,20]$, changing what one wants is not generally considered to be a valid means of achieving autonomy. Instead, it is considered 'the easy way' that runs the risk of self-abnegation: rather than realising what they want, people might be convincing themselves that what they have is what they want. The present study, however, suggests that changing what one wants is certainly not an easy way to achieve autonomy. People were reluctant to give up valued activities and if they did, it was because they felt they had to be realistic about their possibilities. In other words, people did not change what they wanted because it was an easy thing to do, but because they considered it necessary. A study by Falter, Gignac and Cott [21] has also suggested that people do not simply give up valued activities in the face of disability, but rather try to maintain these by doing things differently or with the use of medication or aids. Hence, both the study by Falter et al. [21] and the present study do not provide empirical support to the concern of philosophers that people might give up too easily $[19,20]$.

\section{Differences between COPD and diabetes}

The way in which chronic illness affected autonomy seemed to be related to the immediacy and severity of repercussions, as well as the tangibility of long-term consequences. Hence, both type and phase of disease seem relevant. Type, because the prospect of further gradual deterioration of present activity limitations is typical for COPD, while the prospect of chronic complications with sudden onset is typical for diabetes. Phase is relevant, because in the stabilisation phase of 
diabetes, the failure to adapt activity rarely results in immediate, severe repercussions and long-term consequences are intangible, but this changes in the complication phase [15].

\section{Limitations of the study}

Grounded theory studies usually involve theoretical sampling, which means that researchers determine before and during data collection and analysis what kind of participants they want to sample, based on the variation needed for analysis [14]. In this study, we wanted to explore differences in people's experience of autonomy for different types of chronic illness and therefore decided beforehand to compose a sample with variations in disease type and severity.

We could also have sampled for other factors that might be related to variations in the experience of autonomy and that were known to the caregivers referring potential participants. In particular, we discussed sampling for variation in gender, adherence and marital status, but we decided against this, in consultation with the caregivers referring potential participants, because it would have considerably reduced the feasibility of sampling given the small number of participants.

Instead, we applied the principle of theoretical sampling in decisions about the analysis order of interviews. That is, we decided which interview to analyse next, based on the questions raised by the previous interview analysed (when more than one interview was available for analysis). There proved to be sufficient variation in the sample to analyse issues that came up during analysis, except with regard to smoking. Part of the analysis involved comparing incidents of healthy and unhealthy behaviour. As regards the latter, respondents had given examples like not adhering to a diet (diabetes) or going to smoky places (COPD), but our sample did not contain one person with COPD who continued to smoke. Because we wanted to find out whether this might add new information, we decided to include one additional person with COPD who continued to smoke. A comparison between this interview and interviews already analysed showed no differences between smoking and other types of unhealthy behaviour, so we did not include more smokers with COPD.

Although we sampled for variation in disease severity, the study did not include people with diabetes with severe complications. This may have affected our finding that autonomy is affected differently in diabetes than in COPD, because people with diabetes in the complication phase might actually experience similar activity limitations as people with COPD. Future research should therefore study the prevalence of the two types of disturbance in other types and phases of chronic disease not included in this study, beginning with the complication phase of diabetes. Also, additional types of disturbance might be discovered in other types and phases of chronic disease. 


\section{Implications for practice}

This study suggests two ways to support the personal autonomy of people with a chronic illness. First, practitioners could work together with their clients to prevent and overcome situations in which people are in an impasse or torn between the different things that they want. The former might be overcome by adequately treating diseases, improving physical fitness and providing special equipment and devices. Care-givers, for example occupational therapists, could also advise people about alternative ways of performing activities and provide emotional support to accept the changed circumstances as the new frame of reference. The latter impasse might be overcome by discussing the integration of the treatment regimen into daily life.

Second, broad self-management interventions might improve people's skills for coping with the impact of chronic illness on autonomy. Broad approaches to self-management, such as developed by Lorig $[22,23]$ do not only focus on managing the disease, but also on maintaining meaningful roles in life and coping with the emotional consequences of illness and using individual action planning to meet personal needs. These types of programmes might be particularly suited to supporting the different ways to restore autonomy.

\section{Acknowledgements}

We would like to thank the following people for inviting patients to participate in our study: René van den Heuvel, Geertjan Wesseling, Bert Vrijhoef and the diabetes nurse specialists and respiratory nurse specialists of the University Hospital Maastricht. Also, we are greatly indebted to the participants in this study for sharing their stories with us. 


\section{References}

1. Michie, S., Miles, J., Weinman, J. (2003). Patient-centredness in chronic illness: What is it and does it matter? Patient Education and Counseling, 51, 197-206.

2. Charles, C., Gafni, A., Whelan, T. (1999). Decision-making in the physician-patient encounter: Revisiting the shared treatment decision-making model. Social Science \& Medicine, 49, 651-61.

3. Barlow, J., Wright, C., Sheasby, J., Turner, A., Hainsworth, J. (2002). Self-management approaches for people with chronic conditions: A review. Patient Education and Counseling, 48, 177-87.

4. Williams, G. H., Wood, P. H.N. (1998). Coming to terms with chronic illness: The negotiation of autonomy in rheumatoid arthritis. International Disability Studies, 10 (3), 128-33.

5. McWilliam, C. L., Brown, J. B., Carmichael, J. L., Lehman, J. M. (1994). A new perspective on threatened autonomy in elderly persons: The disempowering process. Social Science \& Medicine, 38, 327-38.

6. Proot, I. M., Crebolder, H. F. J. M., Huijer Abu-Saad, H., Macor, T. H. G. M., Ter Meulen, R. H. J. (2000). Stroke patients' needs and experiences regarding autonomy at discharge from nursing home. Patient Education and Counseling, 41, 275-83.

7. Cardol, M. (2001). Beyond disability; assessing participation and autonomy in medical rehabilitation [dissertation]. Amsterdam: University of Amsterdam.

8. Christman, J. (1989). Introduction. In: Christman J., editor. The inner citadel: Essays on individual autonomy. New York: Oxford University Press.

9. Agich, G. J. (1993). Autonomy and long-term care. New York: Oxford University Press.

10. May, T. (1994). The concept of autonomy. American Philosophical Quarterly, 31(2), 133-44.

11. Collopy, B. J. (1988). Autonomy in long term care: Some crucial distinctions. The Gerontologist, 28, Supplement(June), 10-7.

12. Cardol,M., De Jong, B. A., Ward, C. D. (2002). On autonomy and participation in rehabilitation. Disability and Rehabilitation, 24, 970-4.

13. Mars, G. M. J., Kempen, G. I. J. M., Janssen, P. P. M., Widdershoven, G. A. M., Van Eijk, J. T. M. (2008). Autonomy in the context of physical chronic illness: Relating philosophical theories to social scientific literature. Health, 12, 333-348.

14. Strauss, A., Corbin, J. (1998). Basics of qualitative research: Techniques and procedures for developing grounded theory. Thousand Oaks: Sage.

15. Van Eijk, J. T. M., De Haan, M. (1998). Care for the chronically ill: The future role of health care professionals and their patients. Patient Education and Counseling, 35, 233-40.

16. Blumer, H. (1954). What is wrong with social theory? American Sociological Review, 19(1), 3-10.

17. Muhr, T. (1998). Atlas.Ti - visual qualitative data analysis, management and theory building. Release 4.2. Berlin: Scientific Software Development.

18. Diener, E., Emmons, R. A., Larsen, R.J., Griffin, S. (1985). The satisfaction with life scale. Journal of Personality Assessment, 49(1), 71-5.

19. Berlin, I. (1969). Four essays on liberty. Oxford: Oxford University Press.

20. Dworkin, G. (1988). The theory and practice of autonomy. Cambridge: Cambridge University Press.

21. Falter, L.-B., Gignac, M. A. M., Cott, C. (2003). Adaptation to disability in chronic obstructive pulmonary disease: Neglected relationships to older adults' perceptions of independence. Disability and Rehabilitation, 25, 795-806.

22. Lorig, K. (2001). Self management in chronic illness. In: Funk, S. G., Tornquist, E. M., Leeman, J., Miles, M.S., Harrell, J. S. (editors). Key aspects of preventing and managing chronic illness. New York: Springer Publishing Company.

23. Lorig, K. R., Holman, H. R. (2003). Self-management education: History, definition, outcomes, and mechanisms. Annals of Behavioral Medicine, 26, 1-7. 


\section{Chapter 4}

\section{The Maastricht Personal Autonomy}

Questionnaire (MPAQ): development and psychometric properties in older adults with a chronic physical illness 


\section{Abstract}

Purpose: To develop and test the Maastricht Personal Autonomy Questionnaire (MPAQ), an instrument measuring personal autonomy of older adults with a chronic physical illness in accordance with their experience of autonomy. Achievement of personal autonomy is conceptualized as correspondence between the way people's lives are actually arranged and the way people want to arrange their lives.

Methods: A field test was conducted in three waves $(n=412, n=125$ and $n=$ 244) among a random sample of people older than 59 years with either Chronic Obstructive Pulmonary Disease or Diabetes Mellitus. Construct validity, internal consistency, reproducibility and responsiveness were evaluated.

Results: The MPAQ entailing 16 items consists of three scales: degree of (personal) autonomy, working on autonomy and dilemmas. Construct validity was largely supported by confirmatory factor analysis and correlations between the MPAQ and other instruments. Cronbach's alpha ranged from .77 to .93, ICCs from 0.61 to 0.80 and $S R D s_{\text {group }}$ from 0.10 to 0.13 . Mean change was larger (0.54) than was $\mathrm{SRD}_{\text {group }}(0.11)$ in patients who had deteriorated, but smaller in patients who had improved (0.07).

Conclusions: The MPAQ has good content and construct validity and internal consistency and moderate reproducibility. Responsiveness is weak, although better for deterioration than for improvement. 


\section{Introduction}

Patient centred methods in health care have been developed to increase autonomy of patients with a chronic illness. These methods stress the need to see people as individuals rather than patients [1]. One should not only be concerned with autonomy people experience in interaction with caregivers, but also with autonomy in individuals' lives in general i.e. personal autonomy. Evaluations of patient oriented methods should therefore include an assessment of personal autonomy. To this end, we developed the Maastricht Personal Autonomy Questionnaire (MPAQ).

Existing instruments for autonomy beyond the consultation room far mostly measure autonomy in relation to participation [2], assess autonomy as a trait rather than a state [3], or refer to contexts other than chronic illness, like adolescence or gender identity $[4,5]$. In contrast, the MPAQ intends to measure personal autonomy of older adults with a chronic physical illness in a way that agrees with their own experience of autonomy. Based on a previous work [6] and a qualitative study [7], the MPAQ measures 1) achievement of autonomy, 2) the dilemmas people with a chronic illness may face, and 3) the efforts these people make to achieve autonomy. First, achievement of personal autonomy might be understood as correspondence between what people want their lives to be like and what their lives are actually like [6]. Importantly, a qualitative study among older adults with a chronic physical illness [7] suggests that these people take account of their life circumstances when talking about the way they want their lives to be arranged. In their experience, autonomy involves a sense of realism. Hence, achievement of personal autonomy in the context of chronic physical illness might be conceptualized as correspondence between the way people's lives are actually arranged and the way people want their lives to be arranged, considering their circumstances [7]. Second, people with a chronic illness may face restricted opportunities to arrange life (not assessed by the MPAQ) and may feel torn between continuing valued activities on the one hand and acting in the best interest of health on the other hand, while people actually want to do both [7]. Finally, people with a chronic illness continuously may be challenged to work on autonomy in their daily activities and in their relationships with family, friends and society [8]. This involves exploring alternatives, reconsidering priorities and making choices and changes. Sometimes, people act in the best interest of their health, while at other times, they consciously give priority to valued activities and social roles [7, 9]. These situations are a common source of tension for caregivers striving to promote health, but also to support autonomous choices [10].

The present study describes the development of the MPAQ and its validity, internal consistency, reproducibility and responsiveness. The self-administered MPAQ was to be used in evaluation (changes over time) or discrimination research (measurement of differences between persons). 


\section{Methods}

The MPAQ was developed with a sample of older adults with either Chronic Obstructive Pulmonary Disease (COPD) or diabetes mellitus type 2 (diabetes). COPD and diabetes both take a gradually deteriorating course, but COPD has intermittent exacerbations, while diabetes is characterized by a long stabilization phase with eventual sudden complications [11].

The development process consisted of several steps, after each of which the MPAQ was revised (see Figure 1). This section explains the steps and the methods of the final step (second field test). The results section will focus on the final selection of items and the evaluation of the final version's validity, internal consistency, reproducibility and responsiveness.

Approval for conducting this study was granted by the Medical Ethics Committee of the Maastricht University/University Hospital Maastricht.

\section{Development of the semi-final version}

Based on a literature [6] and qualitative study [7], a list of 17 items about personal autonomy was compiled. Content validity of these items was assessed in two focus groups for adults older than 59 years with either COPD $(n=3$, group 1 ) or diabetes ( $n=6$, group 2). Discussed was which items agreed with participants' experiences of personal autonomy and why. Also, participants were asked whether they found particular items unclear, superfluous or whether they missed aspects of autonomy.

The questionnaire was then drafted. Authors GM, GK, IM, IP and JvE systematically evaluated content validity and response accuracy [12]. Content validity refers to 'the extent to which an empirical measurement reflects a specific domain of content' [13: 20].

Next, we conducted ten cognitive interviews to test whether items were interpreted as intended (content validity). Participants were one man and two women with COPD and six men and one woman with diabetes, ranging in age between 65 and 83 years. They were asked to formulate retrospectively (or concurrently if they preferred) how they had interpreted items and decided on their answers. Probing techniques were used to check feasibility and response accuracy $[14,15]$.

The first field test involved a random sample of adults older than 59 years with COPD $(n=71)$ or diabetes $(n=75)$. We analysed missing value patterns, frequency distributions, inter-item correlations and comments written on questionnaires. Dimensionality was assessed with exploratory factor analysis, in particular principal axis factoring with varimax and oblimin rotation. All statistical analyses 
were conducted with the SPSS computer program version 12.0.1 [16], unless stated otherwise.

Parallel to the first field test, content validity was assessed by six Dutch experts in the area of autonomy research, who had not been involved in the project so far. The experts received the MPAQ, a schematic representation of its operationalization, and the argumentation behind it. They were asked to comment on the operationalization and the underlying conceptualization of personal autonomy.

In the second assessment of content validity, three colleague researchers not involved in the project sorted, independently of each other, the items of the MPAQ to the hypothesized dimensions. The outcomes were compared, and the intended ordering and differences were discussed.

\section{Semi-final version of the MPAQ}

The semi-final questionnaire consisted of 21 items in three scales: Degree of Autonomy (DA, 5 items), Working on Autonomy (WA, 10 items) and Dilemmas (Di, 6 items) reflecting the three elements mentioned in the Introduction. MPAQ-DA intends to measure the degree in which people experience correspondence between the way they want their life to be arranged and the way their life is actually arranged. MPAQ-WA intends to measure how people achieve, maintain or restore personal autonomy by changing what they want, do and can do. MPAQ-Di intends to measure how often people experience tensions between doing what they enjoy and doing what is best for their health [7].

\section{Sample and data collection}

The semi-final version of the MPAQ was sent out to a new selection of people older than 59 years with either COPD or diabetes. They had previously been screened for a study about chronic illness and depression (Delta study) [17]. People not eligible for the depression study were invited to participate in the present study. The Delta study recruited participants through 89 family practices in the south of the Netherlands.

In wave one, 600 questionnaires were sent out to people with either diabetes $(N=300)$ or COPD ( $N=300)$. Respondents who returned the questionnaire were randomly assigned to wave two (one third) or three (two thirds). Wave two took place four weeks after wave one and wave three six months after wave one. In case of non-response, a telephone reminder was issued after two weeks in all three waves. Participants were also called about item non-response after the questionnaire was returned. 


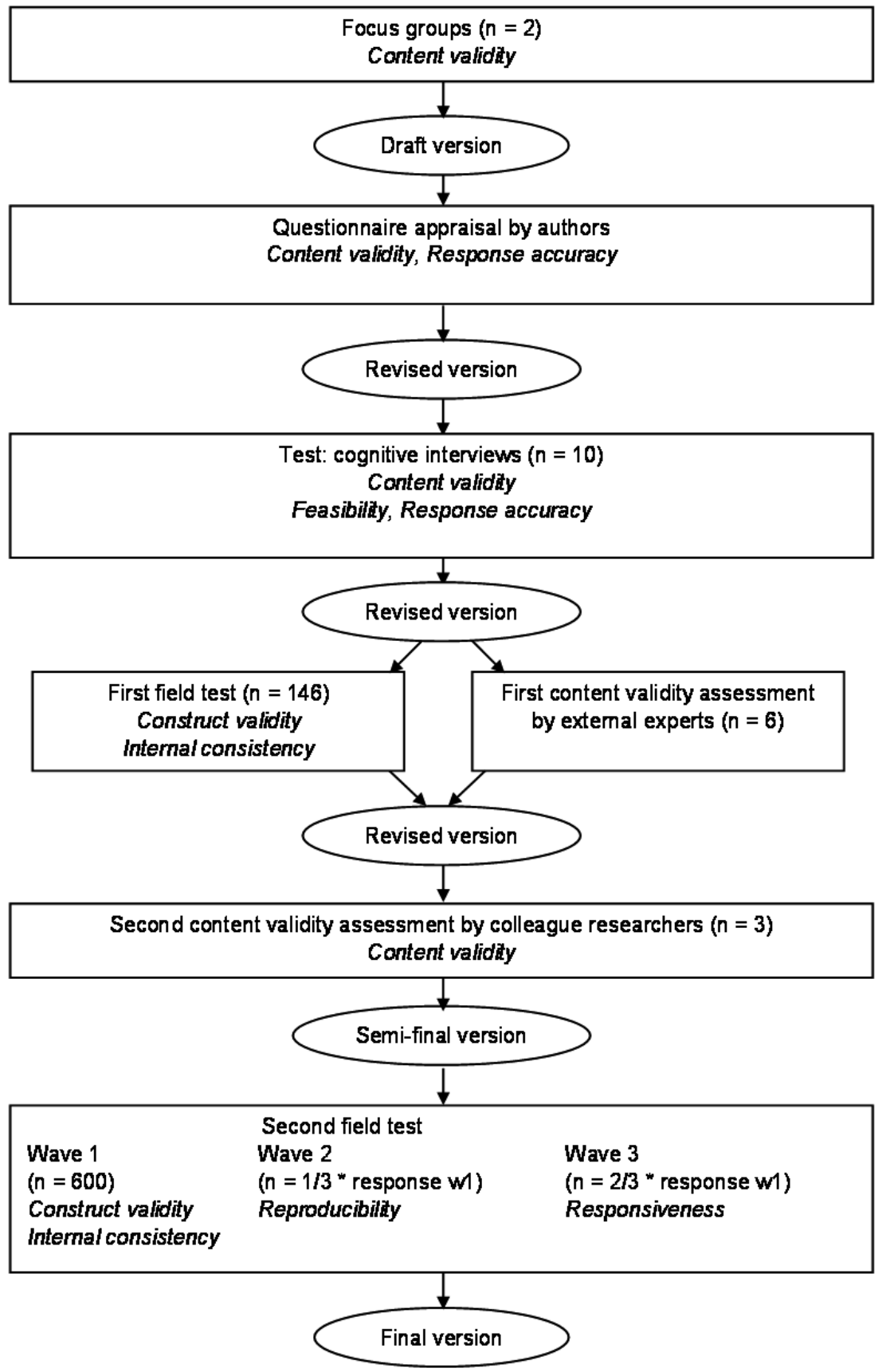

Figure 1 Development of the Maastricht Personal Autonomy Questionnaire 


\section{Instruments}

Besides the semi-final version of the MPAQ and questions about background characteristics (socio-demographics, health status, co-morbidity), the questionnaire of wave one included the following instruments:

- parts of the RAND-36, i.e. general health perceptions and physical functioning $[18,19]$ (descriptive purposes),

- Impact on Participation and Autonomy Questionnaire (IPA) [2, 20] (construct validity),

- Satisfaction With Life Scale (SWLS) [21] (construct validity),

- 12-item version of the (GSES-12) [22-24] (construct validity),

- three scales (active, passive, avoidance) of the Utrecht Coping List (UCL) [25] (construct validity),

- Autonomy Visual Analogue Scale (A-VAS) (construct validity).

All instruments have been validated in Dutch samples, except the A-VAS. The AVAS was self-developed to measure perceived decisional autonomy, like the IPA [2]. It consists of a short introduction, followed by one item: 'To what extent do you feel you can lead the life you prefer?' Answers are scored on a visual analogue scale ranging from 'Not at all' to 'To a very great extent'.

The questionnaire of the second wave at four weeks repeated the measurement of the MPAQ and the A-VAS.

The questionnaire of the third wave at six months repeated the MPAQ-DA and IPA [2]. It also comprised a self-constructed item about improvement or deterioration in autonomy: 'Compared to six months ago, is your life now more or less as you want it to be? Much more, somewhat more, more or less the same, somewhat less, much less'.

\section{Analyses}

Final selection of items

We analysed missing value patterns, frequency distributions and comments written on questionnaires. To test whether the three scales represented three distinct dimensions, we inspected inter-item correlations and item-rest correlations. We also checked whether items correlated (Pearson) higher with the scale they were expected to be part of (item-rest correlation) than with the other scales [26]. Furthermore, we conducted a path analysis with latent variables to confirm the expected factor structure and to test the expected relations between the three scales of the MPAQ.

We expected 1. more dilemmas to coincide with lower degrees of autonomy, 2. more work on autonomy to result in higher degrees of autonomy later in time and 3. higher degrees of autonomy to predict higher degrees of autonomy later in 
time. We did not model a relationship between work on autonomy and dilemmas, because dilemmas may instigate people to work on autonomy on the one hand and work on autonomy may lessen dilemmas on the other.

Path analysis was conducted with the LISREL computer program version 8.30 [27]. The Root Mean Square Error of Approximation (RMSEA) should be $\leq 0.08$ as a rule of thumb [28]. The Adjusted Goodness of Fit Index (AGFI) should be $\geq 0.90$ [29]. The Goodness of Fit Index (GFI) should be $\geq 0.95$. When deciding between two alternative models, the model with the lowest Akaike Information Criterion (AIC) should be preferred [29].

\section{Construct validity}

Construct validity was examined by calculating Pearson correlation coefficients ( $r$ ) between the final scales of the MPAQ and the other instruments to test several basic assumptions. We expected the degree of autonomy (MPAQ-DA) to correlate positively with decisional autonomy (A-VAS) and satisfaction with life (SWLS) [21] and negatively with restrictions on autonomy (IPA) [2] (three hypotheses). A-VAS and IPA were expected to correlate more strongly with each other than with MPAQ-DA, which we tested with Steiger's Z [30], because they both measure decisional autonomy, while MPAQ-DA measures personal autonomy (two hypotheses). Working on autonomy (MPAQ-WA) was expected to correlate positively with self-efficacy expectancies (GSES-12) [23] and an active coping style (UCL) [25] (two hypotheses). We expected MPAQ-WA to correlate more strongly with an active than with a passive or avoidant coping style, which we tested with Steiger's Z [30] (two hypotheses). To our knowledge, no validated instruments were available to evaluate construct validity of dilemmas (MPAQ-Di).

As a quality criterion, seven of these nine hypotheses (75 per cent) should find empirical support [31].

\section{Internal consistency}

Internal consistency of the MPAQ scales was examined with Cronbach's coefficient alpha [13], using data of the first wave. As a rule of thumb alphas should be in the 0.70 to 0.95 range [31].

\section{Reproducibility}

Reproducibility of the MPAQ was evaluated with intraclass correlation coefficients (ICCS) $[32,33]$ and with smallest real differences on group level (SRDs group [34]. ICCs were computed using a two way random effects model with absolute agreement between the scores of wave one and two [33]. ICCs are relevant if the MPAQ is used for discrimination purposes and should be at least 0.70 [31]. SRDs group were computed according to the following formula [34]: 


$$
S R D_{\text {group }}=\frac{S D_{\text {wave } 2-1}}{\sqrt{n}} \times 1.96
$$

$\mathrm{SRD}_{\text {group }}$ is relevant if the MPAQ is used for evaluation purposes, because it indicates the magnitude of difference that may, with $95 \%$ confidence, be expected between two measurements on the same, stable group of participants ('noise'). The SRD is expressed in the same units as the scales and should be smaller than the minimal amount of change that is considered to be important (Minimal important change - MIC) [31]. As we do not know yet which amount of change researchers and/or patients may consider important, readers should judge for themselves what change levels they consider important. To facilitate interpretation, we here define the MIC (rather arbitrarily) as the amount of change in the mean scores if half of the respondents remain stable and the other half score one point higher on one item.

\section{Responsiveness}

Responsiveness of the DA-scale was evaluated by calculating the mean difference in observed scores on MPAQ-DA in wave one and three separately for respondents who reported improvement and respondents who reported deterioration in autonomy on the transition item. If these mean differences are larger than $\mathrm{SRD}_{\text {group }}$, it may be interpreted that the instrument is able to capture true change on group level [34].

\section{Comparison between COPD and diabetes}

Construct validity, internal consistency, reproducibility and responsiveness analyses were repeated for COPD and diabetes separately. We furthermore tested whether the relations were the same in participants with diabetes and COPD.

\section{Results}

\section{Response and sample characteristics}

Of the 600 questionnaires sent out in wave one, 412 (69\%) were returned (206 COPD and 206 diabetes). Four weeks later, in wave two, 125 of 137 questionnaires were returned (91\%). Six months after wave one, in wave three, 244 (88\%) of 276 questionnaires were returned. The percentage of respondents in wave one without missing values on a scale was 95\% for MPAQ-DA, 92\% for MPAQ-WA and $97 \%$ for MPAQ-Di (before telephone follow-up). Mean age in wave one was 70 (range 60-87). More men than women participated, as a result of a skewed sex distribution in the sampling frame. General health perception and physical func- 
tioning $[18,19]$ were significantly worse in participants with COPD compared to participants with diabetes. Co-morbidity was common in both. Table 1 presents various characteristics of participants.

Table 1 Characteristics of the study population in the validation study (as measured in wave 1)

\begin{tabular}{|c|c|c|}
\hline & $\begin{array}{l}\text { COPD } \\
n=206\end{array}$ & $\begin{array}{l}\text { Diabetes } \\
n=206\end{array}$ \\
\hline Mean age (SD) & $70.5(6.6)$ & $70.0(6.2)$ \\
\hline \multicolumn{3}{|l|}{ Sex $(\%)$} \\
\hline Male & 67.5 & 68.4 \\
\hline Female & 32.5 & 31.6 \\
\hline Educational level (\%) & * & * \\
\hline Primary & 28.4 & 18.6 \\
\hline Secondary & 61.3 & 63.7 \\
\hline Tertiary & 10.3 & 17.6 \\
\hline Paid employment measured (\%) & 3.9 & 4.4 \\
\hline Living together with partner or other person(s) (\%) & 75.1 & 73.2 \\
\hline \multicolumn{3}{|l|}{ RAND-36 (scale 0-100, higher is better) } \\
\hline Mean general health perception (SD) & $46.0(18.7)^{*}$ & $50.1(18.1)^{*}$ \\
\hline Mean physical functioning (SD) & $55.7(27.1)^{*}$ & $62.6(28.9)^{*}$ \\
\hline Mean duration of disease in years (SD) & $18.9(18.1)^{*}$ & $9.6(8.6)^{*}$ \\
\hline Duration of disease in years (min-max) & $0-79$ & $0-44$ \\
\hline Mean number of chronic conditions (SD) & $2.8(2.1)$ & $3.0(2.0)$ \\
\hline
\end{tabular}

* Significant difference between COPD and Diabetes at 0.05 level (Pearson chi-square or one-way analysis of variance)

\section{Final selection of items}

Inspection of frequency distributions suggested that one item in MPAQ-WA (which had been added after the first field test) had been misinterpreted, probably due to a double negative in the question wording. This item was deleted subsequently. Inter-item correlations and item-rest correlations suggested that MPAQ-WA consisted of two clusters, one referring to using aids and asking and accepting help and one referring to reorganization, reorientation and adaptation in a more general way. Nonetheless all items correlated higher (and significantly) with the rest of their own scale than with the other scales (e.g. all MPAQ-WA- 
items correlated higher with the rest of MPAQ-WA than with MPAQ-DA or MPAQDi), suggesting that all items were in the right scales.

We specified a latent path model with four latent variables: MPAQ-DA, MPAQ-Di and MPAQ-WA measured in wave one and MPAQ-DA measured in wave three. The model was specified in accordance with the hypotheses described in the methods section (construct validity). The relationship between MPAQ-Di and MPAQ-WA was not specified, because we had no hypothesis regarding this relationship. All corresponding items (except the deleted one) were included as indicator variables. All latent variables were fixed on the same scale as the observed indicators by setting one coefficient per latent variable equal to one. Error terms of the MPAQ-DA indicators were set to correlate between the first and third wave. Expected relations are illustrated in Figure 2.

The specified model did not fit the data. RMSEA was 0.10 and AGFI 0.70. Modification indices suggested adding error covariances as well as paths from three indicators of MPAQ-WA about using aids or accepting help to MPAQ-Di. The latter suggestion was in line with the clustering of items we had noticed when inspecting inter-item correlations.

In three steps, we removed four items about using aids and asking or accepting help (thereby limiting MPAQ-WA to reorganization, reorientation and adaptation in a more general way), deleted the effect from MPAQ-WA on MPAQ-DA in the third wave (because results indicated there was no effect), and let the error terms of the first two items of MPAQ-DA, MPAQ-WA and MPAQ-Di correlate (we modelled a halo effect). Observed relations in the final model are illustrated in Figure 3. The final model had an AGFI of 0.82 , which is below the criterion of 0.90 , but also a reasonable RMSEA (0.07) and the lowest Akaike Information Criterion (AIC) of all four models (which is positive).

Finally, we tested the equality of the model in the sample of respondents with COPD and the sample of respondents with diabetes. RMSEA was 0.08 for both groups. GFI was 0.77 for COPD and 0.79 for diabetes. 


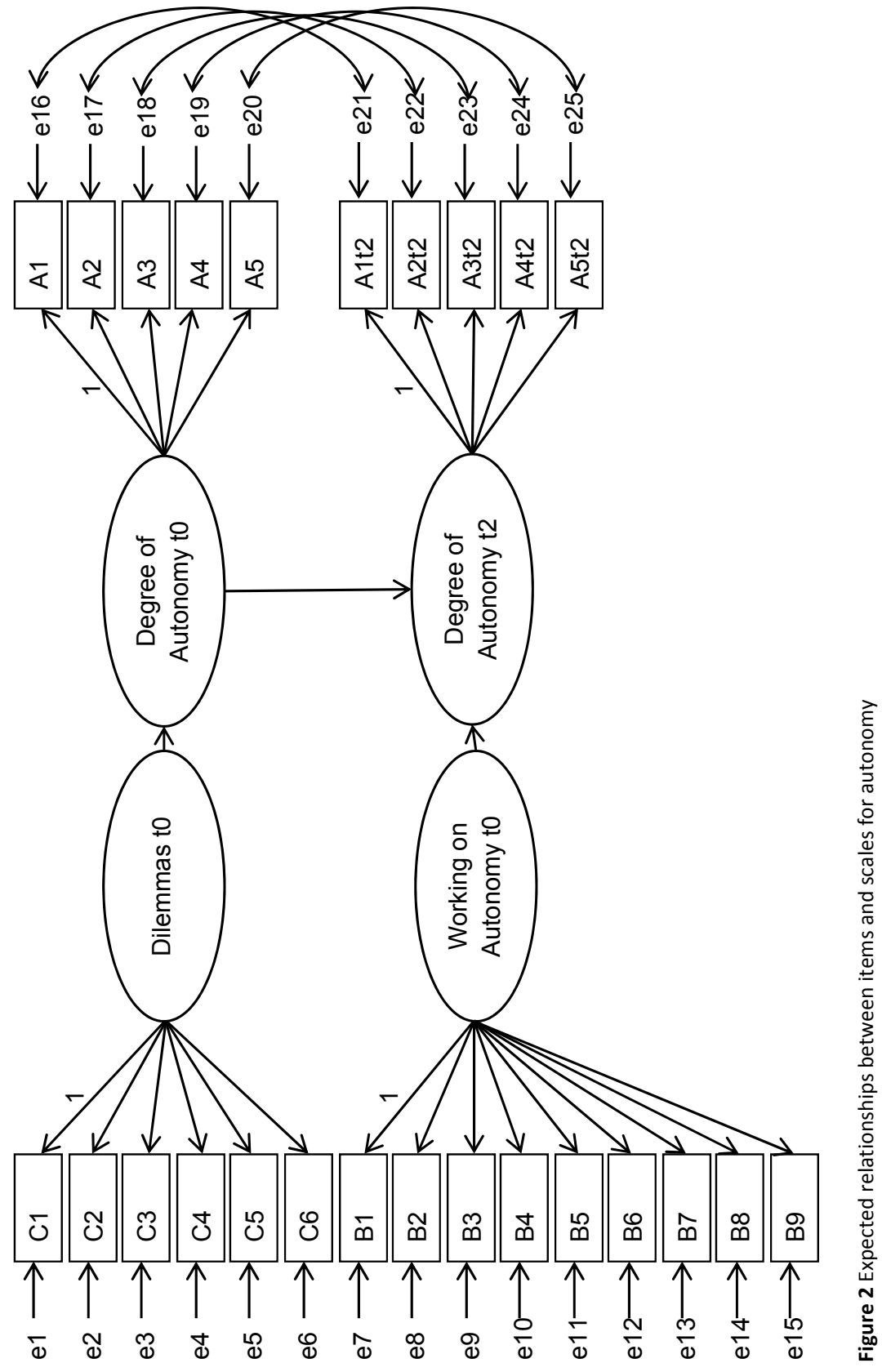




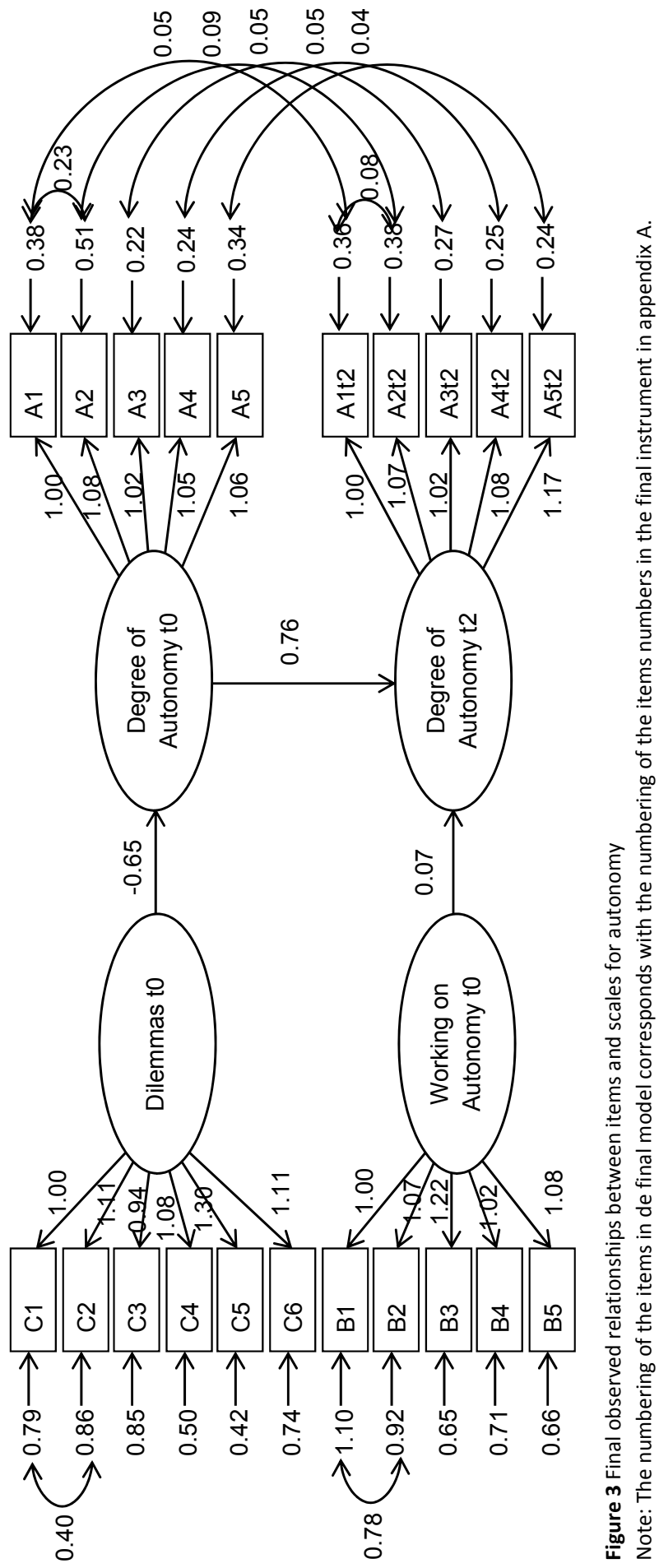




\section{Final version of the MPAQ}

The final version of the MPAQ can be found in Appendix A. It consists of 16 items in three scales: Degree of Autonomy (DA, 5 items), Working on Autonomy (WA, 5 items) and Dilemmas ( $\mathrm{Di}, 6$ items). The scale scores equal the unweighted average of the item scores (ranging from 1 to 5 ). Higher scores indicate that people experience a higher degree of autonomy, work more on their autonomy and face dilemmas more often.

Table 2 presents the mean scores on the MPAQ for participants with COPD and diabetes separately. The results show no significant differences. Observed scores on the MPAQ-DA and MPAQ-WA cover the entire range of theoretically possible scores. MPAQ-Di scores cover almost the entire range.

\section{Construct validity}

Correlations between the MPAQ and other instruments were mostly as expected (seven of nine hypotheses), as Table 3 illustrates. Higher degrees of autonomy (MPAQ-DA) were associated with more decisional autonomy (A-VAS) and life satisfaction (SWLS) and less restrictions in participation and autonomy (IPA). Contrary to our expectations, each IPA subscale correlated more strongly with MPAQ-DA than with A-VAS (differences significant at the 0.01 level).

As we expected, working on autonomy was associated positively with general self-efficacy (GSES-12) and an active coping style (UCL). The passive and avoidant coping styles (UCL) were not associated with working on autonomy (differences significant at the 0.01 level).

\section{Internal consistency}

Table 4 presents the mean, minimum and maximum inter-item correlation and Cronbach's alpha. Mean inter-item correlations ranged between 0.39 for MPAQDi and 0.74 for MPAQ-DA. Cronbach's alpha ranged between 0.77 for MPAQ-Di and 0.93 for MPAQ-DA.

\section{Reproducibility}

Table 4 also shows the ICC and $S R D_{\text {group }}$. ICCs ranged between 0.61 for MPAQ-WA

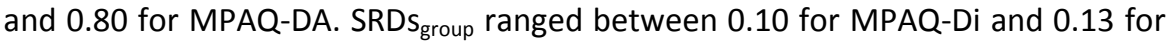
MPAQ-WA and were equal to or larger than the MICs (while they should be smaller). 
Table 2 Scores on the Maastricht Personal Autonomy Questionnaire (MPAQ) by disease

\begin{tabular}{llllll}
\hline & $\begin{array}{l}\text { Number of } \\
\text { participants }\end{array}$ & $\begin{array}{l}\text { Theoretical } \\
\text { score range }\end{array}$ & $\begin{array}{l}\text { Observed } \\
\text { score range }\end{array}$ & $\begin{array}{l}\text { COPD } \\
\text { mean (SD) }\end{array}$ & $\begin{array}{l}\text { Diabetes } \\
\text { mean (SD) }\end{array}$ \\
\hline MPAQ-Degree of Autonomy & 405 & $1-5$ & $1-5$ & $3.30(1.05) 3.43(0.95)$ \\
MPAQ-Working on Autonomy & 406 & $1-5$ & $1-5$ & $2.55(0.86) 2.60(0.89)$ \\
MPAQ-Dilemmas & 404 & $1-5$ & $1-4.5$ & $2.54(0.71) 2.63(0.72)$ \\
\hline
\end{tabular}

No significant differences between COPD and diabetes at 0.05 level (one-way analysis of variance).

Table 3 Pearson correlations between Maastricht Personal Autonomy Questionnaire (MPAQ), Autonomy-Visual Analogue Scale (A-VAS) and other instruments

\begin{tabular}{|c|c|c|c|}
\hline & $\begin{array}{l}\text { MPAQ- } \\
\text { Degree of } \\
\text { Autonomy }\end{array}$ & $\begin{array}{l}\text { MPAQ- } \\
\text { Working on } \\
\text { Autonomy }\end{array}$ & A-VAS \\
\hline Autonomy-Visual Analogue Scale (A-VAS) & $0.71^{* *}$ & & \\
\hline Satisfaction With Life Scale (SWLS) & $0.65^{* *}$ & & \\
\hline \multicolumn{4}{|c|}{ Impact on Participation and Autonomy Questionnaire (IPA) } \\
\hline - indoors & $-0.54 * *$ & & $-0.42 * *$ \\
\hline - family role & $-0.56^{* *}$ & & $-0.41 * *$ \\
\hline - outdoor & $-0.68^{* *}$ & & $-0.55 * *$ \\
\hline - social relations & $-0.46^{* *}$ & & $-0.33^{* *}$ \\
\hline General Self-Efficacy Scale (GSES-12) & & $0.11^{*}$ & \\
\hline \multicolumn{4}{|l|}{ Utrecht Coping List (UCL) } \\
\hline - active & & $0.21 * *$ & \\
\hline - Utrecht Coping List (UCL) passive & & -0.04 & \\
\hline - Utrecht Coping List (UCL) avoidance & & -0.05 & \\
\hline
\end{tabular}

**Correlation is significant at the 0.01 level (two-tailed).

*Correlation is significant at the 0.05 level (two-tailed).

\section{Responsiveness}

Mean change in respondents who had deteriorated was larger (0.54) than $\mathrm{SRD}_{\text {group }}$ (0.11), while mean change in respondents who had improved was smaller (0.07).

It should be noted that deterioration took place, on average, in a lower range of the scale than improvement (data not shown). This suggests that responsiveness, and reproducibility $\left(S_{R D_{\text {group }}}\right)$, of the MPAQ-DA might be better in lower ends of the scale than higher ends. We performed additional analyses to test this [35], but results were inconclusive (data not shown). 
Table 4 Internal consistency and reproducibility of the Maastricht Personal Autonomy Questionnaires (MPAQ)

\begin{tabular}{|c|c|c|c|}
\hline & $\begin{array}{l}\text { MPAQ-Degree of } \\
\text { Autonomy }\end{array}$ & $\begin{array}{l}\text { MPAQ-Working on } \\
\text { Autonomy }\end{array}$ & MPAQ-Dilemmas \\
\hline \multicolumn{4}{|l|}{ Internal consistency } \\
\hline Mean inter-item correlation & 0.74 & 0.46 & 0.39 \\
\hline Minimum inter-item correlation & 0.67 & 0.30 & 0.07 \\
\hline Maximum inter-item correlation & 0.83 & 0.84 & 0.59 \\
\hline Cronbach's alpha & 0.93 & 0.81 & 0.77 \\
\hline \multicolumn{4}{|l|}{ Reproducibility } \\
\hline Intraclass correlation coefficient & 0.80 & 0.61 & 0.71 \\
\hline Smallest real differencegroup ${ }^{a}$ & 0.11 & 0.13 & 0.10 \\
\hline Minimal important change ${ }^{b}$ & 0.10 & 0.08 & 0.10 \\
\hline
\end{tabular}

a The smallest real difference is expressed in observed units and should be interpreted against the scale range, which is 1-5 for all three scales.

$\mathrm{b}$ The minimal important change is here defined as the amount of change in the mean scores if half of the sample remains stable and the other half scores one point higher on one item.

\section{Comparison between COPD and diabetes}

Separate analyses for COPD and diabetes yielded similar results regarding construct validity, internal consistency and responsiveness (data not shown). Reproducibility results were similar in COPD and diabetes for MPAQ-Di, but better in COPD than in diabetes for MPAQ-DA (ICC COPD $=0.88$, ICC diabetes $=0.69$ ) and MPAQ-WA (ICC COPD $=0.67$, ICC diabetes $=0.52$ ).

\section{Conclusion and discussion}

In conclusion, the MPAQ is a valid measurement instrument for personal autonomy of older adults with a chronic physical illness. Its conceptualization is grounded in the experience of autonomy by older adults with a chronic physical illness. Content validity was thoroughly assessed and improved during the development process, again involving older adults with a chronic physical illness. Construct validity and internal consistency were good. Reproducibility for the purpose of discrimination was moderate, because the ICC of one scale (MPAQ-WA) was lower than the threshold of 0.70 . Reproducibility for the purpose of evaluation was weak given the MIC we used. Responsiveness could only be evaluated for the MPAQ-DA. MPAQ-DA was responsive to deterioration, but not to improvement. Results indicate that MPAQ can be used for discrimination purposes and should be used with caution for evaluation purposes. 
This study has several limitations. First, we did not evaluate construct validity of the MPAQ-Di. Second, the MIC that we used to evaluate reproducibility was rather arbitrarily defined. Both these limitations are poor man's choices, since no validated instruments were available to evaluate construct validity of the MPAQDi and we did not know yet which amount of change patients and/or care givers consider important. Third, people with depressive symptoms are underrepresented in our sample. This is because the patients of our study were selected as part of the selection procedure of another study which included only patients with symptoms of depression. We selected the patients from our study from the group without these symptoms. And finally, there might also be reservations about the sample used, because the MPAQ is intended to be a generic instrument for older adults with a chronic physical illness, but the development process involved only two types of chronic disease. By using only two types, we could compare measurement properties. A generic instrument should be robust across different types of disease, meaning that scores may differ, but measurement properties should be the same. Results are promising for generic application of the MPAQ.

Future research should test the MPAQ in other patient groups. Since the items of the DA scale are not specific to people with a chronic physical illness, it would also be worthwhile to test outcomes in a general population of older adults and compare healthy older adults with those with a chronic illness. Furthermore, the minimal change in MPAQ scores deemed important by people with a chronic illness needs to be established to facilitate the evaluation of reproducibility.

In the Netherlands, another instrument relevant in the domain has been developed by Cardol and colleagues [2]. The Impact on Participation and Autonomy Questionnaire (IPA) measures people's chances to participate in an autonomous way in several domains of life. The MPAQ, in contrast, measures autonomy on a general level, distinguishing three dimensions of autonomy. The IPA does not provide insight into these dimensions, while the MPAQ does not focus on specific domains of life (as the IPA does). Hence, the two instruments intend to measure different concepts. To our knowledge, no other instruments in this field have been developed so far.

People with chronic illnesses need different care than people suffering from acute illnesses, since chronic illnesses have long term impact on daily life. Doing what is best for one's physical health may not fit with valued activities or social roles. These conflicts have long been recognized [36, 37] and patient centred methods aim to take account of individual circumstances, but a quantitative measurement instrument was, to our knowledge, not available yet. The MPAQ aims to capture these dilemmas (MPAQ-Di) and their impact on the degree of autonomy people experience (MPAQ-DA). It also captures people's efforts to achieve autonomy (MPAQ-WA), focusing on the actions and active mind-set which self-management programs aim to bring about. It remains to be tested 
whether the three MPAQ scales may be used separately. Together, they provide a detailed picture of the degree of personal autonomy and its underlying mechanisms.

\section{Acknowledgments}

We would like to thank the participants in the study and those who invited them: Karianne Jonkers, Femke Lamers, Jan van Rooij, the team at the Diabetes Care Centre Maastricht and the Dutch Diabetes Organization. Furthermore, we thank Trudi van den Bos, Mieke Cardol, Ingrid Friesema, Mieke le Granse, Marike Hendriks, Femke Lamers, Tineke Schoot and Leontine van de Ven for assessing the content validity of the MPAQ. 


\section{References}

1. Michie, S., Miles, J., \& Weinman, J. (2003). Patient-centredness in chronic illness: what is it and does it matter? Patient Education and Counseling, 51, 197-206.

2. Cardol, M., De Haan, R. J., de Jong, B. A., Van den Bos, G. A. M., \& De Groot, I. J. M. (2001). Psychometric properties of the 'Impact on Participation and Autonomy' (IPA) questionnaire. Archives of Physical medicine and Rehabilitation, 82(2), 210-216.

3. Clark, D.A., Steer, R. A., Beck, A. T., \& Ross, L. (1995). Psychometric characteristics of revised Sociotropy and Autonomy Scales in college students. Behaviour Research and Therapy, 33(3), 325-334.

4. Bekker, M.H. (1993). The development of an Autonomy scale based on recent insights into gender identity. European Journal of Personality, 7, 177-194.

5. Anderson, R. A., Worthington, L., Anderson W. T., \& Jennings, G. (1994). The development of an autonomy scale. Contemporary Family Therapy, 16, 329-345.

6. Mars, G. M. J., Kempen, G. I. J. M., Widdershoven, G. A. M., Janssen P. P. M., \& Van Eijk, J. T. M. (2008). Conceptualizing autonomy in the context of chronic physical illness: relating philosophical theories to social scientific perspectives. Health, 12, 333-348.

7. Mars, G.M.J., Proot, I. M., Janssen, P. P. M., Van Eijk, J. T. M., \& Kempen, G. I. J. M. (2007). How do people with COPD or diabetes type 2 experience autonomy? An exploratory study. Disability and Rehabilitation, 29, 485-493.

8. Williams, G. H., \& Wood, P. H. N. (1988). Coming to terms with chronic illness: the negotiation of autonomy in rheumatoid arthritis. International Disability Studies, 10(3), 128-133.

9. Townsend, A., Wyke, S., \& Hunt, K. (2006). Self-managing and managing self: practical and moral dilemmas in accounts of living with chronic illness. Chronic Illness, 2, 185-194.

10. Hunt, M. R., \& Ells, C. (2011). Partners towards autonomy: risky choices and relational autonomy in rehabilitation care. Disability and Rehabilitation, 33, 961-967.

11. Van Eijk, J. T. M., \& De Haan, M. (1998). Care for the chronically ill: the future role of health care professionals and their patients. Patient Education and Counseling, 35, 233-240.

12. Lessler, J. T., \& Forsyth, B. H. (1996). A coding system for appraising questionnaires. In N. Schwarz \& S. Sudman (Eds.), Answering questions: Methodology for determining cognitive and communicative processes in survey research. San Francisco: Jossey-Bass Publishers.

13. Carmines, E. G., \& Zeller, R. A. (1979). Reliability and validity assessment (Sage university paper series on quantitative applications in the social sciences no. 07-017). Newbury Park, CA: Sage.

14. Esposito, J. L., \& Rothgeb, J. M. (1997). Evaluating survey data: Making the transition from pretesting to quality assessment. In L.Lyberg, P. Biemer, M. Collins, E. de Leeuw, C. Dippo, N. Schwarz, \& D. Trewin (Eds.), Survey measurement and process quality. New York: Wiley.

15. Kurz, K., Prüfer, P., \& Rexroth, M. (1999). Zur Validität von Fragen in standardisierten Erhebungen. Ergebnisse des Einsatzes eines kognitiven Pretestinterviews (On the validity of questions in standardised surveys. Results of a cognitive pretest interview). ZUMA-Nachrichten, 44(23), 83-107.

16. SPSS for Windows, Rel. 12.0.1. (2003). Chicago: SPSS Inc.

17. Lamers, F., Jonkers, C. C., Bosma, H. Diederiks, J. P., \& Van Eijk, J. T. M. (2006). Effectiveness and cost-effectiveness of a minimal psychological intervention to reduce non-severe depression in chronically ill elderly patients: the design of a randomised controlled trial [ISRCTN92331982]. BMC Public Health, 6, 161.

18. Ware, J. E. Jr., \& Sherbourne C. D. (1992). The MOS 36-item short-form health survey (SF-36): I. Conceptual framework and item selection. Medical Care, 30(6), 473-483.

19. Van der Zee, K.I., \& Sanderman, R. Het meten van de algemene gezondheidstoestand met de RAND-36: Een handleiding [Measuring general health with the RAND-36: a manual]. Groningen: Noordelijk Centrum voor Gezondheidsvraagstukken. 
20. Cardol, M., Beelen, A., Van den Bos, G. A., De Jong, B. A., De Groot, I. J., De Haan, R. J. (2002). Responsiveness of the Impact on Participation and Autonomy Questionnaire. Archives of Physical Medicine and Rehabilitation, 83, 1524-1529.

21. Diener, E., Emmons, R. A., Larsen, R. J., \& Griffin, S. (1985). The Satisfaction with Life Scale. Journal of Personality Assessment, 49, 71-75.

22. Sherer, M., Maddux, J. E., Mercandante, B., Prentice-Dunn, S., Jacobs, B., \& Rogers, R. W. (1982). The self-efficacy scale: Construction and validation. Psychological Reports, 51, 663-671.

23. Bosscher, R. J., \& Smit, J. H. (1998). Confirmatory factor analysis of the General Self-Efficacy Scale. Behaviour Research and Therapy, 36, 339-343.

24. Bosscher, R. J., Smit, J. H., \& Kempen, G. I. J. M. (1997). Algemene competentieverwachtingen bij ouderen: Een onderzoek naar de psychometrische kenmerken van de Algemene Competentieschaal (ALCOS) (General self-efficacy expectancies in the elderly: a study about the psychometric properties of the General Self-Efficacy Scale [GSES]). Nederlands Tijdschrift voor de Psychologie, 52, 239-248.

25. Schreurs, P. J. G.,Van de Willige, G., Brosschot, J. F., Tellegen, B., \& Graus, G. M. H. (1993). De Utrechtse Coping Lijst: UCL; herziene handleiding [The Utrecht Coping List: UCL-Manual]. Lisse: Swets \& Zeitlinger.

26. Streiner, D. L., \& Norman, G. R. (1995). Health measurement scales: a practical guide to their development and use. New York: Oxford University Press.

27. LISREL 8.3. (1999). Chicago, IL: Scientific Software International.

28. Browne, M. W., \& Cudeck, R. (1993). Alternative ways of assessing model fit. In K. A. Bollen, \& J. S. Long (Editors), Testing structural equation models. Newbury Park, CA: Sage.

29. Faulbaum, F. (1981). Konfirmatorische Analysen der Reliabilität von Wichtigkeitseinstufungen beruflicher Merkmale. ZUMA-Nachrichten, 9, 22-44.

30. Meng, X.-L., Rosenthal, R., \& Rubin, D. B. (1992). Comparing correlated correlation coefficients. Psychological Bulletin, 111, 172-175.

31. Terwee, C. B., Bot, S. D. M., De Boer, M. R., Van der Windt, D. A. W. M., Knol, D. L., Dekker, J., et al. (2007). Quality criteria were proposed for measurement properties of health status questionnaires. Journal of Clinical Epidemiology, 60, 34-42.

32. Shrout, P. E., \& Fleiss, J. L. (1979). Intraclass correlations: uses in assessing rater reliability. Psychological Bulletin, 86, 420-428.

33. Nichols, D.P. (1998). Choosing an Intraclass Correlation Coefficient. SPSS Keywords, 67.

34. De Vet, H.C., Bouter L.M., Bezemer P. D., \& Beurskens A.J. (2001). Reproducibility and responsiveness of evaluative outcome measures: Theoretical considerations illustrated by an empirical example. International Journal of Technology Assessment in Health Care, 17, 479-487.

35. Bland, J. M., \& Altman, D. G. (1999). Measuring agreement in method comparison studies. Statistical Methods in Medical Research, 8, 135-160.

36. Drummond, N., \& Mason, C. (1990). Diabetes in a social context: just a different way of life in the Age of Reason. In S. Cunningham-Burley \& N. McKeganey (Editors), Readings in Medical Sociology. London: Routledge.

37. Adams, S., Pill, R., \& Jones, A. (1997). Medication, chronic illness and identity: the perspective of people with asthma. Social Science and Medicine, 45, 189-201. 


\section{Chapter 5}

\section{Characteristics of social participation as defined by older adults with a chronic physical illness}

Godelief M. J. Mars, Gertrudis I. J. M. Kempen, Ilse Mesters, Ireen M. Proot, Jacques Th. M. van Eijk

Disability and Rehabilitation (2007) 29, 485-493

DOI: 10.1080/09638280701623554 


\section{Abstract}

Purpose. To conceptualize social participation in line with the experiences of older adults with a chronic physical illness.

Method. Qualitative study consisting of ten individual interviews and two focus group interviews with older adults with Chronic Obstructive Pulmonary Disease or Diabetes Mellitus Type 2.

Results. Four domains of social participation were identified on the basis of the individual interviews: (i) social contacts and social activities, (ii) work and informal support, (iii) cultural activities and public events, and (iv) politics and media. Three characteristics of social participation could be distilled from discussions in the focus groups: social contact, contributing resources to society and receiving resources from society. In addition, only positive experiences were considered to be social participation.

Conclusions. In our study, older adults with a chronic physical illness perceived social participation as a positive experience having one or more of the following three characteristics: social contact, contributing resources to society or receiving resources from society. This is fairly consistent with the literature about social participation, although previous researchers did not mention a positive experience condition and disagreed whether receiving resources could be considered as 'genuine' social participation. 


\section{Introduction}

People with a chronic illness may experience restrictions in social functioning and role fulfilment $[1,2]$. But their social participation is important, both because of the potential personal benefits for themselves and the cohesive and productive benefits for society. Social participation may also be positively related to individual well-being, although this relationship is not yet entirely clear [3].

The International Classification of Functioning, Disability and Health (ICF) provides a conceptual framework of participation in relation to health and disability [4]. It defines participation as involvement in life situations, which results from an interaction between the environment, the individual and that person's health. The ICF provides an extensive list of participation domains, but whether these domains should all be perceived as participation is the subject of on-going debate and empirical research [4-6]. In any case, this list covers a wider range of domains than do most studies about social participation, with some notable exceptions [7].

Most studies into social participation within and beyond the context of health and disability are based on at least one of three interpretations of social participation: first, as social interaction with relatives, friends and acquaintances [8,9], sometimes limited to interaction outside the home [10] or not including the spouse [11]. Second, social participation is used in reference to contributions to society through organized structures such as volunteer work [12]. Third, the term social participation may also include involvement in organizations and exercising influence on, for example, decision-making in civil society organizations [13,14].

Although some definitions of social participation appear to have been constructed in an ad hoc fashion [15], they may actually share a theoretical foundation [16]. Bukov, Maas and Lampert [16] proposed defining social participation 'in terms of the consequences of activities for the social environment' [16: 510], stating that interactions between individuals and their social environment may be understood in terms of allocation of resources. All people possess resources like time, special skills, social knowledge and social competence. People both contribute their own resources to the social environment and benefit from resources contributed by others. For example, in paying a visit someone contributes the resource time, which benefits the person being visited. This example corresponds with the first interpretation in the literature of social participation as social interaction. Second, the treasurer of a hobby association contributes his time and financial knowledge, which benefits the entire club membership. This is an example of the second interpretation, contributions to society through organized structures. Third, the spokeswoman for a forum for disabled people uses her social competence to protect the interests of people with disabilities. Her contribution of resources corresponds with the third interpretation, involvement in organizations and exercising influence. 
Bukov et al. [16] argued that only contributions of resources to the social environment represent the 'genuine phenomenon' of social participation. The definition of social participation should therefore be limited to contributions of resources to society [16]. Paying a visit would thus count as social participation, but receiving a visit would not. Schuyt, Schuijt-Lucassen and Knipscheer [17], on the other hand, considered benefiting from resources an equally genuine form of social participation. Both contributing to and benefiting from resources connect people with society.

Neither the ICF framework nor the allocation-of-resources principle offers a conclusive definition of social participation in the context of chronic illness. The ICF provides a conceptual framework of participation in the context of health and disability, but it remains unclear which participation domains might be labelled social participation. The allocation-of-resources principle offers a theory-based definition of social participation that incorporates the main interpretations of social participation in the literature, both in and beyond the context of health and disability, but it does not answer the question whether social participation involves only giving resources, or receiving as well. This question is particularly relevant in the case of chronic illness, which may severely restrict social participation. By and large, previous research has paid little attention to the perceptions of people with a chronic illness as regards social participation. Instead of trying to resolve the definition issues, above, on theoretical grounds, a conceptualization of social participation might also take account of the experiences of these people.

The aim of the present study was to develop a concept of social participation that agreed with the experiences of older adults with a chronic physical illness. We conducted a qualitative study among older adults with a chronic physical illness to find out what they considered social participation and we related our findings to existing interpretations.

\section{Methods}

The participants in this study were older adults with Diabetes Mellitus Type 2 (diabetes) or Chronic Obstructive Pulmonary Disease (COPD). We included two chronic diseases because experiences of social participation might differ for different types of chronic disease. COPD and diabetes both take a gradually deteriorating course, but COPD has intermittent exacerbations, while diabetes is characterized by a long stabilization phase followed by chronic complications [18].

The study consisted of two parts. First, individual interviews were conducted to find out what kinds of activities people with a chronic illness associate with social participation. Second, we used focus groups to identify characteristics of social participation according to older adults with a chronic illness. The aim here 
was to find out why people associated certain activities with social participation. The results of the individual interviews, together with definitions of social participation from the literature, were used as input for the focus group interviews.

Ethics committee approval was granted.

\section{Individual interviews}

\section{Sample}

We used a purposive sampling strategy, aiming to include 12 community dwelling adults older than 54 years with either diabetes or COPD and with different levels of disease severity. Specifically, selection took account of medication type and glycaemic control in the case of diabetes and spirometry outcomes in the case of COPD.

Diabetes and COPD nurse specialists or a pulmonary specialist gave potential participants oral information about the study. Interested individuals then received additional written and oral information about the study from the researchers. The study was described as a one-off interview about living with diabetes or COPD. People were assured of confidentiality and the possibility to withdraw from the study at any time. Of the 13 individuals referred by the nurse specialists or pulmonary specialist, 12 consented to participate in the study. Of these, one woman with diabetes and one man with COPD were not interviewed about social participation after all because the first part of the interview, related to another study (see below), had tired them too much.

In the end, 10 persons aged 56 to 76 years were interviewed about social participation. Five persons interviewed had diabetes (four men, one woman): two used oral medication and were satisfactorily regulated, two used oral medication and were unsatisfactorily regulated (according to nurse specialist) and one used insulin. The other five persons had COPD (four men, one woman): two had mild or moderate COPD (Forced Expiratory Volume in one second [FEV1] from 50\% to $100 \%$ ) and three had severe or very severe COPD (FEV1 below 50\%). All 10 persons resided in the south of the Netherlands.

\section{Data collection}

The interviews were held between July 2002 and April 2003 and took place at participants' homes. The questions were part of an in-depth interview that also addressed people's experience of autonomy [19]. Social participation was discussed in the second part of the interview. All interviews were conducted by author GM, who is a trained interviewer. Field notes were taken and interviews were audiotaped and transcribed verbatim with all identifying information removed. 


\section{Interview guide}

The interviews consisted of two open-ended questions, namely what did participants associate with social participation (in Dutch 'deelname aan de maatschappij', an existing expression which literally means 'to take part in society') and could they give examples of their own social participation.

\section{Data analysis}

Analysis was facilitated by the Atlas.ti computer programme [20] and made use of grounded theory techniques and procedures [21]. These techniques, developed in the symbolic interactionist research tradition, are suited especially well to understand how concepts are used in everyday life [22].

Analysis of the individual interviews consisted of open and axial coding [21]. Open coding refers to deriving codes from the data and to making an initial classification of these codes. Axial coding refers to developing categories and subcategories systematically and relating these to each other. Although theoretical saturation was not reached (which means that the final interview still added new information [21]), we did not collect more data because we felt that we had enough input for the focus groups.

All interviews were analysed by author GM. The first interview was coded independently by GK as well, to check whether GM approached the interview unbiased and did not miss important aspects. Coding by GM and GK was compared and discussed afterwards, but no substantial differences were found. Coding was compared again at the sixth (GK) and seventh (JVE) interview. GK and JvE used the code list developed until then by GM, and added new codes to the list. Again, a comparison of coding used (GM and GK, GM and JVE) revealed no substantial differences.

\section{Focus group interviews}

We organized two focus groups about social participation, one for adults with COPD and one for adults with diabetes. We decided to make disease-specific homogeneous groups to prevent losing a lot of time explaining differences between COPD and diabetes and building trust [23]. We also expected that, in a heterogeneous group, participants might be inclined to attribute differences between their experiences simply to differences between diabetes and COPD instead of exploring the reasons for these differences in greater depth.

\section{Sample}

We used a purposive sampling strategy, aiming to include six to eight adults older than 59 years in each disease-specific group. People were not invited to participate in the study if they had already taken part in the individual interviews or if 
the recruiting professional care giver (see below) did not consider them eligible for participation in the study, for example because of low cognitive abilities or recent serious life events.

Initially, sampling was done via two general practitioners. Both general practitioners sent written invitations to a random sample of their eligible COPD and diabetes patients $(N=42)$ to take part in the study. The letter contained information about the study and referred patients to the researchers for additional oral information. The letter also assured patients of confidentiality and the possibility to withdraw from the study at any time, and guaranteed that their treatment would continue as usual regardless of their decision about participation in the study. If they agreed to participate, patients returned a signed informed consent form and a brief questionnaire to the researchers. The questions concerned general health perceptions and experienced restrictions, and were derived from the RAND-36 [24,25].

As response was low (19\%), we decided to recruit through additional channels, namely a pulmonary specialist, an internal medicine specialist and the Dutch Diabetes Organization (DVN). The pulmonary specialist gave oral information about the study to potential participants who visited the outpatient clinic on a particular afternoon. Patients interested in the study received the same written information as supplied by the general practitioners, and followed the same procedure to join the study (brief questionnaire and signed informed consent). Recruitment via the internal medicine specialist was done together with author GM. The internal medicine specialist asked all patients who visited the diabetes care centre on a particular morning whether they would agree to receiving information about a study into living with diabetes. If patients agreed, GM gave oral information about the study. Patients interested in the study received the same written information as supplied by the general practitioners and could enter the study following the same procedure. Finally, author GM presented the study at a gathering of the DVN and invited the persons present to participate in the study. Those interested received the same information as supplied by the general practitioners and could enter the study following the same procedure.

In the end, 12 persons were recruited: 6 via the general practitioners, 2 via the pulmonary specialist, 2 via the internal medicine specialist and 2 responded to the invitation at the DVN gathering. Of this group, one person with COPD did not attend the focus group session because he was ill.

Five persons (three men, two women) between 65 and 86 years of age participated in the COPD focus group session. Six persons (all men) between 63 and 78 years of age participated in the diabetes focus group session. All 11 persons resided in the south of the Netherlands. On average, participants assessed their general health as fair to good, while participants with COPD generally experienced 
more restrictions in work and social activities than participants with diabetes (see table 1).

Table 1 Focus group participants' general health perceptions and restrictions ${ }^{1}$

\begin{tabular}{|c|c|c|}
\hline Question & $\begin{array}{l}\text { COPD } \\
(n=5) \\
(\%)\end{array}$ & $\begin{array}{l}\text { Diabetes } \\
(\mathrm{n}=6) \\
(\%)\end{array}$ \\
\hline \multicolumn{3}{|c|}{ In general, would you say your health is... } \\
\hline Excellent & - & - \\
\hline Very good & - & 16.7 \\
\hline Good & 40 & 50 \\
\hline Fair & 60 & 33.3 \\
\hline Poor & - & - \\
\hline \multicolumn{3}{|c|}{$\begin{array}{l}\text { During the past } 4 \text { weeks, to what extent has your physical health inter- } \\
\text { fered with your work or other regular daily activities? }\end{array}$} \\
\hline Not at all & - & 50 \\
\hline Slightly & 40 & 16.7 \\
\hline Moderately & 40 & 16.7 \\
\hline Quite a bit & - & 16.7 \\
\hline Extremely & 20 & - \\
\hline \multicolumn{3}{|c|}{$\begin{array}{l}\text { During the past } 4 \text { weeks, to what extent has your physical health inter- } \\
\text { fered with your normal social activities with family, friends, neighbours } \\
\text { or others? }\end{array}$} \\
\hline Not at all & - & 83.3 \\
\hline Slightly & 40 & - \\
\hline Moderately & - & 16.7 \\
\hline Quite a bit & 40 & - \\
\hline Extremely & - & - \\
\hline Not applicable (no social activities) & 20 & - \\
\hline
\end{tabular}

${ }^{1}$ Derived from RAND-36 [24, 25]

\section{Data collection}

The two focus group sessions were held in September 2003 and took place at a community centre. Transportation was arranged if necessary. The diabetes group was held one week after the COPD group. Both interviews were moderated by GM and assisted by IM, who made field notes. Both interviews were audiotaped and transcribed verbatim with all identifying information removed. At the end of the focus group sessions, participants were asked to fill out an evaluation form, which could be returned by post. In general, the sessions were evaluated positively. All participants felt that the session had met their expectations, except one participant with COPD who had expected more participants in poor physical con- 
dition. All participants thought that everybody had had the opportunity to say what they had wanted to say.

\section{Questioning route}

The focus group sessions were built around lists of examples of social participation, which are reproduced in table 2 . The list for the first session, for people with COPD, was based on information obtained in the individual interviews and the results of a literature search of existing definitions of social participation, as described in the introduction. The list was limited to 22 examples of social participation in order to keep it workable in a focus group session. The examples included did not cover all examples of social participation in the individual interviews and the literature, but they did cover all domains of social participation in individual interviews and literature.

Table 2 Items used in the COPD and the diabetes focus group, arranged per domain ${ }^{1}$

COPD focus group Diabetes focus group

Formal social participation

- Membership of a club

Idem

- To attend meetings of a club

To take part in activities of a club

- To do volunteer work for a club

To do volunteer work

Informal social participation, social contact

- To stay in touch with relatives, friends or acquaintances Idem by phone, letter or email

- To receive visits from relatives, friends or acquaintances Idem

- To attend birthday parties or other parties and ceremo- Idem nies of relatives, friends or acquaintances

- To do something with other people Idem

- To chat with neighbours or to visit each other To chat with neighbours

- -

To chat with strangers

- -

To be interested in other people

Informal social participation, support

- To help other people, for example by doing their grocer- To help other people ies or driving them somewhere

- To be there for others Idem

- To fall back on others Idem

- To receive help from other people, for example shopping To receive help from other people withor getting a ride out requesting it To receive help from other people on request

Consumptive participation

- To take a course or attend a lecture or information even- To take a course ing 
COPD focus group

Diabetes focus group

- To go to the cinema, a concert, the theatre, the museum Idem or something similar

- To go to a pub or restaurant

To go to a pub

To go to a restaurant

- To go on a holiday

Idem

- To go into town

Idem

- To go shopping

To chat with others while shopping

$\bullet-$

To pursue a hobby together with others

- -

To do something sociable outside the home

- -

To listen to music

Politics and news

- To follow the news (in the paper or on TV).

To follow the news

- To vote

Idem

Religious/spiritual participation

- To go to church or other religious meetings

Work participation

- To do paid work

To have (paid) employment

${ }^{1}$ The arrangement of items is sometimes arbitrary, as items might fit into multiple domains. The diabetes focus group was held one week after the COPD focus group.

The 22 examples of participation were printed on index cards (one item per card), which were handed out during the first focus group session (COPD). Based on the preliminary results of the COPD session, which moderator GM and assistant IM discussed in a debriefing session, eight items were rephrased, two were split up, one was removed and five were added. The 28 examples on this new list were also printed on index cards, which were handed out during the second focus group session (diabetes).

During the focus group interviews, participants were asked to go through the items individually and select the activities they themselves engaged in. Next, participants were asked to go through their selected items and mark, with a different symbol, those items that made them feel they participated in society (in Dutch 'deelnemen aan de maatschappij'). After that, participants' selections and markings were inventoried on a flip chart and differences and similarities between participants were discussed. The discussion focused on participants' reasons for classifying certain items as social participation while rejecting others.

\section{Data analysis}

Analysis was facilitated by the Atlas.ti computer programme [20] and made use of grounded theory techniques and procedures [21]. Analysis focused on the reasons 
participants gave for classifying or rejecting individual items as social participation. We had prepared a list of 29 codes beforehand, referring to the individual items on the sets of cards that were handed out during the focus group sessions (22 in first session plus seven new ones in second session). During analysis, we added codes which referred to characteristics of specific items, characteristics of social participation in general, modifications of items suggested by participants, additional items suggested by participants, and other comments by participants, for example about restrictions.

First, transcripts were analysed line-by-line [21] to obtain the characteristics of individual items. Next, transcripts were read and reread entirely to identify the main themes of the groups [21]. The main themes were described in memos, as were other thoughts and discussions between the coding authors GM and IM. GM coded and summarized the transcripts first and IM critically reviewed the coding and summary. GM and IM then discussed the coding and summary, which led to further analysis of the data regarding the positive feelings people associated with social participation. Also, GM reanalysed the individual interviews to see whether or not these too indicated that people associated social participation with positive emotions.

\section{Results}

\section{Individual interviews}

The concept 'social participation' (in Dutch 'deelname aan de maatschappij') had no meaning for two participants, who found the questions difficult. When the questions were rephrased using the expression 'connecting to, being part of society' (in Dutch 'contact maken met, deel uit maken van de maatschappij'), both participants were able to answer. Consequently, all 10 participants gave accounts of their own social participation (or lack thereof) and all were able to describe why they felt that certain activities (own activities at present, own activities in the past or other people's activities) were social participation while others were not.

\section{Examples of social participation}

The examples participants gave of social participation could be categorized into four domains: (1) social contacts and social activities, (2) work and informal support, (3) cultural activities and public events, and (4) politics and media. With respect to the first domain, participants referred to contacts with relatives, friends and neighbours in general, and talked about a sense of belonging and showing an interest in each other's lives. Participants also referred to social activi- 
ties like club meetings, organized trips, events, parties, going out and visiting each other.

Real participation, that would be for example being a member of many music groups or having many many social contacts, being a member of many clubs.

(COPD 1, 1480: 1484)

Second, five participants associated social participation with work and informal support, referring to volunteer or paid work, board memberships of schools, clubs and the like, as well as helping out relatives and friends. One participant felt that paying taxes was also a way to contribute to society.

Getting involved, joining a club or sitting on an executive or something like that.

(Diabetes 5, 1232:1234)

Third, three participants associated social participation with cultural activities (theatre or museum visits) and public events.

I do still visit museums, don't I? I do keep making the effort to improve my mind a little. Thus participating in the social happenings outside the home.

(COPD 2, 2287:2291)

And fourth, one participant also associated social participation with keeping up with politics and other news, and generally taking an interest in what happens in society.

Of course I participate in society; I mean I read the papers, don't I? And I keep up with politics from a distance, both locally and nationally, I mean.

(Diabetes 5, 1219:1224)

Restrictions and declining participation

All participants qualified their own participation as limited, or less than it used to be, for three reasons: participation restrictions due to chronic illness, decline in participation due to life cycle transitions, and decline in participation restrictions without a clear cause.

With regard to participation restrictions, participants described how chronic illness limited their social contacts and activities. With diabetes, the necessity to organize and plan meals and snack times limited opportunities to participate in organized social activities (which required adjustments in mealtimes). Also, the necessity to limit alcohol intake spoiled the fun of social meetings at bars or re- 
ceptions. With COPD, bad weather and smoky places limited opportunities to have neighbourly chats, go to parties, participate in club life and visit public events.

Second, participation appeared to have declined because participants had given up activities like board memberships, active involvement in clubs and volunteer work. Participants seemed to feel that these types of participation belonged to an earlier life phase. At present, they focused more on social contacts in informal settings. Within their own primary network, they were willing to help others if possible and necessary, but beyond that they were disinclined to enter into obligations.

But otherwise I've refused all the other activities that they asked me to do [after I had retired], the conducting and such. I didn't ummm... that time is past.

(Diabetes 1, 1381:1384)

Third, two participants described how their participation had gradually declined without any clear cause, and how they now felt out of place and disconnected when they went to public places or organized social activities that they used to enjoy. Instead, they focused on their family and neighbourhood, or elderly daycare, where they felt they properly belonged.

My life is here, in our home. With my animals, my wife, acquaintances, neighbours. I don't care what happens in the city, even if it fell down.

(Diabetes 2, 1601:1605)

\section{Preliminary conclusion}

In the individual interviews, examples of social participation were identified in four domains: (1) social contacts and activities, (2) work and informal support, (3) cultural activities and public events, and (4) politics and media. The participants themselves focused most on social contacts and activities and, in general, seemed to consider voluntary work as belonging to an earlier life phase. The interviews did not suggest new domains of social participation in comparison to the existing literature. The key result rather seemed to be that the participants associated a wide range of domains with social participation, even though their own social participation consisted mainly of social contacts. This suggests that, although older adults with a chronic illness might concentrate their actual social participation in certain domains, they need not restrict their definitions of social participation to these domains. Importantly, participants also gave examples of social participation which involved benefiting from resources (cultural activities), which Bukov and colleagues [16] did not consider 'genuine' social participation. 
Since the participants in the individual interviews associated social participation with a broad range of domains, we decided to start the focus groups with a broad range of participation domains rather than exclude any domains beforehand. The domains and matching examples of social participation that we used in the focus groups are listed in table 2.

\section{Focus groups}

Participants had difficulty talking about social participation in a general way, but were usually well able to describe which of their own activities made them feel that they participated in society, and why. Participants often disagreed as to whether a specific activity might be considered social participation, which appeared to be related to differences in their experiences of these activities. That is, participants appeared to consider only positive experiences social participation. In addition to this condition, the discussions produced three main characteristics of social participation: social contact, contributing resources to society and receiving resources from society.

\section{Positive experience}

Participants did not always agree on which specific activities might be considered social participation. This appeared to be related to differences in their own experiences of activities. In particular, only positive experiences tended to be regarded as social participation. For example, one participant said that he regarded sitting in a sidewalk café as social participation, while another participant said that he did not. When the moderator asked these two participants what made them feel that sitting in a sidewalk café was or was not to be considered as social participation, it turned out that the former participant evaluated the experience positively because it increased his social contacts, while for the latter it was a negative experience, because it emphasized his lack of social contact. The former always met friends and relatives at the café, while the latter did not meet people there and felt that sitting among strangers underscored his loneliness. Both associated social participation with social contacts, but only the former associated sitting at a sidewalk café with social contacts. Consequently, the latter did not label this item social participation. As he explained:

Participant 4 (P4): And the same goes for sitting in a sidewalk café. This guy [referring to P1], or this lady here [P2], they say they make contact with others [when they sit there]. I don't. So I never go anymore. Because there are no old people there and I am very old. There are only young people there. And they aren't going to pay any attention to me, so the social contact [I have when I sit in a sidewalk café] is worthless. 
P2: [If you don't see old people there,] you should try putting your glasses on.

P1: [Opposing to P4 as well] Well, I can't agree with that, because in my experience...

(COPD, 1405:1420)

Another example concerned contact with neighbours. Neighbourly contacts were generally labelled social participation, but not quarrels with neighbours. Also, one participant did not label birthday parties social participation, in contrast to other participants, because she did not feel happy there:

Moderator (M): Do you feel that you participate in society by going to a birthday party?

P2: No.

$M:$ No?

P2: No, I don't feel at ease there. I have to cough and can't breathe and then I have to [go], so I don't feel comfortable anymore in the midst of these people.

(COPD, 531:544)

Contrary to the above, voting was regarded as a form of social participation by all participants, although some did have negative associations with voting. However, these negative feelings did not so much concern the voting itself, which they regarded as a means of exercising influence, as their opinion of politicians who talk a lot but do nothing.

\section{Social contact}

Social contact was regarded by participants as characteristic for the items that they had labelled social participation. For example, one participant explained that she enjoyed the social aspect of going to a restaurant or pub:

M: What makes you feel that you participate in society by going to a pub or restaurant?

P5: That I leave the house and meet people, who have the same idea as I do at that moment.

M: What do you mean by 'the same idea'?

P5: Wanting to have a good time in enjoyable company.

(COPD, 1118:1129)

Another participant explained that, for him, going to church had a social aspect: 
P1: Well, you know, there's a pub next door to the church. Out of one door and into the other. Because the priest always says 'guys, I'll keep it short, because you are thirsty.'

(COPD, 933:937)

Although participants agreed that, in general, social contact was a characteristic of social participation, they disagreed as to whether this only applied to initiating the contact. Some participants felt that only the person initiating contact, for example by visiting someone else, participated. Others objected, saying that the person being visited also participated by showing a personal interest in the visitor, thus establishing reciprocity.

P5: It already means a lot to me that they come to see me.

P4: [But] it's the other person who does it.

P5: Yes, but the fact that you have a nice time together.

P2: [Agreeing with P5] Yes, of course. [That's what I said.]

P5: In my opinion, that makes me part of society. I'm interested in any problems the other person might have, but this other person is also interested in me.

(COPD, 1346:1366)

Contributing and receiving resources

Participants agreed that items like 'helping others' and 'volunteer work' were examples of social participation, because they involved serving a useful purpose.

P1: You're connected directly to society, aren't you? Am I wrong? [I mean] by helping others or doing volunteer work.

(Diabetes, 1059:1063)

While all participants considered a contribution of resources to society as characteristic for social participation, they disagreed whether receiving resources should be considered social participation. At the root of this disagreement were different assumptions about the experience of receiving resources. Participants explained that they regarded only positive experiences as social participation. If a person appreciated what was received (ranging from assistance in personal care to music) from others, the example was labelled social participation, but if a person received support that he or she did not appreciate, it was not labelled social participation. 
P1: But if they come to help me, I mean if I don't cooperate, if that other person really comes to help me without me asking, then, in my opinion, they might be participating in society, but not me.

(Diabetes, 1104:1110)

Participants took the issue of contributing and receiving resources one step further and contemplated their position on activities in which they did something for their own benefit, like repairing their own house or preparing a meal only for themselves. These activities were not considered social participation and one participant even seemed to consider repairing one's own house as a kind of 'anti participation', because it prevented a professional craftsman from earning a living.

\section{Reanalysis of individual interviews}

We reanalysed the individual interviews to seek confirmation or disconfirmation for the focus groups' conclusion that participants regarded only positive experiences as social participation. We found that the examples participants gave of their own social participation did always refer to positive experiences (which was in keeping with the focus group outcomes). There were, however, no examples of negative experiences which were explicitly labelled 'not social participation' (as we had found in the focus groups). Participants did give examples of social participation that they used to engage in but no longer did because they were not keen on the commitment or because it no longer felt appropriate. These examples might be considered negative associations with social participation. Yet the participants mentioned these negative associations only as reasons for quitting certain activities, not as explanations for not considering these activities to be social participation. In other words, the individual interviews indicated that participants sometimes changed their manner of social participation, but not their definitions.

\section{Discussion}

The results of the present study suggest that from the perspective of older adults with a chronic physical illness, social participation is characterized by a positive feeling and by social contact, contributing resources to society or receiving resources from society. There are two main findings in this conclusion. First, the results of both the individual and the focus group interviews suggest that, from the perspective of older adults with a chronic physical illness, social participation may consist not only of contributing resources, but also of receiving resources. In the individual interviews, examples of both were offered as examples of social 
participation. Focus group participants were subtler on the issue. While contributing resources in general was considered to characterize social participation, receiving resources was only considered to characterize social participation if it was experienced positively. These results suggest that Bukov et al. [16], in limiting social participation to contributions to society, might be going against the experiences of older adults with a chronic illness.

Second, older adults with a chronic illness appeared to regard only positive experiences as social participation. This appears to have been overlooked in previous social participation research. Different experiences of the same activities explained why focus group participants attached different labels to the same activities even though they agreed on the underlying characteristics of social participation. Reanalysis of the individual interviews did not confirm or reject this finding conclusively. The examples participants gave of social participation always referred to positive experiences, which might be considered a confirmation, but there were no examples of negative experiences explicitly labelled as 'not social participation' (confirmation) or social participation (disconfirmation). This might be due to the nature of the individual interviews: participants of the focus groups responded to each other's experiences, which gave them the opportunity to express that they experienced the same activity differently. Participants in the individual interviews obviously could not respond to what others said. It thus remains unclear whether they gave no examples of negative experiences because they did not consider these to be social participation or because these simply did not come to mind.

Besides these two main findings, it is not surprising that focus group participants indicated that they did not regard activities which involved doing or making something solely for oneself, as social participation. If they received assistance for this activity and appreciated this assistance, however, they would consider it social participation. In other words, whether or not an activity is social participation would depend on whether assistance was received and whether this was appreciated. This sheds new light on the discussion which of the ICF domains should be considered social participation. The results imply that social participation might not simply consist of a selection of the ICF domains but rather, that the scope of social participation might vary depending on the reception of assistance (in addition to being experienced positively).

What should be kept in mind with our conclusions is that the question shapes the answer. In quantitative research, there are guidelines and procedures to translate, adapt and test research instruments. In qualitative research, there are not, as there are no standardized research instruments. This makes it more difficult to assess whether interview questions (research instruments) and hence results and conclusions are valid. We discussed the equivalence of 'social participation' and 'deelname aan de maatschappij' (the Dutch expression that we used 
in the interviews) with a professional translator. 'Deelname aan de maatschappij' translates into 'social participation', but it refers explicitly to society ('maatschappij'), while 'social participation' does not. The 'social' in 'social participation' may refer broadly to society, but also more specifically to interactions between people. Since we used a broad equivalent of 'social participation' in the interviews, our conclusion that 'social participation may be understood as broad concept' only means that a broad interpretation of 'deelname aan de maatschappij' has empirical support. It does not mean that a narrow interpretation of 'social participation' has not.

The main strength of this study was the prominent place given to the experiences of social participation by older adults with a chronic illness themselves, rather than comparing and contrasting conceptualizations solely at a theoretical level. This approach added new insights. In particular, older adults with a chronic illness appear to connect social participation with a positive experience and to regard both contributing and receiving resources as social participation.

However, the main strength of this study also turned out to be its weakness. It was not easy to motivate older adults with a chronic illness to participate in the study - we had to recruit through multiple channels to fill two focus groups - and this may have had a selection effect, considering that both the individual and the focus group interviews consisted predominantly of men. Neither the participants in the focus groups nor the professional care givers who invited participants for the individual interviews could think of an explanation for this, when we asked them.

Furthermore, since we had only two focus groups, which used partly different items, and since the analysis of the individual interviews was not saturated, we were unable to develop a full theory of social participation for older adults with a chronic illness. Consequently, our conclusions refer to defining characteristics of social participation instead of a full conceptualization, which was the original aim of this study. Also, we could not make a thorough comparison between participants with diabetes and COPD regarding their definitions of social participation. It might be noted, however, that the individual and focus group interviews indicated no differences between participants with diabetes and COPD.

We decided against further data collection because of the effort involved in recruitment and time constraints. Although there might have been more to discover, we also felt that our findings could already be useful to researchers in the area of disability and rehabilitation who are interested in the conceptualization of social participation.

Future research might shed more light on how older adults with a chronic illness experience social participation. As regards methods, we would recommend focus groups rather than individual interviews for future research on this topic. In this study, participants in both methods found it difficult to discuss an abstract 
concept like social participation, but could argue quite well why they considered something social participation or not once they 'got going'. However, it seemed easier for the participants in the focus groups, because they had the stimulus of interaction.

As regards the research agenda of future research about the conceptualization of social participation of older adults with a chronic illness, our first priority would be to analyse the apparent relationship between dependence and social participation. That is, how does receiving assistance turn the activities supported into social participation? Is there in this regard a difference between assistance received from a health professional, a volunteer worker, a friend or a family member? Answering these questions might help to further improve our understanding of social participation from the perspective of people with a chronic illness.

\section{Conclusion}

The aim of this study was to conceptualize social participation from the perspective of older adults with a chronic physical illness, in particular COPD or diabetes. We first used individual interviews to explore the domains that make up social participation and then tried to identify the underlying characteristics of social participation in focus group sessions.

We may conclude on the basis of the individual interviews that previous research did not overlook any domains of social participation, as we found no new ones. We learned that participants associated a wide range of activities with social participation, which suggests that social participation may be understood as a broad concept. Also, participants' definitions of social participation appeared to remain the same when participants' actual participation changed. The results of the individual interviews appear to provide an empirical foundation for the three major interpretations of social participation found in the literature, because examples were given of all three: social interaction, contributions to society and involvement in organizations and exercising influence.

The results of the focus groups suggest that older adults with a chronic physical illness regard those activities as social participation, which involve social contact, contributing resources to society or receiving resources from society, and which in addition are experienced positively. 


\section{Acknowledgements}

We would like to acknowledge the contribution of Peter Janssen to the conception and design of the present study. We would also like to thank those who invited patients to participate in this study: René van den Heuvel, Geertjan Wesseling, Jan van Rooij, Pieter van den Berg, the team at the Diabetes Care Centre Maastricht, and the Dutch Diabetes Organization. Of course, we are greatly indebted to the participants in this study, who shared their experiences of social participation with us. 


\section{References}

1. Verbrugge, L. M., Jette, A. M. (1994). The disablement process. Social Science and Medicine, 38, 114.

2. Hoeymans, N., Timmermans, J. M., De Klerk, M.M.Y., De Boer, A. H., Deeg, D. J. H., Poppelaars, J. L., Thissen F., Droogleever Fortuijn, J. C., De Hollander, A. E. M. (2005). Gezond actief: De relatie tussen ziekten, beperkingen en maatschappelijke participatie onder nederlandse ouderen [healthy and active: The relationship between disease, disability and social participation among elderly in the netherlands], Report nr 270054001. Bilthoven: RIVM.

3. Levasseur, M., Desrosiers, J., Noreau, L. (2004). Is social participation associated with quality of life of older adults with physical disabilities? Disability and Rehabilitation, 26, 1206-13.

4. World Health Organization (2001). International classification of functioning, disability and health (ICF). Geneva: World Health Organization.

5. Jette, A. M. , Haley, S. M., Kooyoomjian, J. T. (2003). Are the ICF activity and participation dimensions distinct? Journal of Rehabilitation Medicine, 35, 145-50.

6. Perenboom, R. J. M., Chorus, A. M. J. (2003). Measuring participation according to the international classification of functioning, disability and health (ICF). Disability and Rehabilitation, 25, 577-87.

7. Noreau, L., Desrosiers, J., Robichaud, L., Fougeyrollas, P., Rochette, A., Viscogliosi, C. (2004). Measuring social participation: Reliability of the Life-H in older adults with disabilities. Disability and Rehabilitation, 26, 346-52.

8. Avlund, K., Holstein, B. E., Mortensen, E. L., Schroll, M. (1999). Active life in old age. Combining measures of functional ability and social participation. Danish Medical Bulletin, 46, 345-9.

9. Mookherjee, H. N. (1998). Perceptions of happiness among elderly persons in metropolitan USA. Perceptual and Motor Skills, 87, 787-93.

10. Kocken, P. L., Voorham, A. J. J. (1998). Effects of a peer-led senior health education program. Patient Education and Counseling, 34, 15-23.

11. Utz, R. L., Carr, D., Nesse, R., Wortman, C. B. (2002). The effect of widowhood on older adults' social participation: An evaluation of activity, disengagement, and continuity theories. The Gerontologist, 42, 522-33.

12. De Klerk, M. M.Y., Eijsink, M. (1999). Maatschappelijke participatie [social participation]. In: De Klerk, M. M. Y., Timmermans, J. M. (Editors). Rapportage ouderen 1998. Den Haag: Sociaal en Cultureel Planbureau.

13. Dalgard, O. S., Håheim, L.L. (1998). Psychosocial risk factors and mortality: A prospective study with special focus on social support, social participation, and locus of control in Norway. Journal of Epidemiology \& Community Health, 52, 476-81.

14. Lackner, J.B., Joseph, J.G., Ostrow, D. G., Eshleman, S. (1993). The effects of social support on hopkins symptom checklist-assessed depression and distress in a cohort of human immunodeficiency virus-positive and -negative gay men. The Journal of Nervous and Mental Disease, 181, 632-8.

15. Smits, C. H. M., Van Rijsselt, R. J. T., Jonker, C., Deeg, D. J.H. (1995). Social participation and cognitive functioning in older adults. International Journal of Geriatric Psychiatry, 10, 325-31.

16. Bukov, A., Maas, I., Lampert, T. (2002). Social participation in very old age: Cross-sectional and longitudinal findings from BASE. The journals of gerontology. Series B: Psychological sciences and social sciences, 57b, 510-7.

17. Schuyt, T. N. M., Schuijt-Lucassen, N. Y., Knipscheer, C.P.M. (1990). Sociale participatie van ouderen [social participation by the elderly]. Rijswijk: Ministerie van Welzijn, Volksgezondheid en Cultuur.

18. Van Eijk J. T. M., De Haan, M. (1998). Care for the chronically ill: The future role of health care professionals and their patients. Patient Education and Counseling, 35, 233-40. 
19. Mars, G. M. J., Proot, I. M., Janssen, P. P. M., Van Eijk, J. T. M., Kempen, G. I. J. M. (2007). How do people with COPD or diabetes type 2 experience autonomy? An exploratory study. Disability and Rehabilitation, 29, 485-93.

20. Muhr, T. (1998). Atlas.Ti - visual qualitative data analysis, management and theory building [computer programme]. Release 4.2. Berlin: Scientific Software Development.

21. Strauss, A., Corbin, J. (1998). Basics of qualitative research: Techniques and procedures for developing grounded theory. Thousand Oaks: Sage.

22. Hox, J. J. (1997). From theoretical concept to survey question. In: Lyberg, L., Biemer, P., Collins, M., De Leeuw, E., Dippo, C., Schwarz, N., Trewin, D. (Editors). Survey measurement and process quality. New York: Wiley.

23. Morgan, D. L. (1998). Planning focus groups. In: Morgan, D.L., Krueger, R.A. (Editors). The focus group kit. Thousand Oaks: Sage.

24. Van der Zee, K. I., Sanderman, R. Het meten van de algemene gezondheidstoestand met de rand36: Een handleiding [measuring general health with the rand-36: A manual]. Groningen: Noordelijk Centrum voor Gezondheidsvraagstukken. Available from: http://www.med.rug.nl/nch/assessment1.htm\#RAND

25. Ware Jr, J. E., Sherbourne, C.D. (1992). The MOS 36-item short-form health survey (SF-36): I. Conceptual framework and item selection. Medical Care, 30, 473-83. 



\section{Chapter 6}

\section{The Maastricht Social Participation Profile (MSPP): development and clinimetric properties in older adults with a chronic physical illness}

Godelief M. J. Mars, Gertrudis I. J. M. Kempen, Marcel W. M. Post, Ireen M. Proot, Ilse Mesters, Jacques T. M. van Eijk

Quality of Life Research (2009) 18, 1207-1218

DOI 10.1007/s11136-009-9537-4 


\section{Abstract}

Purpose. To develop and test the Maastricht Social Participation Profile (MSPP), an instrument measuring the actual social participation by older adults with a chronic physical illness, in accordance with their own definition of social participation.

Methods. The development process consisted of a number of steps, ending with a field test in two waves ( $n=412$ and $n=125$ ) among a random sample of people older than 59 years with either COPD or diabetes mellitus. Reproducibility was evaluated with intraclass correlation coefficients (ICCS) and smallest real differences at group level (SRDs $\left.s_{\text {group }}\right)$. Convergent and discriminant validity were evaluated with Pearson correlation coefficients between the MSPP and the Frenchay Activities Index (FAI).

Results. The MSPP consists of four indices: consumptive participation, formal social participation, informal social participation-acquaintances and informal social participation-family. Each index measured diversity and frequency of participation. ICCs ranged between 0.63 and 0.83 . SRDs group ranged between 0.05 and 0.09 . Convergent and discriminant validity were supported by the correlations between the $\mathrm{MSPP}_{\text {frequency }}$ and the FAI.

Conclusions. The MSPP has good validity and acceptable reproducibility. Its distinguishing features are its focus on actual social participation and the possibility to calculate both diversity and frequency scores. 


\section{Introduction}

Demographic ageing has drawn the attention of policy makers to the negative effects that diseases and disabilities may have on participation by older people [1, 2]. Participation is defined by the International Classification of Functioning, Disability and Health (ICF) as 'involvement in life situations' [3]. Policy makers aim to promote participation in this group because of the expected benefits for society and increased quality of life for the individuals concerned [1, 2, 4]. For quality of life, research suggests that social roles may be a more important aspect of participation than daily activities $[4,5]$. For society to function, social contact and exchange between people are imperative. Research would therefore benefit from a measurement instrument which focuses on the social aspects of participation. We developed such an instrument, the Maastricht Social Participation Profile (MSPP).

The MSPP intends to measure actual social participation by older adults with a chronic physical illness. It builds on a definition given by older adults with a chronic physical illness themselves. They define social participation as a positive experience having one or more of the following three characteristics: social contact, contributing to society (like paying a visit) or receiving from society (like receiving a visit) [6]. This definition excludes behaviours which do not involve an exchange between people (like doing own household chores), which distinguishes social participation from the broader concept of participation. Furthermore, the definition includes behaviours which involve receiving from society, while other definitions of social participation tend to exclude these behaviours [6-12].

The question of whether social participation involves only contributing or both receiving and contributing is particularly relevant in the case of people with a chronic illness, because their opportunities to contribute may diminish. In response, people may explore alternatives [13]. If social participation involves both receiving and contributing, there are more alternatives, making it easier to maintain a given level of social participation (substitution). For example, instead of paying a painful or fatiguing visit to a friend (contribute), the friend may come to visit (receive).

The MSPP measures actual social participation, which refers to the frequency and diversity of social participation: how often do people engage in social participation and in how many different types of social participation do they engage? Information about actual social participation of people with a chronic illness is important from a societal perspective, because it tells us to what extent people are integrated in society. From an individual perspective, actual social participation may play a less important role in quality of life than its subjective experience [5]. For people are autonomous and differ in the frequency and types of social participation they prefer. Nonetheless, information about actual social participation may improve our understanding of subjective social participation and quality 
of life. This requires the use of additional instruments to measure subjective social participation and quality of life. Are people more satisfied about their social participation if they participate more often or if they participate in several different ways - or are both equally important (or unimportant)? Also, if a measure improves people's subjective social participation, it is important to understand why: did the actual social participation change or did people afterwards feel better about the same actual social participation?

This paper addresses the development and clinimetric properties of the MSPP. The MSPP was developed as a self-administered generic measure for actual social participation by older adults with a chronic physical illness with the purpose of discrimination and evaluation.

\section{Methods}

The MSPP was developed with a sample of older adults with either Chronic Obstructive Pulmonary Disease (COPD) or Diabetes Mellitus type 2 (diabetes). COPD and diabetes both take a gradually deteriorating course, but COPD has intermittent exacerbations, while diabetes is characterized by a long stabilization phase followed by chronic complications [14].

The development process consisted of a number of steps, after each of which the MSPP was revised. Figure 1 outlines the sequence and purpose of the steps. In this section, we explain the steps. The results section will focus on the final step, the second field test, in which we evaluated the reproducibility and validity of the semi-final version in order to arrive at a final version of the MSPP.

Medical ethics committee approval was granted.

\section{Development of the semi-final version}

Initially, we conducted a qualitative study [6]: a literature search and ten individual interviews resulted in a list of social participation examples, which was used in two focus group sessions. The discussion focused on participants' reasons for classifying certain items as social participation while rejecting others. This resulted in the definition of social participation already presented in the introduction. 


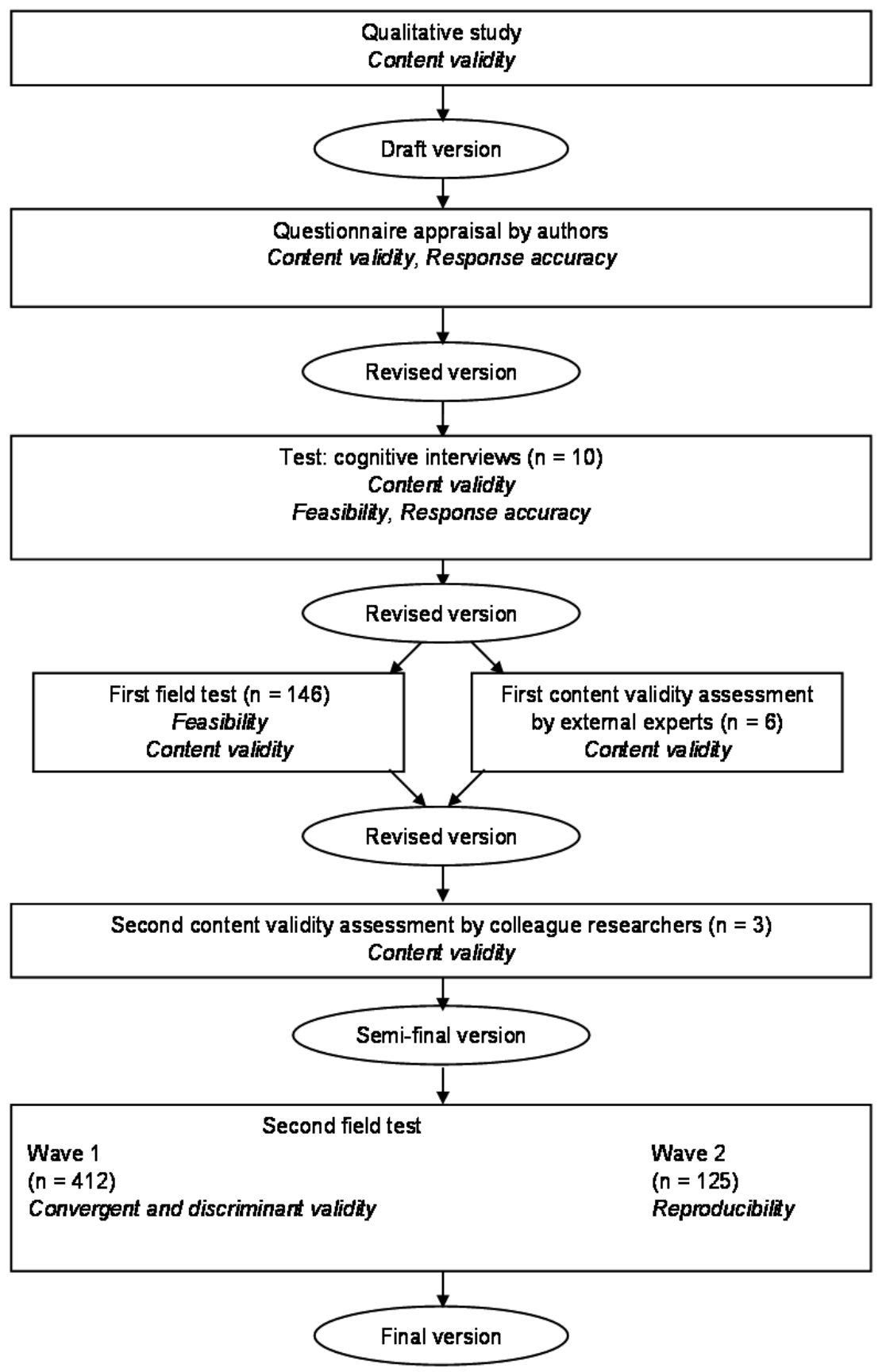

Figure 1 Development of the Maastricht Social Participation Profile (MSPP) 
Next, following guidelines about questionnaire design [15-19], we constructed three indices, based on the presented definition and using items from the list of social participation examples [6]. We deviated from the definition in two ways. First, we did not operationalize that social participation should be a positive experience, because this involves subjective evaluation, while we wanted to develop a measure for actual social participation. Second, we treated 'social contact' as a necessary characteristic to focus the content of the MSPP. Consequently, all three indices included only participation behaviours involving social contact. The first index concerns consumptive participation ( $\mathrm{CP}$, nine items), which is characterized as benefiting from society (for example taking a course or visiting a restaurant). The second index concerns formal social participation (FSP, two items), which is characterized as contributing to society (participation in clubs and volunteer work). The third index concerns informal social participation (ISP, nine items), which is characterized as contributing to society, receiving or both (contact with family, friends and acquaintances).

The response format referred to the number of times something was done in the last 4 weeks, but the response key indicated with how often a week this corresponds. The former is easier to answer when counting (rare and salient behaviours), while the latter is easier when estimating (frequent and mundane behaviours) [20]. The MSPP includes both.

The authors GM, GK, IP, IM and JVE systematically evaluated response accuracy and content validity [21]. Content validity refers to 'the extent to which an empirical measurement reflects a specific domain of content' [22: 20]. The ISP was split into separate indices for acquaintances (ISP-A) and family (ISP-F) (identical items).

Next, we conducted ten cognitive interviews to test whether items were interpreted as intended (content validity). Participants were one man and two women with COPD and six men and one woman with diabetes, ranging in age between 65 and 83 years. Participants were asked to formulate retrospectively (or concurrently if they preferred) how they had interpreted items and decided on their answers $[23,24]$. Probing techniques were used to check feasibility and response accuracy. Although revisions were made, the main result of the interviews was that items had been interpreted as intended.

The first field test involved a random sample of adults older than 59 years with either COPD $(n=71)$ or diabetes $(n=75)$ (May 2004). We analysed missing value patterns, frequency distributions, inter-item correlations and comments written on questionnaires. All statistical analyses in this study were done with the SPSS computer programme version 12.0.1 [25]. The two highest response categories were combined.

Parallel to the first field test, content validity was assessed by six Dutch experts in the area of participation research who had not been involved in the pro- 
ject so far. The experts received the MSPP, a schematic representation of its operationalization, and the argumentation behind it. They were asked to comment on both the operationalization and the underlying conceptualization and could freely structure their response or follow a more detailed list of questions which was provided. Generally, the experts were positive about the conceptualization and operationalization, but they also made some critical remarks. In response, items were added, removed and rephrased. Not all issues raised by the experts resulted in revisions, however, either because we could not (item overlap) or would not (for reasons of feasibility and conceptual choices).

In the second assessment of content validity, three colleague researchers not involved in the project sorted, independently of each other, the items of the MSPP to the hypothesized indices. The sortings were compared and the intended ordering and differences discussed. No revisions were necessary.

\section{Semi-final version of the MSPP}

The semi-final version of the MSPP consisted of 26 social participation items in four indices: CP (seven items), FSP (three items), ISP-A (eight items) and ISP-F (eight items). All items had the same response format: did not do this in last four weeks (zero times), did this less than once a week (one to three times), did this once to twice a week (four to eight times), did this more than twice a week (nine times or more). Two types of scores could be calculated for each index: diversity and frequency. Diversity scores refer to the number of items in the index on which a respondent had a score of at least one. Frequency scores reflect the mean score of the items. In addition, the total diversity score refers to the number of indices on which a respondent had a score of at least one. Higher scores indicate more diverse or more frequent social participation. In the present study, scores were only calculated if there were no missing values in a given index. The MSPP is included in Appendix B.

\section{Methods of the second field test}

\section{Sample and data collection}

The semi-final version of the MSPP was sent out in two waves to a new random selection of people older than 59 years with either COPD or diabetes. They had previously been screened for a study about chronic illness and depression carried out by the School for Public Health and Primary Care of Maastricht University, the Netherlands (Delta study) [26], which had also asked consent to participate in the present study. Those included in the Delta study (inclusion criterion: minor or mild to moderate depression) were not invited to participate in the present study to 
prevent high respondent burden. The Delta study recruited participants through 89 family practices in the south of the Netherlands.

In wave one (October 2004), 600 questionnaires were sent out to people with either diabetes $(N=300)$ or COPD $(N=300)$. To increase response, a telephone reminder was issued after two weeks. Respondents who returned questionnaires with missing values were also followed up by telephone. One-third of the participants who returned the questionnaire (random selection stratified by disease) received the questionnaire again 4 weeks after their first response to assess reproducibility (wave two). A period of 4 weeks was chosen, because the time frame of the items was 'last 4 weeks' and we wanted to avoid partially overlapping time frames. We considered 4 weeks long enough to prevent recall bias.

\section{Instruments}

Besides the MSPP and questions about background characteristics (sociodemographics and health), the questionnaire included parts of the RAND-36 [27, 28 ] to measure general health perception and physical functioning. The Frenchay Activities Index (FAI) $[29,30]$ was included to assess construct validity. It consists of fifteen activities, scored on a four-point scale (zero to three). The activities fall into three subscales: leisure/work domain, outdoors and domestic domain. Higher scores indicate that people are more active. The FAI has been validated in a Dutch sample of stroke patients and a control group of older adults. Construct validity was acceptable and Cronbach's alpha $>.60$ in both groups for all three subscales [29].

\section{Analyses}

Reproducibility Reproducibility of the MSPP was evaluated with Intraclass Correlation Coefficients (ICCS) [31] and with Smallest Real Differences at group level (SRDs $s_{\text {group }}$ ) [32]. ICCs were computed for each index and each item separately using a two-way random effects model with absolute agreement between the scores of wave one and two [33]. ICCs are relevant if the MSPP is used for discrimination purposes and should be at least 0.70 [34]. SRDs group were computed for each index according to the following formula [35]:

$$
\mathrm{SRD}_{\text {group }}=\frac{\mathrm{SD}_{\text {wave2-1 }}}{\sqrt{\mathrm{n}}} \times 1.96
$$

$\mathrm{SRD}_{\text {group }}$ is relevant if the MSPP is used for evaluation purposes, because it indicates the magnitude of difference that may, with $95 \%$ confidence, be expected between two measurements on the same, stable group of participants ('noise'). The SRD is expressed in the same units as the indices and should be smaller than the minimal amount of change that is considered to be important (MIC) [34]. As 
we do not know yet which amount of change researchers and/or patients may consider important, readers should judge the SRD levels for themselves. To facilitate interpretation, we here define the MIC as the amount of change in the mean scores if half of the sample remains stable and the other half scores one point higher on one item (frequency scores) or scores on one item more (diversity scores).

Convergent and discriminant validity To evaluate convergent and discriminant validity of the MSPP, we used the FAI $[29,30]$, because it is a measure for actual participation, like the MSPP. To our knowledge, the FAl is the only concise instrument for actual participation validated in a Dutch sample. The FAI measures the broad concept of participation, rather than social participation and could therefore be used for convergent as well as discriminant validation.

The FAl domestic domain (preparing meals, washing up, washing clothes, light housework, heavy housework) does not measure social participation, but only activities which do not involve an exchange between people (not related to MSPP indices). By contrast, the FAl leisure/work domain (social outings, pursuing hobby, outings/car rides, house/car maintenance, gainful work) covers all three characteristics of social participation: social contact, contributing to society and receiving from society (positively related to all four MSPP indices). Finally, the FAI outdoors domain (local shopping, walking outdoors, driving/bus travel, gardening, reading books) includes items which may involve social contact and receiving from society, but not contributing (positively related to MSPP consumptive participation and MSPP informal social participation, not related to MSPP formal social participation).

We hypothesized that MSPP $\mathrm{CP}_{\text {frequency }}$ should correlate positively (Pearson correlation coefficient) with FAI leisure/work and outdoors (convergent validity) and those correlations should be higher than the correlation with FAl domestic (discriminant validity) [36], tested with Steiger's Z [37] (four hypotheses). The correlation with FAl domestic should be lower rather than absent, because the MSPP and FAl might correlate for other reasons, like physical functioning. We hypothesized the same for MSPP ISP-A $\mathrm{A}_{\text {frequency }}$ and ISP- $\mathrm{F}_{\text {frequency }}$ (eight hypotheses). MSPP FSP frequency should correlate positively with FAl leisure/work and this correlation should be higher than the correlations with FAl outdoors and domestic (three hypotheses). Twelve of the fifteen hypotheses should find empirical support [34].

Comparison between COPD and diabetes Reproducibility and validity analyses were carried out for COPD and diabetes separately. 


\section{Results of the second field test}

\section{Response and sample characteristics}

Of the 600 questionnaires sent out in wave one, 412 (69\%) were returned (206 COPD and 206 diabetes). Four weeks later, in wave two, 125 of 137 questionnaires were returned (91\%). The percentage of respondents in wave one without missing values on an index was: $93 \%$ for CP, 97\% for FSP, 91\% for ISP-A and 91\% for ISP-F (before telephone follow-up). Mean age was 70 (range 60-87). More men than women participated, as a result of a skewed sex distribution in the sampling frame. General health perception and physical functioning $[27,28]$ were significantly worse in participants with COPD than in participants with diabetes. Co-morbidity was common in both. Table 1 presents various characteristics of participants.

Table 1 Characteristics of the study population in the validation study (as measured in wave 1)

\begin{tabular}{|c|c|c|}
\hline & $\operatorname{COPD}(n=206)$ & Diabetes $(n=206)$ \\
\hline Mean age (SD) & $70.5(6.6)$ & $70.0(6.2)$ \\
\hline \multicolumn{3}{|l|}{ Sex $(\%)$} \\
\hline Male & 67.5 & 68.4 \\
\hline Female & 32.5 & 31.6 \\
\hline Education level (\%) & * & * \\
\hline Primary & 28.4 & 18.6 \\
\hline Secondary & 61.3 & 63.7 \\
\hline Tertiary & 10.3 & 17.6 \\
\hline Paid employment (\%) & 3.9 & 4.4 \\
\hline Living together with partner or other person(s) (\%) & 75.1 & 73.2 \\
\hline \multicolumn{3}{|l|}{ RAND-36 (scale 0-100, higher is better) } \\
\hline Mean general health perception (SD) & $46.0(18.7)^{*}$ & $50.1(18.1)^{*}$ \\
\hline Mean physical functioning (SD) & $55.7(27.1)$ & $62.6(28.9)^{*}$ \\
\hline Mean duration of disease in years (SD) & $18.9(18.1)^{*}$ & $9.6(8.6)^{*}$ \\
\hline Duration of disease in years (min-max) & $0-79$ & $0-44$ \\
\hline Mean number of chronic conditions (SD) & $2.8(2.1)$ & $3.0(2.0)$ \\
\hline
\end{tabular}

* Significant difference between COPD and diabetes at 0.05 level (Pearson chi-square or one-way analysis of variance) 


\section{Scores on the MSPP}

Table 2 presents the scores on the MSPP for participants with COPD and diabetes separately. Observed scores on the MSPP covered the entire range of theoretically possible scores for all indices except $\mathrm{CP}_{\text {frequency, }} \mathrm{ISP}-\mathrm{A}_{\text {frequency }}$ and total diversity. On this last score, the observed score range reveals that all participants engaged in at least one type of social participation as measured by the MSPP. The results further suggest that people with diabetes tended towards a more diverse and more frequent social participation than people with COPD, but differences were small. Only total diversity $(p=0.02)$ and $\operatorname{FSP}_{\text {frequency }}(p=0.02)$ were significant at 0.05 level.

Table 2 Scores on the MSPP by disease

\begin{tabular}{llllll}
\hline & $\begin{array}{l}\text { Number of } \\
\text { cases }\end{array}$ & $\begin{array}{l}\text { Theoretical } \\
\text { score range }\end{array}$ & $\begin{array}{l}\text { Observed score } \\
\text { range }\end{array}$ & $\begin{array}{l}\text { COPD } \\
\text { Mean (SD) }\end{array}$ & $\begin{array}{l}\text { Diabetes } \\
\text { Mean (SD) }\end{array}$ \\
\hline $\begin{array}{l}\text { Total diversity }^{\mathrm{a}} \\
\text { Diversity }\end{array}$ & 382 & $0-4$ & $1-4$ & $3.29(0.80)^{*}$ & $3.47(0.73)^{*}$ \\
CP & 410 & $0-7$ & $0-7$ & $2.40(1.61)$ & $2.63(1.57)$ \\
FSP & 410 & $0-3$ & $0-3$ & $0.81(0.96)$ & $1.00(0.99)$ \\
ISP-A & 394 & $0-8$ & $0-8$ & $4.83(2.28)$ & $4.90(2.14)$ \\
ISP-F & 398 & $0-8$ & $0-8$ & $4.50(2.18)$ & $4.72(2.08)$ \\
Frequency & & & & & \\
CP & 410 & $0-3$ & $0-1.86$ & $0.45(0.34)$ & $0.51(0.37)$ \\
FSP & 410 & $0-3$ & $0-3$ & $0.44(0.61)^{*}$ & $0.60(0.70)^{*}$ \\
ISP-A & 394 & $0-3$ & $0-2.75$ & $0.94(0.61)$ & $1.00(0.56)$ \\
ISP-F & 398 & $0-3$ & $0-3$ & $0.88(0.57)$ & $0.95(0.56)$ \\
\hline
\end{tabular}

${ }^{a}$ Number of indices on which respondents had a score of at least one.

${ }^{\mathrm{b}}$ Number of items in the index on which respondents had a score of at least one.

${ }^{c}$ Mean score on the items in the index.

* Difference between COPD and diabetes significant at 0.05 level (one-way analysis of variance)

\section{Reproducibility}

Tables 3 and 4 show reproducibility results. Index ICCs ranged from 0.63 for $\mathrm{CP}_{\text {fre- }}$ quency to 0.83 for $\mathrm{FSP}_{\text {diversity }}$ (should be 0.70 ). Item ICCs were partly low, except in FSP. One might expect low ICCs to be found in particular in items referring to irregular types of participation, but this was not evident. SRDs group $_{\text {were }}$ smaller than the MICs (as they should), except for ISP-A $\mathrm{A}_{\text {frequency }}$ and ISP- $\mathrm{F}_{\text {frequency. }}$ 
Table 3 Reproducibility of the MSPP indices

\begin{tabular}{|c|c|c|c|c|c|}
\hline & $\begin{array}{l}\text { Index ICC } \\
\text { (95\% confidence } \\
\text { interval) }\end{array}$ & $\begin{array}{l}\text { Mean Item } \\
\text { ICC }\end{array}$ & $\begin{array}{l}\text { Range Item } \\
\text { ICC }\end{array}$ & SRD group ${ }^{a}$ & $\begin{array}{l}\text { Minimal Im- } \\
\text { portant Change }{ }^{b}\end{array}$ \\
\hline \multicolumn{6}{|c|}{ Diversity } \\
\hline Total & $0.74(0.65-0.82)$ & & & & \\
\hline $\mathrm{CP}$ & $0.68(0.58-0.77)$ & - & - & 0.22 & 0.5 \\
\hline FSP & $0.83(0.76-0.87)$ & - & - & 0.11 & 0.5 \\
\hline ISP-A & $0.72(0.62-0.80)$ & - & - & 0.28 & 0.5 \\
\hline ISP-F & 0.71 (0.61-0.79) & - & - & 0.30 & 0.5 \\
\hline \multicolumn{6}{|c|}{ Frequency } \\
\hline CP & $0.63(0.51-0.73)$ & 0.58 & $0.38-0.76$ & 0.05 & 0.07 \\
\hline FSP & $0.81(0.74-0.86)$ & 0.72 & $0.61-0.79$ & 0.08 & 0.17 \\
\hline ISP-A & $0.72(0.62-0.79)$ & 0.52 & $0.37-0.61$ & 0.07 & 0.06 \\
\hline ISP-F & $0.64(0.52-0.73)$ & 0.46 & $0.31-0.62$ & 0.09 & 0.06 \\
\hline
\end{tabular}

${ }^{a}$ The SRDs are expressed in observed units and should be interpreted against the theoretical score ranges: 0-3 for the frequency scores, 0-7 for $\mathrm{CP}_{\text {diversity, }}$ 0-3 for $\mathrm{FSP}_{\text {diversity }}$ and 0-8 for ISP-A and ISP-F.

${ }^{b}$ The Minimal Important Change (MIC) is here defined as the amount of change if half of the sample remains stable and the other half scores one point higher on one item (frequency scores) or scores on one item more (diversity scores). 
Table 4 Reproducibility of the MSPP items

\begin{tabular}{|c|c|}
\hline & ICC \\
\hline \multicolumn{2}{|l|}{$\mathrm{CP}$} \\
\hline Organised sport or physical activity & 0.69 \\
\hline Cultural or educational event & 0.53 \\
\hline Eaten out & 0.58 \\
\hline Pub, café or tearoom & 0.63 \\
\hline Public event & 0.38 \\
\hline Organised games afternoon or evening & 0.76 \\
\hline Organised day trip & 0.52 \\
\hline \multicolumn{2}{|l|}{ FSP } \\
\hline Club or similar activity & 0.61 \\
\hline Committee work & 0.79 \\
\hline Organised voluntary work & 0.77 \\
\hline \multicolumn{2}{|l|}{ ISP-A } \\
\hline Phoned, written, e-mailed or chatted & 0.60 \\
\hline They called in to see you & 0.50 \\
\hline You called in to see them & 0.57 \\
\hline Away from home, considerable physical effort & 0.51 \\
\hline Away from home, little physical effort & 0.49 \\
\hline Offered practical help & 0.37 \\
\hline Given advice or tips & 0.61 \\
\hline Someone to talk to & 0.53 \\
\hline \multicolumn{2}{|l|}{ ISP-F } \\
\hline Phoned, written, e-mailed or chatted & 0.62 \\
\hline They called in to see you & 0.59 \\
\hline You called in to see them & 0.52 \\
\hline Away from home, considerable physical effort & 0.50 \\
\hline Away from home, little physical effort & 0.40 \\
\hline Offered practical help & 0.37 \\
\hline Given advice or tips & 0.31 \\
\hline Someone to talk to & 0.39 \\
\hline
\end{tabular}

\section{Convergent and discriminant validity}

Convergent and discriminant validity of the MSPP were supported by the correlations between the MSPP frequency and the FAl, which Table 5 shows. Convergent correlations were higher than discriminant correlations, but not very high. Differences between correlations were significant except for one, which means that 14 of 15 hypotheses found significant empirical support. 
Table 5 Convergent and discriminant validity of the MSPP (Pearson correlations with FAI)

\begin{tabular}{|c|c|c|c|c|c|}
\hline MSPP & FAI Leisure/work & & FAI Domestic & & FAI Outdoors \\
\hline $\mathrm{CP}_{\text {frequency }}$ & $0.41^{*}$ & $>^{*}$ & $0.15^{*}$ & $<^{*}$ & $0.31^{*}$ \\
\hline $\mathrm{FSP}_{\text {frequency }}$ & $0.40^{*}$ & $>^{*}$ & 0.01 & - & $0.22^{*}$ \\
\hline & & & $>^{*}$ & & \\
\hline ISP-A $\mathrm{A}_{\text {frequency }}$ & $0.48^{*}$ & $>^{*}$ & $0.14^{*}$ & $<$ & $0.30^{*}$ \\
\hline ISP- $F_{\text {frequency }}$ & $0.39^{*}$ & $>^{*}$ & $0.22^{*}$ & $<$ & $0.29^{*}$ \\
\hline
\end{tabular}

* Correlation or difference between correlations significant at 0.01 level.

\section{Reproducibility and validity for COPD and diabetes separately}

Separates analyses for COPD and diabetes suggested better reproducibility of $\mathrm{CP}_{\text {diversity, }} \mathrm{CP}_{\text {frequency, }} \mathrm{ISP}-\mathrm{A}_{\text {diversity }}$ and ISP-A $\mathrm{A}_{\text {frequency }}$ in diabetes than in COPD (e.g. ISP$A_{\text {frequency: }}$ ICC diabetes $=0.80$, ICC COPD $\left.=0.64\right)$, while ISP- $F_{\text {diversity }}$ and ISP- $F_{\text {frequency }}$ yielded worse reproducibility results in diabetes than in COPD (e.g. ISP- $\mathrm{F}_{\text {diversity }}$ ICC diabetes $=0.62$, ICC COPD $=0.79$ ). For FSP, results were similar in diabetes and COPD.

Regarding convergent and discriminant validity, analyses for COPD and diabetes separately yielded similar results, except that fewer differences between correlations were significant due to a lower power (data not shown).

\section{Final version of the MSPP}

The results of the second field test did not cause us to change the MSPP. The final version of the MSPP is, therefore, identical to the semi-final version (see Appendix B).

\section{Conclusion and discussion}

Existing instruments for participation (in the broad sense) in the field of health and disability measure its performance [38-41], frequency [30, 42], or subjective experience $[42,43]$. The MSPP also measures frequency of participation, but distinguishes itself, because it can yield both frequency and diversity scores and focuses on the social aspects of participation. Furthermore, it builds on a definition of social participation of older adults with a chronic illness themselves. We first discuss the development, validity and reproducibility of the MSPP and then compare with the development and validation of two other instruments measuring frequency of participation (in the broad sense), namely the FAI [30] and (the objective part of) the Participation Objective Participation Subjective (POPS) [42]. 
The development process of the MSPP did not include the use of standard techniques based on associations between items, like internal consistency and factor analysis. We decided against these techniques because the items of the MSPP are causal variables rather than indicator variables [44]. Indicator variables reflect an underlying concept, which completely explains the correlations between the indicator variables. In this case, techniques based on associations between items are appropriate. In contrast, causal variables 'are part of the definition of what the concept being measured means. (...) if they are present (...) then the concept in question is present.' [44: 237] There is, for instance, no underlying degree of consumptive participation which instigates people to go to the cinema. Rather, people engage in consumptive participation because they go to the cinema. Causal variables may be associated irrespective of the relationship with the concept they are measuring (e.g. social participation items that are impeded by fatigue). This makes techniques based on associations inappropriate, because these techniques may suggest removing items at the cost of content validity [45], or may suggest grouping items together based on other factors (e.g. fatigue) than the concept in question (social participation). We therefore decided not to use these techniques and instead paid close attention to content validity. The results from the first field test show that inter-item Pearson correlations were partly low or even negative, which supports our decision not to use techniques based on associations.

Content validity of the MSPP was scrutinized by experts in the area of participation research and, after amendments, tested again by other researchers. Convergent and discriminant validity were supported by correlations between the indices of the MSPP and the Frenchay Activities Index, but differences between convergent and discriminant correlations were small. One reason might be that the MSPP and FAI are not an optimal match for convergent validation. The social activities in the FAl are spread in the subscales that also include daily activities. Another reason might be that circumstances like physical functioning produced correlations between the MSPP and FAI indices (convergent and discriminant).

Reproducibility of the MSPP is moderate rather than good for the purpose of discrimination, because two of nine ICCs were lower than the threshold of 0.70 (seven if using lower limit of the $95 \%$ confidence intervals). Reproducibility is good for the purpose of evaluation ( $\left.S R D_{\text {group }}\right)$, but it is a limitation of the present study that the MIC was rather arbitrarily defined.

Furthermore, reproducibility of the MSPP differs for COPD and diabetes. It is unclear whether this is a limitation of the MSPP or rather a limitation of the present study. As the MSPP measures actual social participation in the last 4 weeks and the interval between waves one and two in our study was likewise 4 weeks, social participation may really have been different between waves one and two. This is not unlikely, considering that reproducibility results of $\mathrm{CP}_{\text {diversity, }} \mathrm{CP}_{\text {frequency, }}$ ISP-A $A_{\text {diversity }}$ and ISP-A $A_{\text {frequency }}$ were worse in COPD, which is characterized by inter- 
mittent exacerbations. In times of exacerbations, people may be forced to, or choose to, restrict social participation, causing social participation to fluctuate more in COPD than in diabetes. To test whether reproducibility really differs for COPD and diabetes, waves one and two would have to take place within the closest possible time, for example on the same day or on two consecutive days.

There might be reservations about the sample used, because the MSPP is intended to be a generic instrument for older adults with a chronic physical illness, but the development process involved only two types of chronic disease. By using only two types, we could compare measurement properties. A generic instrument should be robust across different types of disease, meaning that scores may differ, but measurement properties should be the same.

Comparison with the development of the FAl and the objective part of the POPS shows that the former was developed using factor analysis [30], while the latter, like the MSPP, was developed using methods for causal variables. These seem more appropriate for measures of observable activity, like frequency of participation [42]. Particularly, validity of the POPS was explored by comparing results with expectations about differences between groups and correlations between subscale scores. Results and expectations did not match well [42].

Regarding reproducibility, ICCs of the FAI, POPS and MSPP are similar $[42,46]$. The ICCs of the POPS subscales vary considerably. The POPS authors suggest as an explanation that participation behaviours that are 'not scheduled into an invariant behaviour' may vary between measurements [42]. Likewise, we suggested true variability as an explanation for the differences between COPD and diabetes in reproducibility of the MSPP.

Future research should try to establish the minimal change in MSPP scores deemed important by people with a chronic illness to facilitate the evaluation of reproducibility. This would also allow the assessment of responsiveness, which is important for evaluation purposes. Furthermore, the MSPP still needs to be tested in other patient groups. Since the items are not specific to people with COPD or diabetes, it might also be worthwhile to test the MSPP in a general population of older adults, and to use it to compare healthy older adults with those with a chronic illness. Given the social participation behaviours it covers, the MSPP does not appear to be valid for use in younger age groups.

Although there are some unresolved issues, we conclude that the Maastricht Social Participation Profile is a measure for actual social participation by older adults with a chronic physical illness, which appears to have good validity and acceptable reproducibility for discrimination purposes. 


\section{Acknowledgments}

We would like to thank the participants in the study and those who invited them: Karianne Jonkers, Femke Lamers, Jan van Rooij, the team at the Diabetes Care Centre Maastricht and the Dutch Diabetes Organization. Furthermore, we thank Trudi van den Bos, Mieke Cardol, Ingrid Friesema, Mieke le Granse, Marike Hendriks, Femke Lamers, Tineke Schoot and Leontine van de Ven for assessing the content validity of the MSPP. 


\section{References}

1. Hoeymans, N., Timmermans, J.M., De Klerk, M.M.Y., De Boer, A.H., Deeg, D.J.H., Poppelaars, J.L., Thissen, F., Droogleever Fortuijn, J.C., De Hollander, A.E.M. (2005). Gezond actief: de relatie tussen ziekten, beperkingen en maatschappelijke participatie onder Nederlandse ouderen [Healthy and active: the relationship between disease, disability and social participation among elderly in the Netherlands]. Bilthoven: RIVM.

2. De Boer, A.H., editor (2006). Rapportage ouderen 2006 [Report on the Elderly 2006]. Den Haag: SCP.

3. World Health Organization (2001). International Classification of Functioning, Disability and Health (ICF). Geneva: World Health Organization.

4. van Campen, C., editor (2006). Gezond en wel met een beperking: Ervaren kwaliteit van leven en functioneren van mensen met langdurige lichamelijke beperkingen [Safe and sound with a disability: Experienced quality of life and functioning of people with chronic physical impairments]. Den Haag: SCP.

5. Levasseur, M., Desrosiers, J., Noreau, L. (2004). Is social participation associated with quality of life of older adults with physical disabilities? Disability and Rehabilitation, 26, 1206-1213.

6. Mars, G.M.J., Kempen, G.I.J.M., Mesters, I., Proot, I.M., Van Eijk, J.T.M. (2008). Characteristics of social participation as defined by older adults with a chronic physical illness. Disability and Rehabilitation, 30, 1298-1308.

7. Avlund, K., Holstein, B.E., Mortensen, E.L., Schroll, M. (1999). Active life in old age. Combining measures of functional ability and social participation. Danish Medical Bulletin, 46, 345-349.

8. Mookherjee, H.N. (1998). Perceptions of happiness among elderly persons in metropolitan USA. Perceptual and Motor Skills, DOI: 10.2466/PMS.87.7.787-793.

9. De Klerk, M.M.Y., Eijsink, M. (1999). Maatschappelijke participatie [Social participation]. In: De Klerk, M. M. Y., Timmermans, J. M. (Editors). Rapportage ouderen 1998. Den Haag: SCP.

10. Dalgard, O.S., Håheim, L.L. (1998). Psychosocial risk factors and mortality: A prospective study with special focus on social support, social participation, and locus of control in Norway. Journal of Epidemiology and Community Health, 52, 476-481.

11. Lackner, J.B., Joseph, J.G., Ostrow, D.G., Eshleman, S. (1993). The Effects of Social Support on Hopkins Symptom Checklist-Assessed Depression and Distress in a Cohort of Human Immunodeficiency Virus-Positive and -Negative Gay Men. The Journal of Nervous and Mental Disease, 181, 632-638.

12. Bukov, A., Maas, I., Lampert, T. (2002). Social Participation in Very Old Age: Cross-Sectional and Longitudinal Findings from BASE. The journals of gerontology: psychological sciences, 57b, 510517.

13. Mars, G.M.J., Proot, I.M., Janssen, P.P.M., Van Eijk, Jacques T.M., Kempen, G.I.J.M. (2007). How do people with COPD or diabetes type 2 experience autonomy? An exploratory study. Disability and Rehabilitation, 29, 485-493.

14. Van Eijk, J.T.M., De Haan, M. (1998). Care for the chronically ill: the future role of health care professionals and their patients. Patient Education and Counseling, 35, 233-240.

15. Schaeffer, N.C., Presser, S. (2003). The science of asking questions. Annual Review of Sociology, 29, 65-88.

16. Belli, R.F., Schwarz, N., Singer, E., Talarico, J. (2000). Decomposition can harm the accuracy of behavioural frequency reports. Applied Cognitive Psychology, 14, 295-308.

17. Schwarz, N. (1999). Self-reports - How the questions shape the answers. American Psychologist, 1999. 54, 93-105.

18. Porst, R. (2000). Question Wording - Zur Formulierung von Fragebogen -Fragen. ZUMA How-toReihe, 2. Mannheim: ZUMA.

19. Fowler, F.J.J., (2001). Why it is Easy to Write Bad Questions. ZUMA-Nachrichten, 48, 49-66. 
20. Rockwood, T.H., Sangster, R.L., Dillman, D.A. (1997). The Effect of Response Categories on Questionnaire Answers; Context and Mode Effects. Sociological Methods \& Research, 26, 118-140.

21. Lessler, J.T., Forsyth, B.H. (1996). A Coding System for Appraising Questionnaires. In Schwarz, N., Sudman, S. (Editors). Answering Questions: methodology for determining cognitive and communicative processes in survey research. San Francisco: Jossey-Bass Publishers.

22. Carmines, E.G., Zeller, R.A. (1979). Reliability and validity assessment. Quantitative Applications in the Social Sciences, Lewis-Beck, M. S. (Editor), Vol. 07-017. Newbury Park: Sage Publications.

23. Esposito, J.L., Rothgeb, J.M. (1997). Evaluating Survey Data: Making the Transition from Pretesting to Quality Assessment. In: Lyberg, L., Biemer, P., Collins, M., De Leeuw, E., Dippo, C., Schwarz, N., Trewin, D. (Editors). Survey Measurement and Process Quality. New York: John Wiley \& Sons.

24. Kurz, K., Prüfer, P., Rexroth, M. (1999). Zur Validität von Fragen in standardisierten Erhebungen. Ergebnisse des Einsatzes eines kognitiven Pretestinterviews (On the validity of questions in standardised surveys. Results of a cognitive pretest interview). ZUMA-Nachrichten 44, 83-107.

25. SPSS for Windows, Rel. 12.0.1. 2003, SPSS Inc.: Chicago.

26. Lamers, F., Jonkers, C.C., Bosma, H., Diederiks, J.P., Van Eijk, J.T.M. (2006). Effectiveness and costeffectiveness of a minimal psychological intervention to reduce non-severe depression in chronically ill elderly patients: the design of a randomised controlled trial [ISRCTN92331982]. BMC Public Health, 6, 161.

27. Ware Jr, J.E., Sherbourne, C.D. (1992). The MOS 36-item short-form health survey (SF-36): I. Conceptual framework and item selection. Medical Care, 30, 473-483.

28. Van der Zee, K.I., Sanderman, R. Het meten van de algemene gezondheidstoestand met de RAND36: Een handleiding [Measuring general health with the RAND-36: a manual], Noordelijk Centrum voor Gezondheidsvraagstukken: Groningen.

29. Schuling, J., De Haan, R., Limburg, M., Groenier, K.H. (1993). The Frenchay Activities Index; Asessment of Functional Status in Stroke Patients. Stroke, 24, 1173-1177.

30. Holbrook, M., Skilbeck, C.E (1983). An activities index for use with stroke patients. Age and Ageing, 12, 166-170.

31. Shrout, P.E., Fleiss, J.L. (1979). Intraclass correlations: uses in assessing rater reliability. Psychological Bulletin, 86, 420-428.

32. De Vet, H.C.W., Bouter, L.M., Bezemer, P.D., Beurskens, A.J.H.M. (2001). Reproducibility and responsiveness of evaluative outcome measures: Theoretical considerations illustrated by an empirical example. International Journal of Technology Assessment in Health Care, 17, 479-487.

33. Nichols, D.P. (1998). Choosing an Intraclass Correlation Coefficient. SPSS Keywords, 67.

34. Terwee, C.B., Bot, S.D.M., De Boer, M.R., Van der Windt, D.A.W.M., Knol, D.L., Dekker, J., Bouter, L.M., De Vet, H.C.W. (2007). Quality criteria were proposed for measurement properties of health status questionnaires. Journal of Clinical Epidemiology, 60, 34-42.

35. Bland, J.M., Altman, D.G. (1986). Statistical methods for assessing agreement between two methods of clinical measurement. The Lancet, 327(8476), 307-310.

36. Trochim, W.M. (2005). The Research Methods Knowledge Base. Online document. http://www.socialresearchmethods.net/kb/convdisc.htm. Accessed 4 May 2006.

37. Meng, X.-L., Rosenthal,R., Rubin, D.B. (1992). Comparing correlated correlation coefficients. Psychological Bulletin, 111(1), 172-175.

38. Post, M.W.M., de Witte, L.P., Reichrath, E., Verdonschot, M.M., Wijlhuizen, G.J., Perenboom, R.J.M. (2008). Development and validation of IMPACT-S, an ICF-based questionnaire to measure activities and participation. Journal of Rehabilitation Medicine, 40(8), 620-627.

39. Van Brakel, W.H., Anderson, A.M., Mutatkar, R.K., Bakirtzief, Z., Nicholls, P.G., Raju, M.S., DasPattanayak, R.K. (2006). The Participation Scale: Measuring a key concept in public health. Disability and Rehabilitation, 28(4), 193-203. 
40. Wilkie, R., Peat, G., Thomas, E., Hooper, H., Croft, Peter R. (2005). The Keele Assessment of Participation: a new instrument to measure participation restriction in population studies. Combined qualitative and quantitative examination of its psychometric properties. Quality of Life Research, 14(8), 1889-1899.

41. Noreau, L., Desrosiers, J., Robicaud, L., Fougeyrollas, P., Rochette, A., Viscogliosi, C. (2004). Measuring social participation: reliability of the LIFE-H in older adults with disabilities. Disability and Rehabilitation, 26(6), 346-352.

42. Brown, M., Dijkers, M.P., Gordon, W.A., Ashman, T., Charatz, H., Cheng, Z. (2004). Participation objective, participation subjective: a measure of participation combining outsider and insider perspectives. The Journal of Head Trauma Rehabilitation, 19(6), 459-481.

43. Cardol, M., De Haan, R.J., de Jong, B. A., Van den Bos, G.A.M., De Groot, I.J.M. (2001). Psychometric properties of the 'Impact on Participation and Autonomy' (IPA) questionnaire. Archives of Physical medicine and Rehabilitation, 82(2), 210-216.

44. Fayers, P.M., Hand, D.J. (2002). Causal Variables, Indicator Variables and Measurement Scales: an example from quality of life. Journal of the Royal Statistical Society. Series A (Statistics in Society), 165(2), 233-261.

45. Streiner, D.L., Norman, G.R. (1995). Health measurement scales: a practical guide to their development and use. New York: Oxford University Press.

46. Turnbull, J.C., Kersten, P., Habib, M., McLellan, L. Mullee, M.A., George, S. (2000). Validation of the Frenchay Activities Index in a general population aged 16 years and older. Archives of Phyisical medicine and Rehabilitation, 81(8), 1034-1038. 
Chapter 7

General discussion 
CHAPTER 7 
This chapter discusses the results of this thesis. We first draw some general conclusions and then describe the content and psychometric properties of the instruments we developed. Next, we discuss strengths and limitations of the study and make recommendations for further validation research. After that, we discuss what this study does and does not add and we end with some final remarks.

\section{General conclusions}

In chapter 2, we concluded, based on an extensive literature study, that autonomy might be conceived of as correspondence between what people want their lives to be like and what their lives are actually like. The work of Dworkin and Agich inspired us to develop the conceptualization of autonomy in the direction of what it means to people in their daily living. In chapter 3, we elaborated this theoretical approach with empirical data derived from in-depth interviews and focus groups. We found that autonomy involves a sense of realism. People take account of their personal circumstances. Personal autonomy did not appear to be a simple correspondence between what people do and want, but specifically a correspondence between what people do and want considering their specific circumstances. So, personal autonomy means that people with a comparable chronic condition may make different choices, because their experiences, circumstances and preferences differ. In chapter 4, we operationalized and validated this theoretical concept into a measurement instrument for personal autonomy, the Maastricht Personal Autonomy Questionnaire (MPAQ). The MPAQ appeared to be suitable for research with the purpose of discrimination (measurement of differences between persons) and should be used with caution for evaluation purposes (measurement of changes over time).

In chapter 5, we arrived at a conceptualization of social participation as a positive experience having one or more of the following three characteristics: social contact, contributing to society (like paying a visit) or receiving from society (like receiving a visit). This definition excludes behaviours which do not involve an exchange between people (like doing own household chores), which distinguishes social participation from the broader concept of participation. Furthermore, the definition includes behaviours which involve receiving from society, while other definitions of social participation tend to exclude these behaviours. In chapter 6 , we operationalized and validated this conceptualization into a measurement instrument on social participation that includes the three characteristics social contact, contributing to society and receiving from society, the Maastricht Social Participation Profile (MSPP). The instrument appears to be suitable for discrimination purposes. First results regarding reproducibility suggest that the instrument may also be suitable for evaluation purposes. 


\section{Conclusions regarding psychometric properties of the instruments}

If we consider the aims mentioned in the introduction of this thesis, we may conclude that with regard to the measurement instrument of personal autonomy, a valid instrument was developed that approached the patients experiences as close as possible. Doing what is best for one's physical health may not fit with valued activities or social roles. The MPAQ aims to capture these dilemmas (MPAQ-Di) and their impact on the degree of autonomy people experience (MPAQ-DA). It also captures people's efforts to achieve autonomy (MPAQ-WA), focusing on the actions and active mind-set which self-management programs aim to bring about.

The MPAQ appears to be a useful tool in comparative studies, because it has good validity, good internal consistency and moderate reproducibility for discrimination purposes. With regard to the purpose of evaluation, we have to be cautious. Reproducibility for the purpose of evaluation was weak given our benchmark, which was rather arbitrarily defined. Responsiveness was acceptable for deterioration, but not for improvement.

With regard to the second aim, we may conclude that a valid instrument was developed measuring actual social participation by older adults with a chronic physical illness, in close accordance with their own definition of social participation. Part of this definition is that older adults experience social participation as something positive. We chose to not operationalize this part of the definition, because this involves subjective evaluation, while we wanted to develop a measure for actual social participation.

The MSPP appears to be a useful instrument for comparative goals, because it has good validity and acceptable reproducibility for discrimination purposes. With regard to the purpose of evaluation, we have to be cautious. Reproducibility for the purpose of evaluation was good given our benchmark, which was also rather arbitrarily defined. We had to drop the analysis of the responsiveness of the MSPP. Parts of the instrument refer to events of participation that do not occur regularly, which means that it is difficult to assess change therein. It would furthermore be quite demanding of respondents to remember whether their social participation in the third wave was the same as in the first one six months earlier and compress this into an answer to one question about changes in social participation (more so than with respect to the degree of autonomy, we expected). For this reason we did not test the responsiveness of the MSPP.

The measurement properties of both instruments were largely similar across diabetes and COPD, which is promising for a generic application. 


\section{Strengths and limitations of the study}

A major strength of this study lies in its thorough approach. Our stepped approach to depart from theoretical conceptualizations of autonomy and participation (chapters 2 and 5) and empirically ground these concepts (chapters 3 and 5), made it possible to arrive at valid instruments for personal autonomy and social participation (chapters 4 and 6) that approached the patients' experiences as close as possible.

A second strength of this study is the inclusion of two types of chronic disease with a different course. This way, we could explore whether different types of chronic disease have a different impact on autonomy and participation and we could measure properties of the instruments across both diseases. A generic instrument should be robust across different types of disease, meaning that scores may differ, but measurement properties should be the same.

This study also has its limitations. First, it is plausible to assume that people with depressive symptoms are underrepresented in our sample. This is because the patients of our study were selected as part of the selection procedure of another study which included only patients with symptoms of depression (criterion: minor or mild to moderate depression). We selected the patients from our study from the group without these symptoms (i.e. we selected patients without 'minor or mild to moderate depression' and without severe depression) and a positive answer to the question 'are you prepared to take part in another study on chronic disease', causing for selection bias. Our psychometric results may therefore not be completely generalizable to the general population of older adults with a chronic physical illness, since this population also includes people with depressive symptoms.

Second, some might consider the inclusion of only two types of chronic disease a limitation of our study, since we aimed for a generic approach. By doing so, we could make a start with the evaluation of robustness. Our results are promising, but not yet sufficient to claim generic applicability of the MPAQ and MSPP in older adults with a chronic physical illness.

\section{Recommendations for further validation research}

Future research should aim to improve and test measurement properties of the MPAQ and MSPP. We make four recommendations, the first three relating to the applicability of the instruments in evaluation research.

First of all, our results showed that MPAQ-DA was responsive to deterioration, but not to improvement. This seems problematic, since interventions obviously aim at improvement rather than deterioration, and research evaluating such 
interventions consequently requires instruments that are able to detect improvement over time. In our study, however, deterioration took place, on average, in a lower range of the scale than improvement. In other words, participants who deteriorated had a lower degree of autonomy at the start of the study than participants who improved. This suggests, that maybe our conclusion 'responsive to deterioration but not to improvement' should actually read 'responsive in persons with low autonomy but not in persons with high autonomy'. Put differently, responsiveness might be better in lower ends of the scale than in higher ends. We performed analyses to test this, but results were inconclusive. Future research should test whether the MPAQ-DA is responsive to improvement in the lower range of the scale, for example in an intervention study aimed at improving low autonomy. If the instrument shows responsiveness to improvement in lower ranges of the scale, than the problem lies with responsiveness in the higher scale range. This might not be problematic when the instrument is used to evaluate interventions aimed at improving autonomy in persons with low autonomy. But it is problematic if the instrument is to be used to monitor autonomy during the course of illness, where decline needs to be detected in persons with high autonomy at the start of the study. One way to improve responsiveness might be to increase the number of response options. It might also be worthwhile to experiment with question wording, changing the 'difficulty' of items, to refine measurement of changes in the higher end of the scale.

Second, the responsiveness of the MSPP needs to be evaluated. We found it problematic to do so in a design which requires participants to indicate whether true change has occurred. We therefore suggest adopting a design in which social participation of participants is expected to change in the same direction (either increase of decrease).

For the consumptive participation dimension of the MSPP, besides, we believe that the reference period in which participation events are interrogated may have the disadvantage that it is too short for certain irregular or infrequent participation events. This is reflected in the item ICC's, which are rather low for infrequent events as compared to more frequent events. Hence, this dimension of the instrument may prove to be more suitable to be used in comparative than in evaluative designs.

Third, the minimal changes in MPAQ and MSPP scores deemed important by people with a chronic illness need to be established to facilitate the evaluation of reproducibility.

Fourth, future research should test whether the measurement properties of the MPAQ and the MSPP are robust across other patient groups. Since the items of the MSPP and the MPAQ-DA are not specific to people with a chronic physical illness, it would also be worthwhile to test outcomes in a general population of 
older adults and compare healthy older adults with those with specific chronic illnesses. This might be different for the MPAQ-Di and MPAQ-WA.

\section{Considerations}

\section{Comparison with existing instruments}

In the Netherlands, another instrument relevant in the domain has been developed by Cardol and colleagues [1]. The Impact on Participation and Autonomy Questionnaire (IPA) measures autonomy in relation to participation in the context of disability. In particular, it measures people's chances to participate autonomously in several domains of life. The MPAQ and MSPP, in contrast, measure autonomy and participation separately. It depends on the need of information of the researchers which instrument (or which combination of these) is most appropriate.

The IPA focusses on specific participation domains of life. It provides insight into perceptions of participation and may show in what domains people need support to achieve autonomous participation. The focus of the MPAQ is more on the type of challenges and problem-solving behaviour than on the domains of life in which these take place. It measures autonomy on a more general level than the IPA does and provides insight into the degree of autonomy people experience, how much effort they put into arranging life the way they want, and to what extent their health poses dilemmas. Researchers striving to understand differences in autonomy might use the MPAQ to identify patient groups with low and high degrees of autonomy and compare their characteristics, like self-management competencies, social support, coping style and type of disease and severity. The MPAQ might also be used to monitor autonomy during the course of illness. Furthermore, it might help to evaluate and understand the effectiveness of interventions in different types of patient groups. People who struggle with dilemmas which their health poses may benefit from different interventions than those who struggle with limited opportunities.

The MSPP measures people's actual social participation. Although perceptions of participation, like the IPA measures, are important, it is also relevant to know about actual participation behaviours. If people for instance take part in an intervention aimed at decreasing loneliness, it is not only relevant to measure whether people afterwards feel less lonely. Is it of interest to know whether the intervention changed how they felt or how they behaved?

To our knowledge, no other instruments in the field of health and disability have been developed so far to measure personal autonomy. Other instruments for participation (including social participation) do exist in this field, measuring its 
performance [2-5], frequency [6, 7] or subjective experience [7]. The MSPP also measures frequency of participation, but distinguishes itself, because it can yield both frequency and diversity scores and focuses on the social aspects of participation. Furthermore, it builds on a definition of social participation of older adults with a chronic illness themselves.

\section{Barriers to personal autonomy and social participation in different types of chronic illness}

In the comparison of the results between patients with diabetes and COPD, we discovered that patients with these different types of chronic diseases also encounter specific barriers to autonomy and participation. Patients with COPD are more often confined in their opportunities, while patients with diabetes more often struggle with choices they have to make regarding life style changes. One can wonder whether other types of chronic diseases, like high prevalence disorders of the musculoskeletal system (e.g. rheumatoid arthritis), have the same impact on personal autonomy and social participation as the diseases under study. As musculoskeletal disorders have quite different limitations and complaints following the course of the disease, the burden of disease might be quite different. For example, these disorders cause more mobility and pain problems than COPD and diabetes do. Hence, the present study may not have discovered exhaustively the barriers that chronic physical illness may present to autonomy and social participation. It would be worthwhile to study the impact of other types of chronic disease on personal autonomy and social participation, starting with in-depth interviews and focus groups.

In relation to this, it should be noted that the MPAQ includes a scale that addresses struggles with choices (MPAQ-Di), but lacks a scale that addresses opportunities. In other words, the MPAQ does not measure all barriers that chronic physical illness may present to autonomy. If other types of chronic disease present additional barriers to autonomy, these obviously are also not addressed by the MPAQ.

\section{Relationship between personal autonomy and social participation}

This study departed from the idea that the combination of the concepts personal autonomy and social participation allows a comprehensive understanding of living with chronic illness. Due to our approach to develop distinct instruments for distinct, though related, concepts, the focus of the previous chapters has been either on the one concept or on the other. To study the mutual influence between personal autonomy and social participation was beyond the scope of this study, but the following may be said about it here. 
Personal autonomy is realized through relations and interactions with other people, as we stated in chapters 1 and 2 . In an instrumental way, social participation may serve as a mean to achieve autonomy when help and support from others make it possible to realize a goal. At the same time, social participation presents a goal in itself, when people value social participation and want it to be a part of their lives. Preliminary results of the present study indeed show that more work on autonomy is (cross-sectionally) associated with more frequent and diverse participation, although not very strongly (please refer to Table 1 in Appendix C). Also, and more strongly, higher degrees of personal autonomy are associated with more frequent and diverse participation. We would welcome further analyses of the association between autonomy and social participation, for which our dataset might provide a starting point, and also between these two concepts and other outcomes like depressive symptoms, subjective health, quality of life and healthcare use.

\section{Final remarks}

The MPAQ and MSPP were developed for research ends. This is not to say that problems with autonomy and participation are not relevant for care-givers. On the contrary, care-givers should take personal autonomy and social participation into account in their treatment strategies especially regarding patients who are not able to master the adaptive tasks of living with a chronic condition. After further validation, the instruments can be used to evaluate to what degree these treatment strategies are effective. Self-management strategies, in particular, should not only focus on medical self-management, but also on emotional and role self-management [8]. Educating patients also in these respects, enables them to actively set and pursue their own goals and thereby to arrive at a higher level of personal autonomy and/or social participation.

The healthcare in the Netherlands is developing into a direction where people live longer in their own homes, with more serious health problems than is now common. In the future people will be more dependent on support and help from their kinship, social networks and communities. In a positive conceptualization of autonomy, which we departed from in this study (chapter 2), dependence may disable, but also enable people with a chronic illness to shape their lives. So the increasing responsibility to organize help to continue living at home might, on the one side, work out positively for those chronic patients who are competent selfmanagers on their personal autonomy and social participation, if we take for granted that informal support is available. People who continue to live in their own homes may more easily or to a greater extent succeed to arrange their lives the way they want to. On the other side we know that especially people with 
lower socioeconomic status lack these competencies in a larger extent and therefore should be educated to self-manage living with their chronic condition. It is a big challenge for the current and future generation of care-givers to provide care that not only incorporates medical treatment but also self-management support, as all people are expected to arrange their care to a considerable degree in cooperation with neighbours, friends and family. Asking and accepting help from others is a way to achieve autonomy. The MPAQ and MSPP may help monitor the impact of changes in the provision of care on the personal autonomy and social participation of older adults with a chronic illness. 


\section{References}

1. Cardol, M., De Haan, R. J., de Jong, B. A., Van den Bos, G. A. M., \& De Groot, I. J. M. (2001). Psychometric properties of the 'Impact on Participation and Autonomy' (IPA) questionnaire. Archives of Physical medicine and Rehabilitation, 82(2), 210-216.

2. Post, M. W. M., de Witte, L. P., Reichrath, E., Verdonschot, M.M., Wijlhuizen, G. J., \& Perenboom, R. J. M. (2008). Development and validation of IMPACT-S, an ICF-based questionnaire tomeasure activities and participation. Journal of Rehabilitation Medicine, 40(8), 620-627.

3. Van Brakel, W. H., Anderson, A. M., Mutatkar, R. K., Bakirtzief, Z., Nicholls, P. G., Raju, M. S., et al. (2006). The participation scale: Measuring a key concept in public health. Disability and Rehabilitation, 28(4), 193-203.

4. Wilkie, R., Peat, G., Thomas, E., Hooper, H., \& Croft, P. R. (2005). The Keele assessment of participation: A new instrument to measure participation restriction in population studies. Combined qualitative and quantitative examination of its psychometric properties. Quality of Life Research, 14(8), 1889-1899.

5. Noreau, L., Desrosiers, J., Robicaud, L., Fougeyrollas, P., Rochette, A., \& Viscogliosi, C. (2004). Measuring social participation: Reliability of the LIFE-H in older adults with disabilities. Disability and Rehabilitation, 26(6), 346-352.

6. Holbrook, M., \& Skilbeck, C. E. (1983). An activities index for use with stroke patients. Age and Ageing, 12(2), 166-170.

7. Brown, M., Dijkers, M. P., Gordon, W. A., Ashman, T., Charatz, H., \& Cheng, Z. (2004). Participation objective, participation subjective: A measure of participation combining outsider and insider perspectives. The Journal of Head Trauma Rehabilitation, 19(6), 459-481.

8. Lorig K. R. \& Holman H.R. (2003). Self-management education: History, definition, outcomes, and mechanisms. Ann Behavioral Med, 26(1), $1-7$. 

Summary 
SUMMARY 
An increasing number of older adults face the challenge to come to terms with chronic illness. A range of concepts is used to study and understand what it means to live with the limitations as a result of chronic illness. The focus of the present thesis is on the concepts personal autonomy and social participation. The social participation concept captures the impact of chronic illness on the performance of valued activities and social roles. The personal autonomy concept draws attention to the fact that different persons value different activities and social roles. While all people are embedded in a social context, they harbour different ideas and preferences about how this embeddedness takes shape. Moreover, personal autonomy is considered to be realized through relations and interactions with others.

Many studies on living with a chronic illness use qualitative research methods. To facilitate quantitative research on the subject, quantitative measurement instruments are needed. Most existing instruments measuring personal autonomy and social participation focus on the medical context of chronic disease. A notable exception is the Impact on Participation and Autonomy (IPA) questionnaire, which measures people's chances to participate autonomously in several domains of life. The application of the IPA in research and its translation into multiple languages illustrate, that the research field has a need for quantitative measuring instruments for participation and autonomy in relation to disability and chronic illness. The IPA covers the intersection of participation and autonomy. We focussed on developing instruments that allow separate measurement of autonomy and social participation. Our context was living with the limitations of chronic disease, especially valued activities related to social functioning.

As described in chapter 1, the aim here was to develop instruments that measure personal autonomy and social participation of older adults with a chronic physical illness corresponding with their own experience of autonomy and social participation. This aim was twofold, namely to develop:

1. a valid, reliable and responsive measurement instrument for personal autonomy of older adults with a chronic physical illness with the purpose of discrimination and evaluation;

2. a valid, reliable and responsive measurement instrument for social participation of older adults with a chronic physical illness with the purpose of discrimination and evaluation.

The development of the actual instruments was preceded by pre-studies to conceptualize personal autonomy and social participation in the context of chronic physical illness in older adults.

In chapter 2, we conceptualized autonomy in the context of chronic physical illness. To this end, we compared and contrasted a selection of contemporary philosophical theories of autonomy with social scientific perspectives on chronic illness, particularly models of disability and symbolic interactionism. The philo- 
sophical theories mainly depart from a positive conceptualization of autonomy, which involves actively shaping one's life and identifying with fundamental values. We preferred this conceptualization over a negative conceptualization, which defines autonomy as non-interference, for its compatibility with social models of disability and with the assumption that people are interdependent. Interference may disable, but also enable people with a chronic illness to shape their lives. What matters is that people can realize what they want to realize. We suggested that, in the context of chronic physical illness, autonomy might be conceptualized as correspondence between what people want their lives to be like and what their lives are actually like. Disturbed autonomy might be restored either by expanding opportunities to arrange life or by adjusting how one wants life to be arranged. The grounds for the latter approach might be questioned, first, if people have not adjusted what they want carefully, and second, if reorganization of the material and social environment would have made it unnecessary to adjust one's arrangement of life.

In chapter 3, we developed an empirically grounded conceptualization of personal autonomy in the context of chronic physical illness and investigated the impact of two chronic illnesses on autonomy. We conducted a grounded theory study, consisting of 13 in-depth interviews with older adults with Chronic Obstructive Pulmonary Disease (COPD) or Diabetes Mellitus type 2 (diabetes). The results indicated that autonomy involves taking account of current circumstances as the frame of reference in which people can arrange their lives. Chronic illness disturbed autonomy by limiting opportunities and by prompting a reappraisal of the value that people placed on different activities or aspects of life. The participants responded to this disturbance differently, in ways that did not always restore autonomy. Limited opportunities occurred more often in COPD, while reappraisal occurred more often among older persons with diabetes. We concluded that personal autonomy in the context of chronic physical illness might be conceptualized as correspondence between the way people's lives are actually arranged and the way people want their lives to be arranged, considering the circumstances. Health professionals could stimulate their clients to prevent and overcome impasses in the realization of autonomy, while broad self-management interventions might improve people's skills for coping with the impact of chronic illness on autonomy.

In chapter 4, we describe how the Maastricht Personal Autonomy Questionnaire (MPAQ) was developed. The MPAQ measures personal autonomy of older adults with a chronic physical illness, departing from the conceptualization of autonomy that was developed in chapters 2 and 3 . Achievement of personal autonomy is conceptualized as correspondence between the way people's lives are actually arranged and the way people want to arrange their lives. A field test was conducted in three waves $(n=412, n=125$ and $n=244)$ among a random sample 
of people older than 59 years with either COPD or diabetes. Construct validity, internal consistency, reproducibility and responsiveness were evaluated. The MPAQ entailing 16 items consists of three scales: degree of (personal) autonomy, working on autonomy and dilemmas. Construct validity was largely supported by confirmatory factor analysis and correlations between the MPAQ and other instruments. Cronbach's alpha ranged from 0.77 to 0.93 , Intraclass Correlation Coefficients (ICCS) from 0.61 to 0.80 and Smallest Real Differences at group level (SRDs group) from 0.10 to 0.13 . Mean change was larger (0.54) than was SRD group (0.11) in patients who had deteriorated, but smaller in patients who had improved (0.07). We concluded that the MPAQ has good content and construct validity and internal consistency and reproducibility. Responsiveness is weak, although better for deterioration than for improvement.

In chapter 5, we conceptualized social participation in line with the experiences of older adults with a chronic physical illness. We conducted a qualitative study consisting of ten individual interviews and two focus group interviews with older adults with COPD or diabetes. Four domains of social participation were identified on the basis of the individual interviews: (1) social contacts and social activities, (2) work and informal support, (3) cultural activities and public events, and (4) politics and media. Three characteristics of social participation could be distilled from discussions in the focus groups: social contact, contributing resources to society and receiving resources from society. In addition, only positive experiences were considered to be social participation. We concluded that, in our study, older adults with a chronic physical illness perceived social participation as a positive experience having one or more of the following three characteristics: social contact, contributing resources to society or receiving resources from society. This is fairly consistent with the literature about social participation, although previous researchers did not seem to mention a positive experience condition and disagreed whether receiving resources could be considered as 'genuine' social participation.

In chapter 6, we describe how the Maastricht Social Participation Profile (MSPP) was developed and tested. The MSPP measures the actual social participation by older adults with a chronic physical illness, in accordance with the definition that was developed in chapter 5 . The development process consisted of a number of steps, ending with a field test in two waves ( $n=412$ and $n=125$ ) together with the MPAQ, among the same sample of older adults as described in chapter 4. Reproducibility, convergent and discriminant validity were evaluated. The MSPP consists of four indices: consumptive participation, formal social participation, informal social participation-acquaintances and informal social participation- family. Each index measured diversity and frequency of participation. ICCs ranged between 0.63 and 0.83 . SRDs sroup ranged between 0.05 and 0.09 . Convergent and discriminant validity were supported by the correlations between the 
MSPP $_{\text {frequency }}$ and the FAI. We concluded that the MSPP has good validity and acceptable reproducibility. Its distinguishing features are its focus on actual social participation and the possibility to calculate both diversity and frequency scores.

In chapter 7, we draw some general conclusions and describe the content and psychometric properties of the instruments we developed. Strengths and limitations of the study are discussed and recommendations made for further validation research. We conclude that both the MPAQ and the MSPP appear suitable instruments for research with the purpose of discrimination and recommend that future research aims to improve and test measurement properties of the MPAQ and MSPP for research with the purpose of evaluation and for application across other patient groups.

The healthcare in the Netherlands is developing into a direction where people live longer in their own homes, with more serious health problems than is now common. It is a big challenge for the current and future generation of care-givers to provide care that not only incorporates medical treatment but also selfmanagement support, as all people are expected to arrange their care to a considerable degree in cooperation with neighbours, friends and family. After further validation research, the MPAQ and MSPP may help monitor the impact of changes in the provision of care on the personal autonomy and social participation of older adults with a chronic illness. 
Samenvatting 
SAMENVATTING 
Steeds meer ouderen moeten leren omgaan met een chronische ziekte. Verschillende concepten worden gebruikt om te onderzoeken en te begrijpen wat het betekent om met de beperkingen van een chronische ziekte te leven. In dit proefschrift ligt het accent op de concepten persoonlijke autonomie en maatschappelijke participatie. Het concept maatschappelijke participatie maakt de weerslag van chronisch ziek zijn op het vervullen van gewaardeerde activiteiten en sociale rollen zichtbaar. Het concept persoonlijke autonomie vestigt de aandacht er op dat voor verschillende personen andere activiteiten en sociale rollen belangrijk kunnen zijn. Alle mensen bewegen zich in een sociale context, maar zij hebben verschillende voorstellingen en voorkeuren over de manier waarop zij dit willen doen. Persoonlijke autonomie krijgt bovendien vorm via relaties en interacties met anderen.

Veel onderzoekers die het leven met een chronische ziekte bestuderen, gebruiken kwalitatieve onderzoeksmethoden. Om kwantitatief onderzoek over dit onderwerp te faciliteren, zijn kwantitatieve meetinstrumenten nodig. De meeste bestaande instrumenten voor autonomie en participatie focussen op de medische context van chronisch ziek zijn. Een noemenswaardige uitzondering is de Impact on Participation and Autonomy (IPA) vragenlijst, die meet in hoeverre mensen de mogelijkheid hebben om autonoom te participeren in een aantal levensdomeinen. De toepassing van de IPA in onderzoek en de vertaling ervan in meerdere talen laten zien, dat er in het onderzoeksveld behoefte is aan kwantitatieve meetinstrumenten voor participatie en autonomie in relatie tot gezondheidsbeperkingen en chronisch ziek zijn. De IPA brengt het snijpunt van participatie en autonomie in kaart. Wij leggen ons toe op het ontwikkelen van instrumenten voor de afzonderlijke meting van autonomie en participatie. Daarbij richten we ons op de brede context van het leven met de beperkingen van chronische ziekte, in het bijzonder gewaardeerde activiteiten en sociale rollen.

Zoals in hoofdstuk 1 is beschreven, was ons doel om instrumenten te ontwikkelen die persoonlijke autonomie en maatschappelijke participatie meten van ouderen met een chronische lichamelijke ziekte op een manier die overeenstemt met hun eigen beleving van autonomie en maatschappelijke participatie. Dit doel was tweeledig, namelijk het ontwikkelen van:

1. een valide, betrouwbaar en responsief meetinstrument voor persoonlijke autonomie van ouderen met een chronische lichamelijke ziekte voor onderzoek met als doel te kunnen discrimineren of te evalueren;

2. een valide, betrouwbaar en responsief meetinstrument voor maatschappelijke participatie van ouderen met een chronische lichamelijke ziekte voor onderzoek met als doel te kunnen discrimineren of te evalueren.

Het ontwikkelen van de instrumenten zelf werd voorafgegaan door voorstudies om persoonlijke autonomie en maatschappelijke participatie te conceptualiseren in de context van chronische lichamelijke ziekte bij ouderen. 
In hoofdstuk 2 hebben we autonomie geconceptualiseerd in de context van leven met een chronische lichamelijke ziekte. Daartoe vergeleken en contrasteerden we een selectie van hedendaagse filosofische theorieën van autonomie en sociaalwetenschappelijke perspectieven op chronisch ziek zijn, in het bijzonder modellen van beperkingen in het dagelijks leven en symbolisch interactionisme. De filosofische theorieën vertrekken vanuit een positieve conceptualisering van autonomie, die betrekking heeft op het actief vorm geven van het eigen leven en op identificatie met fundamentele waarden. We gaven de voorkeur aan deze benadering boven een negatieve conceptualisering, die autonomie definieert als het ontbreken van inmenging. De positieve benadering is namelijk compatibel met sociale modellen van beperkingen in het dagelijks leven en met de aanname dat mensen wederzijds van elkaar afhankelijk zijn. Inmenging kan mensen met een chronische ziekte beletten hun leven vorm te geven, maar het kan ze ook meer mogelijkheden hiertoe geven. Het gaat er in deze benadering om of mensen realiseren wat ze willen realiseren. We stelden voor dat, in de context van leven met een chronische lichamelijke ziekte, autonomie geconceptualiseerd zou kunnen worden als overeenstemming tussen hoe mensen willen dat hun leven er uit ziet en de manier waarop het er daadwerkelijk uit ziet. Verstoorde autonomie zou hersteld kunnen worden door uitbreiding van mogelijkheden om het leven in te richten of door aanpassingen te doen in hoe men het leven wil inrichten. Bij de geldigheid van die laatste manier kunnen vraagtekens geplaatst worden als het bijstellen van wat men wil niet zorgvuldig is gebeurd. Ook als men door een andere organisatie van de materiële en sociale omgeving zou hebben kunnen realiseren wat men wilde, kan betwijfeld worden of bijstelling van wat men wil een geldige manier is om autonomie te realiseren.

In hoofdstuk 3 hebben we een empirisch onderbouwde conceptualisering van persoonlijke autonomie in de context van chronische lichamelijke ziekte ontwikkeld en de weerslag van twee chronische ziekten op autonomie onderzocht. We voerden een grounded theory study uit, bestaande uit 13 diepte-interviews met ouderen met Chronic Obstructive Pulmonary Disease (COPD) of Diabetes Mellitus type 2 (diabetes). The resultaten wijzen er op dat rekening houden met de huidige omstandigheden als referentiekader om het leven in te richten een belangrijk aspect van autonomie is. Chronisch ziek zijn verstoort autonomie doordat mogelijkheden worden beperkt en mensen worden aangezet tot het herwaarderen van de waarde die ze hechten aan verschillende activiteiten of aspecten van hun leven. De deelnemers reageerden verschillend op de verstoring van hun autonomie en niet alle reacties leidden tot een herstel van autonomie. Beperking van mogelijkheden kwam vaker voor bij mensen met COPD, terwijl herwaardering vaker bij mensen met diabetes aan de orde was. We concludeerden, dat persoonlijke autonomie in de context van chronische lichamelijke ziekte geconceptualiseerd zou kunnen worden als overeenstemming tussen de manier waarop het leven van 
mensen daadwerkelijk is ingericht en de manier waarop mensen het in willen richten, waarbij de omstandigheden in acht worden genomen. Zorgverleners zouden hun cliënten kunnen stimuleren bij het voorkómen en overwinnen van impasses in het realiseren van autonomie, terwijl breed georiënteerde zelfmanagement interventies de competenties van mensen zouden kunnen versterken om om te gaan met de gevolgen van chronisch ziek zijn voor autonomie.

In hoofdstuk 4 beschrijven we hoe de Maastricht Personal Autonomy Questionnaire (MPAQ) is ontwikkeld en getest. De MPAQ meet persoonlijke autonomie van ouderen met een chronische lichamelijke ziekte en vertrekt daarbij vanuit de conceptualisering die in hoofdstuk 2 en 3 is ontwikkeld. Het bereiken van persoonlijke autonomie wordt geconceptualiseerd als overeenstemming tussen de manier waarop het leven van mensen daadwerkelijk is ingericht en de manier waarop mensen willen dat hun leven is ingericht. Een veldtest werd in drie rondes uitgevoerd ( $n=412, n=125$ en $n=244$ ) onder een willekeurige steekproef van personen van 60 jaar en ouder met COPD of diabetes. Construct validiteit, interne consistentie, reproduceerbaarheid en responsiviteit werden geëvalueerd. De MPAQ bestaat uit 16 items verdeeld over drie schalen: mate van (persoonlijke) autonomie, werken aan autonomie en dilemma's. Construct validiteit werd grotendeels ondersteund door confirmatieve factoranalyse en correlaties tussen de MPAQ en andere instrumenten. Cronbach's alfa voor de verschillende schalen varieerde van 0.77 tot 0.93 , Intraclass Correlation Coefficients (ICC's) van 0.61 tot 0.80 en Smallest Real Differences at group level (SRD's group ) van 0.10 tot 0.13 . De gemiddelde verandering over de tijd was groter (0.54) dan de $\operatorname{SRD}_{\text {group }}(0.11) \mathrm{bij}$ deelnemers die achteruit waren gegaan, maar kleiner bij deelnemers die vooruit waren gegaan (0.07). We concludeerden dat de MPAQ een goede inhouds- en constructvaliditeit en interne consistentie heeft en een matige reproduceerbaarheid. Responsiviteit was zwak, hoewel beter bij achteruitgang dan bij vooruitgang.

In hoofdstuk $\mathbf{5}$ hebben we maatschappelijke participatie geconceptualiseerd in overeenstemming met de beleving van ouderen met een chronische lichamelijke ziekte. We voerden ook hier een kwalitatieve studie uit, bestaande uit tien individuele interviews en twee focus group interviews met ouderen met COPD of diabetes. Vier domeinen van maatschappelijke participatie werden onderscheiden op basis van de individuele interviews: (1) sociale contacten en sociale activiteiten, (2) werk en informele steun, (3) culturele activiteiten en publieke evenementen, en (4) politiek en media. Drie kenmerken van maatschappelijke participatie konden uit de discussies in de focus groups afgeleid worden: sociaal contact, bijdragen aan de maatschappij en ontvangen van de maatschappij. Bovendien werden alleen positieve ervaringen als maatschappelijke participatie beschouwd. We concludeerden dat, in ons onderzoek, ouderen met een chronische lichamelijke ziekte maatschappelijke participatie beschouwden als een positieve ervaring met een of meer van de volgende drie kenmerken: sociaal contact, bijdragen aan de 
maatschappij of ontvangen van de maatschappij. Dit is redelijk consistent met de literatuur over maatschappelijke participatie, hoewel eerder onderzoek geen gewag lijkt te maken van de voorwaarde dat de beleving positief moet zijn en er in de literatuur onenigheid is of het ontvangen van de maatschappij als 'echte' maatschappelijke participatie moet worden beschouwd.

In hoofdstuk 6 beschrijven we hoe de Maastricht Social Participation Profile (MSPP) is ontwikkeld en getest. De MSPP meet de daadwerkelijke maatschappelijke participatie van ouderen met een chronische lichamelijke ziekte, in overeenstemming met de definitie van maatschappelijke participatie die ontwikkeld is in hoofdstuk 5 . Het ontwikkelproces bestond uit een aantal stappen, eindigend in een veldtest met twee rondes ( $n=412$ en $n=125$ ) samen met de MPAQ, bij dezelfde steekproef als beschreven in hoofdstuk 4 . Reproduceerbaarheid, convergente en discriminante validiteit werden geëvalueerd. De MSPP bestaat uit vier indices: consumptieve participatie, formele sociale participatie, informele sociale participatie-bekenden en informele sociale participatie-familie. Elke index meet diversiteit en frequentie van participatie. De ICC's varieerden van 0.63 tot 0.83 , de SRD's sroup van 0.05 tot 0.09 . Convergente en discriminante validiteit werden ondersteund door correlaties tussen de MSPP $_{\text {frequentie }}$ en de FAI. We concludeerden dat de MSPP goede validiteit heeft en acceptabele reproduceerbaarheid. De MSPP kenmerkt zich door de focus op daadwerkelijke maatschappelijke participatie en de mogelijkheid om zowel diversiteits- als frequentiescores te berekenen.

In hoofdstuk 7 trekken we een aantal algemene conclusies en beschrijven we de inhoud en psychometrische kenmerken van de ontwikkelde instrumenten. Sterke en zwakke punten van het onderzoek worden benoemd en aanbevelingen worden gedaan voor verder validatieonderzoek. We concluderen dat de MPAQ en MSPP allebei geschikte instrumenten zijn voor onderzoek met als doel te discrimineren tussen personen. We raden aan verder onderzoek te doen om de meetkenmerken van beide instrumenten voor onderzoek met als doel te evalueren verder te verbeteren en te testen. Ook raden we aan te testen of de meetkenmerken van de instrumenten vergelijkbaar zijn bij ouderen met andere chronische ziektes.

De gezondheidszorg in Nederland ontwikkelt zich in een richting waarin mensen langer thuis blijven wonen, met ernstigere gezondheidsproblemen dan nu gebruikelijk is. De huidige en toekomstige generaties van zorgverleners zien zich voor de grote uitdaging gesteld om zorg te verlenen die verder gaat dan medische behandeling en ook ondersteuning van zelfmanagent insluit, aangezien van mensen verwacht wordt dat ze hun zorg tot op zekere hoogte organiseren met hulp van buren, vrienden en familie. Na verder validatieonderzoek kunnen de MPAQ en MSPP ingezet worden om te monitoren welke weerslag veranderingen in de zorgverlening hebben op de persoonlijke autonomie en maatschappelijke participatie van oudere volwassenen met een chronische ziekte. 


\section{Dankwoord}


DANKWOORD 
Velen hebben bijgedragen aan de totstandkoming van dit proefschrift en met mij meegeleefd. Ik wil hen hiervoor hartelijk danken.

Allereerst gaat mijn dank uit naar alle deelnemers aan de diepte-interviews, focus groups, cognitieve interviews en veldtests. Uit hun persoonlijke verhalen, uitwisseling van ervaringen en invulgedrag heeft dit proefschrift mogen groeien. Dank voor jullie vertrouwen en medewerking. Ook dank aan degenen die mijn 'toegangspoort' tot de deelnemers vormden: René van den Heuvel, Geertjan Wesseling, Jan van Rooij, Pieter van den Berg, Bert Vrijhoef, de diabetes- en longverpleegkundigen van het azM, het Diabetes zorgcentrum Maastricht, de Diabetes Vereniging Nederland en de delta ladies Femke Lamers en Karianne Jonkers. Het spande er even om of in alle fasen van het onderzoek voldoende deelnemers benaderd zouden kunnen worden. Gelukkig onderschreven jullie het belang van dit onderzoek en kwam het allemaal goed.

Jacques en Ruud, op mijn eerste werkdag bij medische sociologie omschreef een collega Ruud als een rots in de branding. Dat bleken jullie allebei te zijn. Jullie beider gedrevenheid, de uitgesproken integriteit van de een en het immer kordate optreden van de ander maken jullie tot een zeer goed begeleidingsteam. Ik heb het ook zeer gewaardeerd dat we vanaf dag één discussies open en kritisch voerden. Zeker in het eerste deel van het traject was dat nodig om koers te bepalen. Ook Peter droeg zijn steentje bij aan deze discussies. Ik betreur het dat hij niet het hele traject heeft mogen meemaken.

Ruud, het was heel fijn dat ik altijd bij je terecht kon als ik door de bomen het bos niet meer zag of alleen niet verder kwam. Jacques, je had altijd oog voor de werk-privébalans die ik zocht en dacht met me mee. Dat heeft me goed gedaan. Gelukkig kunnen jullie allebei ook goed motiveren. Door jullie peptalk en handen-uit-de-mouwen-hulp heb ik de eindstreep toch gehaald. Dankjewel.

Ook de overige leden van de begeleidingscommissie en coauteurs wil ik hartelijk danken: Ireen Proot, Ilse Mesters, Marcel Post, Guy Widdershoven en Frans Nijhuis. Ireen, je hebt me veel geleerd over het afnemen en analyseren van diepte-interviews en me daarin terzijde gestaan. Ilse, dank voor je aanstekelijke enthousiasme, kennis en hulp bij de focus groups. Marcel, dank voor je kritische en onderlegde inbreng. Verder ben ik junioren Ingrid, Marike en Femke dankbaar voor het beoordelen van de validiteit van de meetinstrumenten, net als Trudi van den Bos, Mieke Cardol, Mieke le Granse, Tineke Schoot en Leontine van de Ven.

Praktische hulp en ondersteuning waren er ook. Vonca en Marja, dank voor jullie hulp bij de uitvoering van het kwantitatieve deel van het onderzoek. Terwijl ik met zwangerschapsverlof was, wist ik het onderzoek bij jullie in goede handen. Ook de dames van het secretariaat en Arnold bedank ik voor de ondersteuning.

Bij medische sociologie heb ik me thuis gevoeld. De befaamde thee-roep kon het teken zijn voor kletspraatjes en grappen, maar evengoed kon er advies gevraagd worden en inhoudelijk gediscussieerd. Fijn dat we zo'n vast moment had- 
den. De juniorensoepavonden waren altijd gezellig, lekker en nuttig. Hannerieke, Coen en Esther, ik vond het erg gezellig om met jullie een kamer te delen. Ingrid, ik vond het een eer om jouw paranimf te mogen zijn en ben blij dat jij andersom ook aan mijn zijde zult staan. Je zult op die dag waarschijnlijk nóg een makkelijker 'hap'-slachtoffer aan me hebben dan je gewend bent. Mooi hoe jij vrolijkheid en nuchterheid combineert.

Mijn collega's bij het CBS wil ik bedanken voor hun betrokkenheid. Jarenlang was mijn proefschrift 'bijna af' en het stak me een hart onder de riem dat jullie belangstelling bleven tonen. Xandra, Sabine, Madelon, Frank en Marleen, bewoners van het Robbeneiland en anderen bij DV, jullie waren mijn sisters-and-brothers-in-arms bij het ontwikkelen en testen van vragenlijsten. In de samenwerking met jullie heb ik hierover het nodige bijgeleerd en bovendien veel samen gelachen. De afgelopen maanden liep mijn hoofd soms om. Hendrika en Henk-Jan, bedankt dat jullie bijstuurden waar nodig, zodat het werk op de rails bleef. Hendrika, dank ook voor je geruststelling en advies als ik in de stress zat en voor je subtiele manier om een andere kijk op zaken te geven. Ik ben blij dat je mijn paranimf wil zijn.

Familie en schoonfamilie dank ik voor jullie liefde, steun en praktische hulp. En zeker ook voor afleiding. Mayke, Marc, Cleo, Roan, Jos, Nicole, Davy, Remco, Valeria, Wim, Marion en Frans, dank dat we samen konden zijn zonder de beruchte vraag hoe het ervoor stond. Han, je staat altijd klaar om te helpen en hebt heel wat keren op de kinderen gelet, zodat ik aan mijn boekje kon werken. Dankjewel daarvoor. Papa en mama, ook jullie hebben heel wat keren de kinderen opgevangen of mij van een toevluchtsoord voorzien als ik rust nodig had om te schrijven. Mama, wenn ich dich in Sachen Erziehung frage, meinst du dazu oft 'wir haben einfach mit euch zusammen gelebt'. Ihr habt uns vorgelebt, wie man sein Leben gestaltet und dabei in Verbindung zu anderen steht. Het Witte Donderdag Diner vind ik daar een mooi voorbeeld van. Misschien zijn autonomie en participatie daarom voor mij zo vanzelfsprekend met elkaar verbonden.

Heren Scheenen, genieten van en met jullie vond ik vaak belangrijker dan mijn proefschrift 'af' hebben in plaats van 'bijna af'. Maar uiteindelijk moest het er wel van komen. Daarom hebben jullie, gedoseerd, toch heel wat tijd zonder mij doorgebracht. René, de totstandkoming van dit proefschrift is met de nodige chagrijnige buien en juichroepen gepaard gegaan. Jij hebt dat lief en leed met me gedeeld. Je bood talloze keren je luisterend oor als ik mijn gedachten moest ordenen, maar voelde ook feilloos aan wanneer je maar beter niets kon vragen. Bovendien wierp je je op als mijn check-dubbelcheck-proefdrukleesmaatje. Op het eind moesten we zorgvuldig plannen om proefschrift- én racedeadlines te halen. Dat is ons gelukt.

Thomas en Julian, onderzoeker en ontdekker, jullie enthousiaste verhalen en verrassingsknuffels waren altijd een welkome afleiding, ook als ik eigenlijk door 
moest werken (dat kan ik nu wel verklappen). Thomas, jouw proefschrift was vlugger af dan het mijne $(-)$. Mijn 'origineel' is voor jou. Julian, het duurt inderdaad keilang tot het af is $:$. Let op wat ik nu ga doen:

Ik zet er een punt achter. 

Curriculum vitae 
CURRICULUM VITAE 
Godelief Mars werd op 5 februari 1977 in Heerlen geboren en groeide op in Hulsberg. Vanaf 1989 bezocht zij het gymnasium aan het Bernardinuscollege in Heerlen. Hiervoor slaagde zij in 1995 met lof.

In datzelfde jaar begon Godelief haar studie Sociologie aan de Katholieke Universiteit Brabant, tegenwoordig Tilburg University geheten. Tijdens haar studie vervulde zij verschillende functies als student-assistent, onder meer bij de European Values Study. In 2001 studeerde zij met lof af, met een aantekening Methoden en technieken van onderzoek. Haar scriptie betrof de gevolgen van de hereniging van Oost- en West-Duitsland voor de mobiliteit tussen werk en werkloosheid in Oost-Duitsland. Deze won in 2002 de scriptieprijs van de Nederlandse Sociologische Vereniging.

Van 2001 tot 2006 werkte Godelief als Assistent in Opleiding aan de Univeristeit Maastricht bij het Care and Public Health Research Institute. Hier verrichtte zij het promotieonderzoek dat resulteerde in het onderhavige proefschrift. In 2006 werd op het $8^{\mathrm{e}}$ Nationaal Gerontologiecongres de $2^{\mathrm{e}}$ prijs van de Janneke Witsenburg-posterprijs toegekend aan haar poster 'Validatie van een meetinstrument voor maatschappelijke participatie'.

Sinds 2006 is Godelief werkzaam bij het Centraal Bureau voor de Statistiek. Hier heeft zij zich enkele jaren beziggehouden met vragenlijstontwikkeling. Daarna maakte zij de overstap naar analyse en output, eerst over sociale samenhang en later over de arbeidsmarkt. Momenteel houdt zij zich voornamelijk bezig met de projectleiding van de Nationale Enquête Arbeidsomstandigheden, die TNO en CBS samen uitvoeren. 



\section{Appendix A \\ Maastricht Personal Autonomy \\ Questionnaire (MPAQ)}




\section{Scoring instructions}

The MPAQ consists of 16 items in three scales:

The items relate to the scales and item list of the MPAQ as follows:

MPAQ-Degree of autonomy (DA): $\quad$ item A1-A5

MPAQ-Working on autonomy (WA): $\quad$ item B1-B5

MPAQ-Dilemmas (Di): $\quad$ item C1-C6

Scale scores can be obtained by adding up item scores 1 to 5 divided by number of scale items. In the validation study, scale scores were only calculated if all items of a scale were completed.

\section{Translation procedure}

The English version of the MPAQ was translated in a translation - back translation procedure involving two professional translators (one native English and one native Dutch) and authors Godelief Mars and Jacques van Eijk. 


\section{English version}

\section{A Living the way you want}

First a few general statements about your life. These are about the way you live now and how you feel about it. Will you please indicate to what extent each statement applies to you.

\begin{tabular}{|c|c|c|c|c|c|}
\hline Please circle one number for each statement & $\begin{array}{l}\text { No, not } \\
\text { at all }\end{array}$ & $\begin{array}{c}\text { Yes, to } \\
\text { a } \\
\text { limited } \\
\text { extent }\end{array}$ & $\begin{array}{l}\text { Yes, } \\
\text { more or } \\
\text { less }\end{array}$ & $\begin{array}{l}\text { Yes, to } \\
\text { a large } \\
\text { extent }\end{array}$ & $\begin{array}{c}\text { Yes, } \\
\text { completel } \\
\text { y }\end{array}$ \\
\hline 1. My life now is as I want it to be. & 1 & 2 & 3 & 4 & 5 \\
\hline 2. The life I lead now suits the person I am. & 1 & 2 & 3 & 4 & 5 \\
\hline $\begin{array}{l}\text { 3. Considering the possibilities I have now, my life } \\
\text { is as I want it to be. }\end{array}$ & 1 & 2 & 3 & 4 & 5 \\
\hline $\begin{array}{l}\text { 4. I am comfortable with the way I lead my life } \\
\text { now. }\end{array}$ & 1 & 2 & 3 & 4 & 5 \\
\hline 5. My life is arranged now the way I want it to be. & 1 & 2 & 3 & 4 & 5 \\
\hline
\end{tabular}

\section{B Arranging your life}

Some people find it easy to arrange things the way they want. For others, it takes much more effort. The following statements are about the different ways that this can be achieved.

Please circle one number for each statement.

$\begin{array}{ccccc}\begin{array}{c}\text { No, not } \\ \text { at all }\end{array} & \begin{array}{c}\text { Yes, just } \\ \text { a bit }\end{array} & \begin{array}{c}\text { Yes, } \\ \text { quite a } \\ \text { bit }\end{array} & \begin{array}{c}\text { Yes, I } \\ \text { make a } \\ \text { real } \\ \text { effort }\end{array} & \begin{array}{c}\text { Yes, I go } \\ \text { all out }\end{array} \\ & & & \begin{array}{c} \\ \end{array} & \end{array}$

1. I try to find things that I like doing and can cope with in my present state of health.

1

2

3

4

5

2. I try to find a way to do things I like doing within the limitations of my present state of health.

1

2

3. I try to arrange my life in the way that suits me best (maybe with help from other people).

1

2

3

45

4. I try to create conditions that fit in with what I want.

5. I try to adapt my wishes to my capabilities.

\begin{tabular}{|c|c|c|c|c|}
\hline 1 & 2 & 3 & 4 & 5 \\
\hline 1 & 2 & 3 & 4 & 5 \\
\hline
\end{tabular}




\section{Doing what you enjoy and doing what's best for your health}

Some things are enjoyable and good for your health. But perhaps you sometimes feel that you have to choose between something enjoyable and your health. That is what the following questions are about.

\begin{tabular}{|c|c|c|c|c|c|}
\hline Please circle one number for each question & Never & Rarely & Sometimes & $\begin{array}{l}\text { Quite } \\
\text { often }\end{array}$ & $\begin{array}{l}\text { Very } \\
\text { often }\end{array}$ \\
\hline $\begin{array}{l}\text { 1. How often do you have to choose between what } \\
\text { you like doing and what's best for your health? }\end{array}$ & 1 & 2 & 3 & 4 & 5 \\
\hline
\end{tabular}

2. How often do you decide, because of your health, not to do something that you really felt you wanted to do?

1

2

3

4

5

3. How often do you do something because it's good for your health, although you don't really like doing it?

1

2

3

4

4. How often do you do something that you like doing, although the doctor has advised you not to do it?

1 2

3

4

5

5. How often do you find it difficult to decide between doing something you like and doing what's best for your health?

1
your health?

6. How often do you do something that you like doing, although you know that it could be bad for
1

2

2

3

4 5 


\section{Dutch version}

\section{A Leven zoals ú dat wilt}

Om te beginnen volgt hieronder een aantal uitspraken over uw leven in het algemeen. Over de manier waarop uw leven er nu uit ziet en wat u daarvan vindt. Wilt $u$ voor elke uitspraak aangeven in hoeverre deze op $u$ van toepassing is?

\begin{tabular}{|c|c|c|c|c|c|}
\hline Omcirkel bij elke vraag één antwoord. & $\begin{array}{c}\text { Nee, } \\
\text { helema } \\
\text { al niet }\end{array}$ & $\begin{array}{l}\text { Ja, een } \\
\text { beetje }\end{array}$ & $\begin{array}{l}\text { Ja, } \\
\text { redelijk }\end{array}$ & $\begin{array}{c}\text { Ja, } \\
\text { groten- } \\
\text { deels }\end{array}$ & $\begin{array}{c}\text { Ja, } \\
\text { helema } \\
\text { al }\end{array}$ \\
\hline 1. Mijn leven ziet er nu uit zoals ik het wil. & 1 & 2 & 3 & 4 & 5 \\
\hline 2. Het leven dat ik nu leid, past bij mij. & 1 & 2 & 3 & 4 & 5 \\
\hline $\begin{array}{l}\text { 3. Binnen de mogelijkheden die ik nu heb, ziet mijn } \\
\text { leven er uit zoals ik het wil. }\end{array}$ & 1 & 2 & 3 & 4 & 5 \\
\hline $\begin{array}{l}\text { 4. Ik sta achter de manier waarop ik mijn leven nu } \\
\text { leid. }\end{array}$ & 1 & 2 & 3 & 4 & 5 \\
\hline $\begin{array}{l}\text { 5. Mijn leven is nu zó ingericht als ik dat zelf het } \\
\text { liefste wil. }\end{array}$ & 1 & 2 & 3 & 4 & 5 \\
\hline
\end{tabular}

\section{B Uw leven inrichten}

Bij sommige mensen gaat alles bijna vanzelf zoals ze het graag willen. Andere mensen moeten zich daar meer moeite voor doen. De volgende uitspraken gaan over een aantal manieren waarop dat kan.

Omcirkel bij elke vraag één antwoord.

\begin{tabular}{|ccccc|}
\hline $\begin{array}{c}\text { Nee, } \\
\text { helemaal } \\
\text { niet }\end{array}$ & $\begin{array}{c}\text { Ja, } \\
\text { een } \\
\text { beetje }\end{array}$ & $\begin{array}{c}\text { Ja, } \\
\text { nogal }\end{array}$ & $\begin{array}{c}\text { Ja, } \\
\text { erg }\end{array}$ & $\begin{array}{c}\text { Ja, } \\
\text { heel erg }\end{array}$ \\
\end{tabular}

1. Ik ben op zoek naar dingen die ik leuk vind om te doen en die ik gezien mijn gezondheid aan kan.

1

2

3

4

5

2. Ik zoek naar een manier om binnen de grenzen van mijn gezondheid dingen te doen die ik graag wil doen.

1

2

3

4

5

3. Ik probeer mijn leven zó in te richten als ik het zelf graag wil hebben (eventueel met hulp van anderen).

1

2

$3 \quad 4$

4. Ik probeer omstandigheden te creëren die passen bij wat ik wil.

1

5. Ik probeer mijn wensen aan te passen aan mijn mogelijkheden.

1 2 


\section{Doen wat plezierig is en doen wat het beste is voor de gezondheid}

Sommige dingen zijn leuk om te doen én goed voor de gezondheid. Maar het kan ook voorkomen dat $u$ het idee hebt te moeten kiezen tussen iets plezierigs en uw gezondheid. Daarover gaan de volgende vragen.

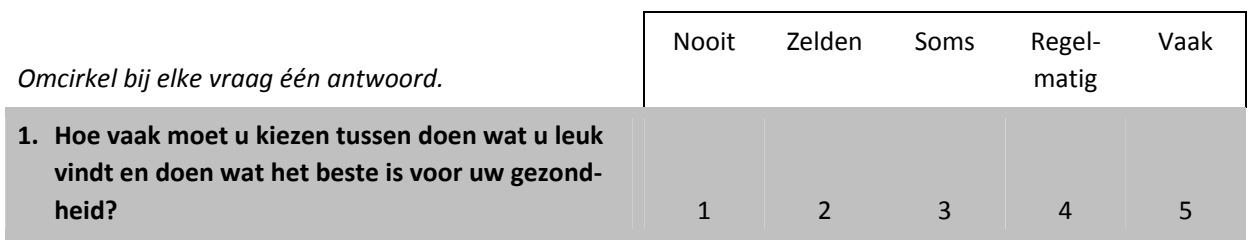

2. Hoe vaak besluit u vanwege uw gezondheid iets achterwege te laten dat u eigenlijk graag zou doen? 1

2

3

4

3. Hoe vaak doet $u$ iets omdat het goed is voor uw gezondheid, hoewel $u$ het eigenlijk onplezierig vindt?

1

2

3

4

5

4. Hoe vaak doet $u$ iets dat $u$ graag wil doen, hoewel de dokter $u$ dat heeft afgeraden?

2

3

$4 \quad 5$

5. Hoe vaak twijfelt u tussen doen wat u leuk vindt en doen wat het beste is voor uw gezondheid?

1

2

3

4

5

6. Hoe vaak doet $u$ iets dat $u$ graag wil doen, hoewel $u$ weet dat dat nadelig kan zijn voor uw gezondheid? 


\section{Appendix B}

Maastricht Social Participation Profile (MSPP) 


\section{Scoring instructions}

The MSPP consists of 26 social participation items in four indices:

Consumptive Participation:

items $A 1, A 3-8$

Formal Social Participation:

items $A 2, A 9, A 10$

Informal Social Participation - Acquaintances:

items $\mathrm{B} 1-8$

Informal Social Participation - Family:

items $\mathrm{C} 1-8$

Two types of scores can be calculated for each index: diversity scores and frequency scores. Diversity scores refer to the number of items in the index on which a respondent had a score of at least one. Frequency scores reflect the mean score of the items in the index. In addition, the total diversity score refers to the number of indices on which a respondent had a score of at least one. Higher scores indicate more diverse or more frequent social participation. In the validation, scores were only calculated if there were no missing values in a given index.

\section{Translation procedure}

The English version of the MSPP was translated in a translation - back translation procedure involving two professional translators (one native English and one native Dutch) and authors Godelief Mars and Jacques van Eijk. 


\section{English version}

\section{A Undertaking activities}

The following questions are about things you have undertaken in the past four weeks.

If a question refers to several activities, you can say how often you have done these things in total.

\section{How to answer}

Not done in the past four weeks =

Done 1, 2 or 3 times (less than once a week) =

Done 4 to 8 times (once or twice a week) =

\begin{tabular}{|llll|}
\hline Not at all & $\begin{array}{l}\text { Less than } \\
\text { once a } \\
\text { week }\end{array}$ & $\begin{array}{l}\text { Once or } \\
\text { twice a } \\
\text { week }\end{array}$ & $\begin{array}{l}\text { More } \\
\text { than } \\
\text { twice a } \\
\text { week }\end{array}$ \\
\hline 0 & $1-3$ & $4-8$ & $9+$ \\
\hline
\end{tabular}

2. have you taken part in a club, interest group or activity group, church or other similar activity? 0 1-3 4-8 $9+$

3. have you been to a cultural or educational event such as the cinema, theatre, museum, talk or course. 0

4. have you eaten out? 0

5. have you been out to a pub, café or tearoom? 0

6. have you been to a public event?

0 $1-3$ 4-8 $9+$

7. have you taken part in an organised games afternoon or evening? For instance, bingo, quiz or card games. 0 $1-3$ 4-8 $9+$

8. have you been on a day trip organised by a club or society?

$$
0
$$$$
1-3
$$

9. have you carried out committee work for a club, society or other group?

0

10. have you done any organised voluntary work?

0
1-3

$1-3$

4-8 9+

$9+$




\section{B Contact with friends and acquaintances}

These questions are about how often you do things with people you know. By people you know we mean friends, acquaintances, (ex) colleagues and neighbours, people who do not live with you. If a question refers to different activities, you can say how often you have done these things in total.

\section{How to answer}

Not done in the past four weeks =

Done 1, 2 or 3 times (less than once a week) =

Done 4 to 8 times (once or twice a week) =

$\begin{array}{lll}\text { Less than } & \text { Once or } & \begin{array}{l}\text { More } \\ \text { than }\end{array} \\ \text { once a } & \text { twice a } & \text { twice a } \\ \text { week } & \text { week } & \text { week }\end{array}$

1. have you phoned, written, e-mailed or chatted to friends or acquaintances? 0 $1-3$

4-8 9+

2. have any friends or acquaintances called in to see you? 0

3. have you called in to see any friends or acquaintances? 0 $1-3$

4-8 9+

4. have you done something away from home with friends or acquaintances that required considerable physical effort, such as walking or cycling? 0 $1-3$ $4-8$ $9+$

5. have you done something away from home with friends or acquaintances that required little physical effort, such as taking a car trip or going out for a cup of tea or drink? 0

$1-3 \quad 4-8 \quad 9+$

6. have you offered any of your friends or acquaintances practical help, such as doing the shopping, giving them a lift, doing odd jobs or filling in forms?

0

$1-3$

$4-8$

$9+$

7. have you given any of your friends or acquaintances advice or tips?

8. have you supported a friend or acquaintance when they needed someone to talk to? 


\section{Contact with family}

Perhaps you do things with the family as well as friends and acquaintances. In these questions, when we refer to family we mean all members of your family who do not live with you.

If a question refers to different activities, you can say how often you have done these things in total.

\section{How to answer}

Not done in the past four weeks =

Done 1, 2 or 3 times (less than once a week) =

Done 4 to 8 times (once or twice a week) =

$\begin{array}{lll}\text { Less than } & \text { Once or } & \begin{array}{l}\text { More } \\ \text { than }\end{array} \\ \text { once a } & \text { twice a } & \text { twice a } \\ \text { week } & \text { week } & \text { week }\end{array}$

1. have you phoned, written, e-mailed or chatted to family?

0

$1-3$

4-8 9+

2. have any of your family called in to see you? 0 $1-3$

4-8 9+

3. have you called in to see anyone from your family? 0 $1-3$

4-8 9+

4. have you done something away from home with a family member that required considerable physical effort, such as walking or cycling?

0 $1-3$ $4-8$ $9+$

5. have you done something away from home with a family member that required little physical effort, such as taking a car trip or going out for a cup of tea or drink? 0 $1-3$ 4-8 $9+$

6. have you offered any of your family practical help, such as doing the shopping, giving them a lift, doing odd jobs, or filling in forms.

$0 \quad 1-3 \quad 4-8 \quad 9+$

7. have you given a family member advice or tips? 0

$1-3$

4-8

$9+$

8. have you supported a family member when they needed someone to talk to? 


\section{Dutch version}

\section{A Dingen ondernemen}

De volgende vragen gaan over dingen die $u$ in de afgelopen vier weken hebt ondernomen.

Als er verschillende activiteiten in één vraag staan, kunt $u$ aangeven hoe vaak $u$ al die dingen in totaal gedaan hebt.

\section{Uitleg antwoordmogelijkheden:}

niet gedaan in de afgelopen vier weken $=$

1,2 of 3 keer gedaan (minder dan eens per week) =

Aantal keer gedaan in de afgelopen vier weken

Meer

Minder 1 tot 2 dan 2

dan eens keerper keer per

HOE VAAK IN DE AFGELOPEN VIER WEKEN...

perweek week week

\section{1. hebt $\mathrm{u}$ deelgenomen aan georganiseerde sport of} beweging? Bijvoorbeeld gymnastiekclub of zwemuurtje.

0

$1-3$
9+

1-3 4-8 9+

2. hebt u deelgenomen aan activiteiten van een vereniging, bond, de Kerk of iets dergelijks?

0

3. bent u naar iets cultureels of educatiefs geweest? Bijvoorbeeld bioscoop, schouwburg, museum, lezing of cursus.

4. bent u uit eten geweest?

5. bent u naar een café of lunchroom geweest of hebt u op een terrasje gezeten?

6. bent u naar een publiek evenement geweest? 0 0

0

0 $1-3$

$1-3$

4-8 9+

7. bent u naar een georganiseerde spelmiddag of spelavond geweest? Bijvoorbeeld kienen of klaverjassen. $1-3$ 4-8 $9+$

$1-3$

4-8 9+

. bent u met een georganiseerd dagje uit mee geweest? Bijvoorbeeld met de Zonnebloem of Ouderenbond. 0 $1-3$ 4-8 $9+$

9. hebt $u$ bestuurlijke taken verricht voor een vereniging, stichting of iets dergelijks? 0 $1-3$

0

$\begin{array}{lll}1-3 & 4-8 & 9+ \\ 1-3 & 4-8 & 9+\end{array}$




\section{B Contact met bekenden}

Bij de volgende vragen gaat het er om hoe vaak $u$ iets met bekenden hebt gedaan. Met bekenden bedoelen we vrienden, kennissen, (oud)collega's en buren, die niet deel uitmaken van uw huishouden.

Als er verschillende activiteiten in één vraag staan, kunt $u$ aangeven hoe vaak $u$ al die dingen in totaal gedaan hebt.

\section{Uitleg antwoordmogelijkheden:}

Niet gedaan in de afgelopen vier weken =

1,2 of 3 keer gedaan (minder dan eens per week) =

Aantal keer gedaan in de afgelopen vier weken

Meer

Minder 1 tot 2 dan 2

dan eens keer per keer per

HOE VAAK IN DE AFGELOPEN VIER WEKEN...

1. hebt u gebeld, geschreven, ge-e-maild of gechat met bekenden?

0

$1-3$

4-8
$9+$

2. zijn er bekenden bij u langs geweest? 0

3. bent $\mathrm{u}$ bij bekenden langs geweest? 0 $1-3$ 4-8 9+

4. hebt $u$ buiten de deur iets gedaan met bekenden waarvoor relatief veel lichamelijke inspanning nodig is? Bijvoorbeeld wandelen of fietsen.

0 $1-3$ 4-8 $9+$

5. hebt u buiten de deur iets gedaan met bekenden waarvoor relatief weinig lichamelijke inspanning nodig is? Bijvoorbeeld met de auto toeren of ergens koffie gaan drinken. 0 $1-3$ 4-8 $9+$

6. hebt u bekenden praktische hulp geboden? Denk bijvoorbeeld aan boodschappen doen, een lift geven, klussen of formulieren invullen.

$\begin{array}{llll}0 & 1-3 & 4-8 & 9+\end{array}$

7. hebt $u$ bekenden advies of tips gegeven?

0

$1-3$

4-8

$9+$

8. hebt $u$ bekenden opgevangen toen ze een luisterend oor nodig hadden?
4-8

9+ 


\section{Contact met familie}

Niet alleen met bekenden, maar ook met familieleden kunt $u$ iets doen. Met familie bedoelen we in de volgende vragen alle familieleden die niet deel uitmaken van uw huishouden.

Als er verschillende activiteiten in één vraag staan, kunt $u$ aangeven hoe vaak $u$ al die dingen in totaal gedaan hebt.

\section{Uitleg antwoordmogelijkheden:}

niet gedaan in de afgelopen vier weken $=$

1,2 of 3 keer gedaan (minder dan eens per week) =

Aantal keer gedaan in de afgelopen vier weken

Meer

Minder 1 tot 2 dan 2

dan eens keer per keer per

HOE VAAK IN DE AFGELOPEN VIER WEKEN...

1. hebt u gebeld, geschreven, ge-e-maild of gechat met familie?

0

$1-3$

4-8

$9+$

2. is er familie bij u langs geweest? 0 1-3 4-8

3. bent $\mathrm{u}$ bij familie langs geweest? 0 $1-3$ 4-8 $9+$

4. hebt $\mathrm{u}$ buiten de deur iets gedaan met familie waarvoor relatief veel lichamelijke inspanning nodig is? Bijvoorbeeld wandelen of fietsen.

0

$1-3$

4-8 9+

5. hebt u buiten de deur iets gedaan met familie waarvoor relatief weinig lichamelijke inspanning nodig is? Bijvoorbeeld met de auto toeren of ergens koffie gaan drinken.

0
$1-3$ 4-8 $9+$

6. hebt u familie praktische hulp geboden? Denk bijvoorbeeld aan boodschappen doen, een lift geven, klussen of formulieren invullen.

0

$1-3$

4-8

9+

7. hebt u familie advies of tips gegeven?

0

$1-3$

4-8

$9+$

8. hebt $u$ familie opgevangen toen ze een luisterend oor nodig hadden? 


\section{Appendix C \\ Correlations between MPAQ and MSPP}


Table 1 Pearson correlations between Maastricht Personal Autonomy Questionnaire (MPAQ) and Maastricht Social Participation Profile (MSPP)

\begin{tabular}{llll}
\hline & $\begin{array}{l}\text { MPAQ-Degree of } \\
\text { Autonomy }\end{array}$ & $\begin{array}{l}\text { MPAQ-Working } \\
\text { on autonomy }\end{array}$ & $\begin{array}{l}\text { MPA- } \\
\text { Dilemmas }\end{array}$ \\
\hline MSPP Diversity & & & 0.04 \\
Total & $0.30^{* *}$ & $0.11^{*}$ & -0.02 \\
Consumptive Participation & $0.30^{* *}$ & $0.13^{* *}$ & -0.01 \\
Formal Social Participation & $0.18^{* *}$ & $0.10^{*}$ & 0.03 \\
Informal Social Participation - Acquaintances & $0.32^{* *}$ & $0.18^{* *}$ & 0.05 \\
Informal Social Participation - Family & $0.31^{* *}$ & $0.13^{*}$ & \\
MSPP Frequency & & & -0.01 \\
Consumptive Participation & $0.27^{* *}$ & $0.16^{* *}$ & -0.01 \\
Formal Social Participation & $0.20^{* *}$ & $0.11^{*}$ & 0.02 \\
Informal Social Participation - Acquaintances & $0.31^{* *}$ & $0.16^{* *}$ & 0.06 \\
Informal Social Participation - Family & $0.28^{* *}$ & $0.15^{* *}$ & \\
\hline
\end{tabular}

** Correlation is significant at the 0.01 level (2-tailed).

* Correlation is significant at the 0.05 level (2-tailed). 


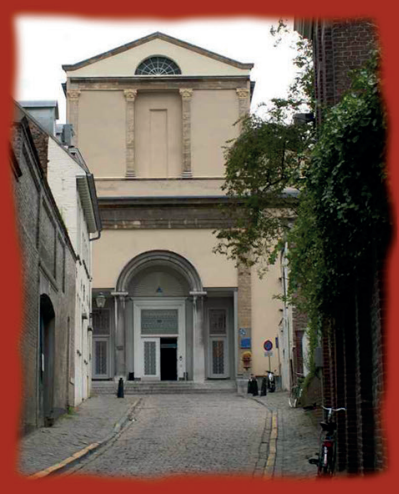

